\title{
The State of
}

Research, Development

\section{and Innovation of}

\section{ELECTRICAL ENERGY}

EFFICIENCY TECHNOLOGIES

\section{in South Africa}

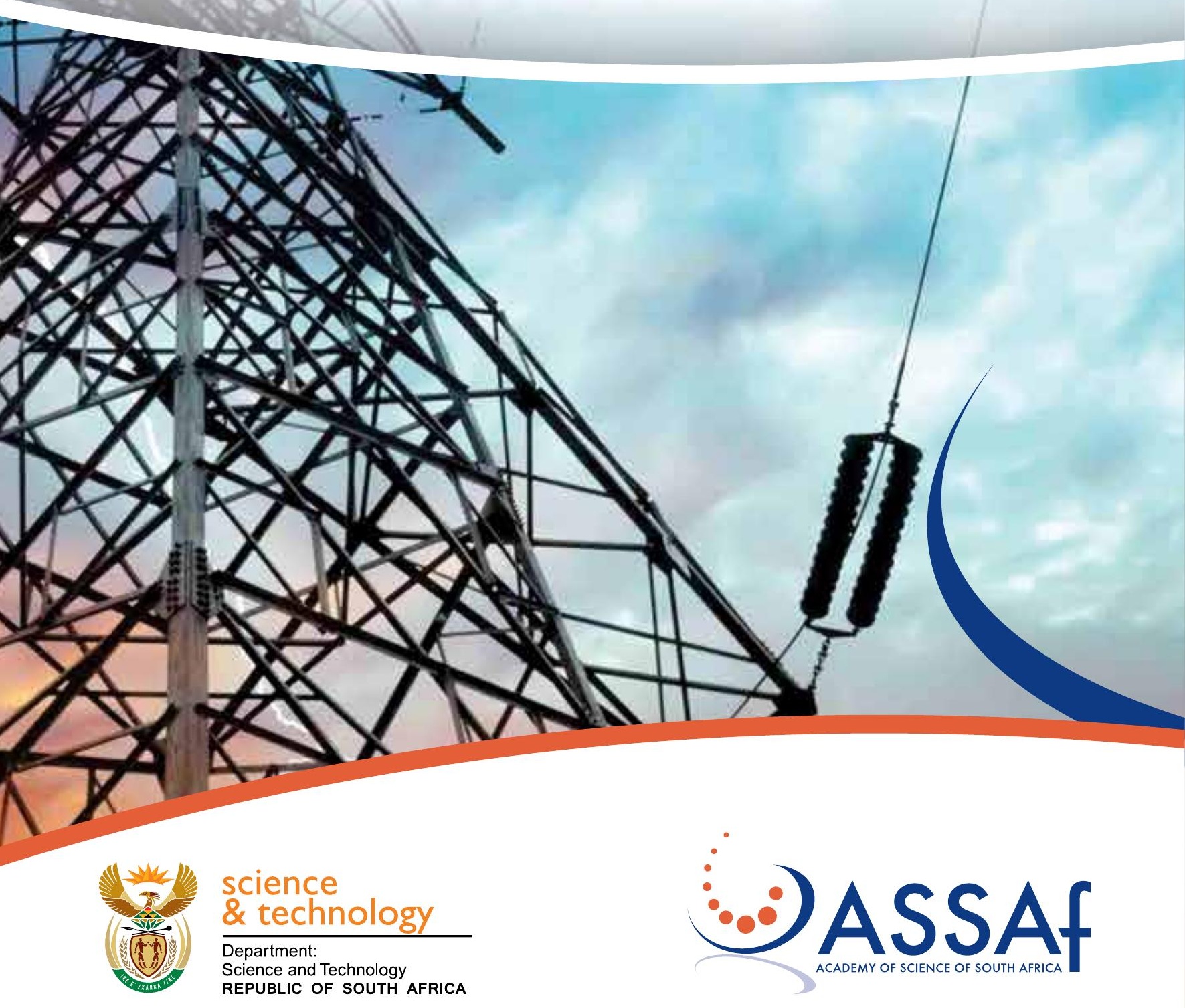


(C) Academy of Science of South Africa

September 2017

ISBN 978-0-99471 17-2-4

DOI http://dx.doi.org/10.17159/assaf.2017/0017

Published by:

Academy of Science of South Africa (ASSAf)

PO Box 72135, Lynnwood Ridge, Pretoria, South Africa, 0040

Tel: +27 123496600 • Fax: +27 865769520

E-mail: admin@assaf.org.za

Reproduction is permitted, provided the source and publisher are appropriately acknowledged.

The Academy of Science of South Africa (ASSAf) was inaugurated in May 1996. It was formed in response to the need for an Academy of Science consonant with the dawn of democracy in South Africa: activist in its mission of using science and scholarship for the benefit of society, with a mandate encompassing all scholarly disciplines that use an open-minded and evidence-based approach to build knowledge. ASSAf thus adopted in its name the term 'science' in the singular as reflecting a common way of enquiring rather than an aggregation of different disciplines. Its Members are elected on the basis of a combination of two principal criteria, academic excellence and significant contributions to society.

The Parliament of South Africa passed the Academy of Science of South Africa Act (No 67 of 2001), which came into force on 15 May 2002. This made ASSAf the only academy of science in South Africa officially recognised by government and representing the country in the international community of science academies and elsewhere. 


\section{The State of}

Research, Development

and Innovation of

ELECTRICAL ENERGY

EFFICIENCY TECHNOLOGIES

in South Africa 


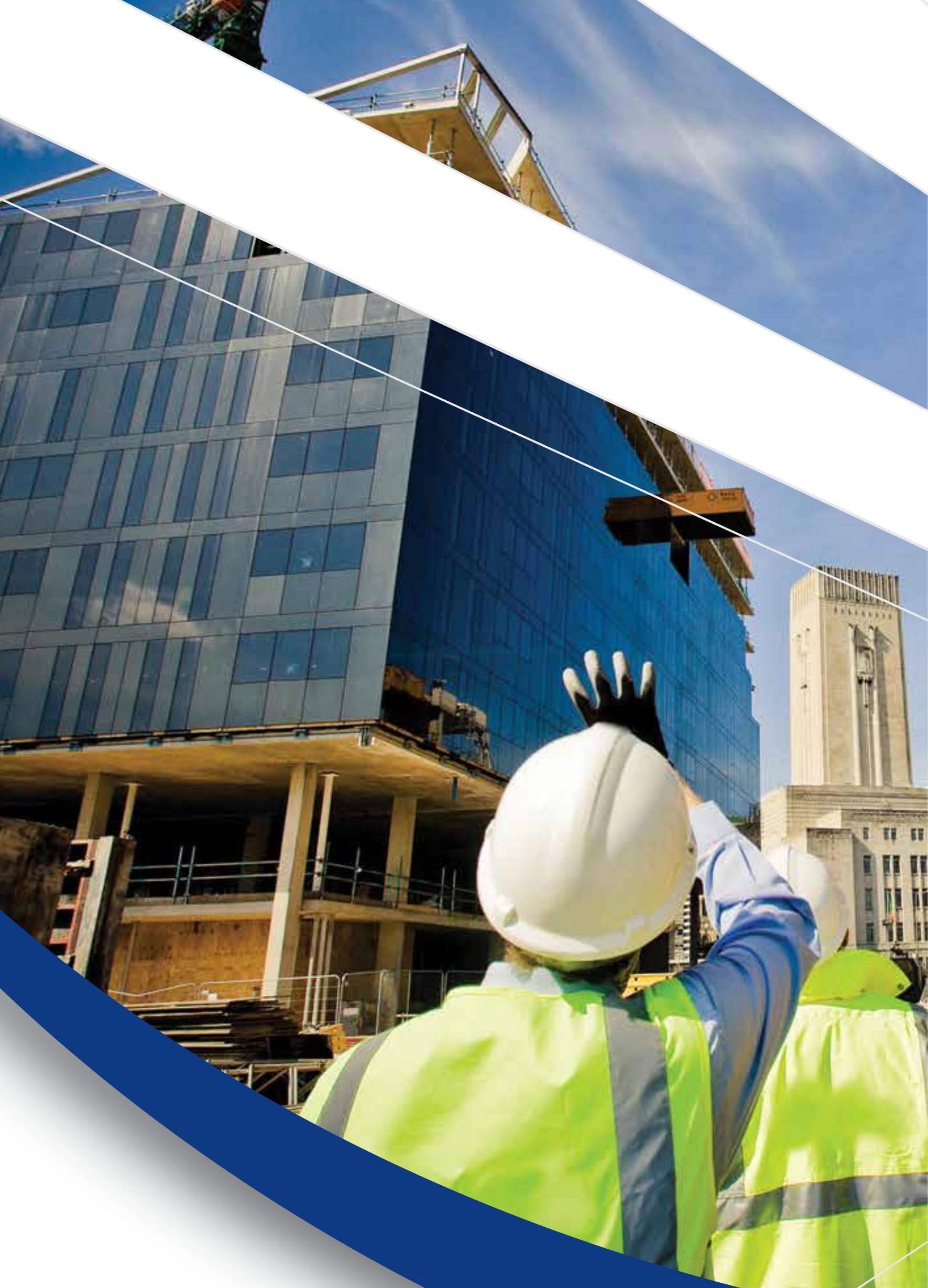




\section{TABLE OF CONTENTS}

LIST OF FIGURES

LIST OF TABLES

LIST OF ACRONYMS 9

FOREWORD 11

ACKNOWLEDGEMENTS 12

EXECUTIVE SUMMARY 13

1 INTRODUCTION 17

$\begin{array}{lll}1.1 \text { Background } & 17\end{array}$

1.2 Scope 18

2 METHODOLOGY 19

3 OVERVIEW OF ENERGY EFFICIENCY TECHNOLOGIES 21

3.1 Introduction 21

$\begin{array}{lll}3.2 & \text { Scope and extent } & 24\end{array}$

\begin{tabular}{ll|l} 
3.3 Methodology & 24
\end{tabular}

3.4 Energy efficiency technology classifications for South Africa by keywords

3.5 Results 29

3.5.1 National performance comparison in the selected areas 29

3.5.2 International comparisons $\quad 30$

3.5.3 Results in individual research areas $\quad 32$

3.6 Technology-enabled EEDSM options, implementation and potential

3.7 Observations and analysis ( $\quad 43$

3.7.1 Research, development, and innovation 47

$\begin{array}{ll}\text { 3.7.2 Policy } & 48\end{array}$

4 IN FOCUS: SMART GRIDS $\quad 51$

4.1 Introduction 51

4.2 Technology landscape $\quad 55$

4.2.1 South African landscape $\quad 55$

4.2.2 International landscape $\quad 60$ 
4.3 Research and development opportunities in South Africa 63

$\begin{array}{lll}4.4 & \text { Summary } & 67\end{array}$

5 IN FOCUS: SOLID-STATE LIGHTING $\quad 71$

5.1 Introduction 71

5.2 Technology landscape 71

5.2.1 South African landscape 71

$\begin{array}{ll}5.2 .2 \text { International landscape } & 72\end{array}$

5.3 Research and development opportunities in South Africa $\quad 75$

$\begin{array}{lll}5.4 & \text { Summary } & 75\end{array}$

$6 \quad$ IN FOCUS: TRIBOLOGY $\quad 79$

6.1 Introduction 79

6.2 Technology and research and development landscape $\quad 79$

6.2.1 South African industry landscape 79

6.2.2 South African research and development landscape $\quad 82$

6.2.3 International landscape 85

6.3 Research and development opportunities in South Africa 87

$7 \quad$ KEY FINDINGS AND RECOMMENDATIONS 89

$\begin{array}{lll}7.1 & \text { Findings } & 89\end{array}$

7.1.1 Energy efficiency 89

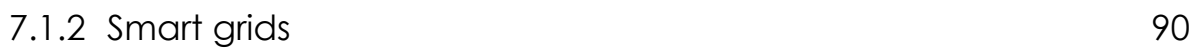

7.1.3 Solid-state lighting 90

$\begin{array}{ll}7.1 .4 \text { Tribology } & 91\end{array}$

$\begin{array}{lll}7.2 & \text { Recommendations } & 91\end{array}$

$\begin{array}{ll}\text { REFERENCES } & 95\end{array}$

$\begin{array}{ll}\text { APPENDICES } & 101\end{array}$

$\begin{array}{ll}\text { Appendix 1: Biographies of panel members } & 101\end{array}$

$\begin{array}{ll}\text { Appendix 2: Biographies of reviewers } & 105\end{array}$

Appendix 3: Keywords used in the energy efficiency overview 107

$\begin{array}{ll}\text { Appendix 4: EEDSM solution analysis } & 111\end{array}$ 


\section{LIST OF FIGURES}

Figure 3-1: Number of publications originating from South Africa per year in each area

Figure 3-2: Names of the most active (a) institutions and (b) authors in industrial energy systems in MMM

Figure 3-3: Number of publications in industrial energy systems in MMM per year originating from (a) selected countries and

(b) South Africa

Figure 3-4: Name of most active (a) institutions and (b) authors in renewable energy in South Africa

Figure 3-5: Number of publications in renewable energy per year originating from (a) selected countries and (b) South Africa

Figure 3-6: Names of most active (a) institutions and (b) authors in power systems in South Africa

Figure 3-7: Number of publications in power systems per year originating from (a) selected countries and (b) South Africa

Figure 3-8: Names of most active (a) institutions and (b) authors in integrated building energy systems in South Africa

Figure 3-9: Number of publications in integrated building energy systems per year originating from (a) selected countries and (b) South Africa

Figure 3-10: Names of most active (a) institutions and (b) authors in energy storage in South Africa

Figure 3-11: Number of publications in energy storage per year originating from (a) selected countries and (b) South Africa

Figure 3-12: Names of most active (a) institutions and (b) authors in solid-state lighting in South Africa

Figure 3-13: Number of publications in solid-state lighting per year originating from (a) selected countries and (b) South Africa

Figure 3-14: Names of most active (a) institutions and (b) authors in batch chemical processes in South Africa

Figure 3-15: Number of publications in batch chemical processes per year originating from (a) selected countries and (b) South Africa

Figure 3-16: Names of most active (a) institutions and (b) authors in tribology in South Africa

Figure 3-17: Number of publications in tribology per year originating from (a) selected countries and (b) South Africa

Figure 3-18: Name of most active (a) institutions affiliations and (b) authors in smart grids in South Africa 
Figure 3-19: Number of publications in smart grids per year in (a) selected countries and (b) South Africa

Figure 3-20: Names of most active (a) institutions and (b) authors in M\&V in South Africa

Figure 3-21: Number of publications in M\&V per year originating from

(a) selected countries and (b) South Africa

Figure 3-22: Comparison of energy efficiency-related research outputs according to country groupings

Figure 5-1: City of Los Angeles before and after LED retrofit programme (US DoE, 2016)

Figure 5-2: A parking lot of Edgewater marketplace (Colorado-USA) before and after lighting retrofit using LED fixtures (US DoE, 2016) 


\section{LIST OF TABLES}

Table 2-1: Members of the panel including affiliations

Table 3-1: Number of South African and selected country originating publications (1986 - 2016) and South Africa's contribution to the world total

Table 3-2: Number and percentage of patents originating from South Africa compared with world totals

Table 4-1: Energy efficiency targets and performance achieved (DoE, 2016) 52

Table 4-2: Technology applications

Table 4-3: Energy efficiency-related initiatives by South African utilities

Table 4-4: Pilot sites for smart grids

Table 4-5: Eskom smart grid-related research

Table 4-6: University smart grid-related research

Table 5-1: Numbers of known presently installed LED street light points (CLASP, 2013) 



\section{LIST OF ACRONYMS}

$\begin{array}{ll}\text { ASSAf } & \text { Academy of Science of South Africa } \\ \text { BRICS } & \text { Brazil, Russia, India, China and South Africa } \\ \text { CFL } & \text { Compact fluorescent lamp } \\ \text { CNES } & \text { Centre of New Energy Systems } \\ \text { COE } & \text { Centre of Excellence } \\ \text { CSIR } & \text { Council for Scientific and Industrial Research } \\ \text { DEA } & \text { Department of Environmental Affairs } \\ \text { DoE } & \text { Department of Energy } \\ \text { DST } & \text { Department of Science and Technology }\end{array}$

EEDSM Energy Efficiency and Demand Side Management

EPRI Electricity Power Research Institute

ESI Electricity supply industry

ETPSG European Technology Platform Smart Grid

EU European Union

GDP Gross domestic product

GIZ Deutsche Gesellschaft für Internationale Zusammenarbeit

HID High-intensity discharge

IDM Integrated demand management

IEA International Energy Agency

IEP Integrated Energy Plan

IRP Integrated Resource Plan

ISGAN International Smart Grid Action Network

IT Information technology

LBNL Lawrence Berkeley National Laboratory

LED Light-emitting diode

M\&V Measurement and verification

MMM Mining, metallurgy and mineral processing

MYPD Multi-Year Price Determination

NCPC National Cleaner Production Centre

NERSA National Energy Regulator of South Africa

NIST National Institute for Standards and Technology

NREL National Renewable Energy Laboratory 
NRF National Research Foundation

NWU North-West University

OLED Organic light-emitting diode

OT Operational technology

PLED Polymer light-emitting diode

PV Photo-voltaic

R\&D Research and development

RDI Research, development and innovation

REIPPP Renewable Energy Independent Power Producers Programme

SAIT South African Institute of Tribology

SANEDI South African National Energy Development Institute

SANERI South African National Energy Research Institute

SARChi South African Research Chair Initiative

SASGI South African Smart Grid Initiative

SSL Solid-state lighting

STI Science, technology and innovation

STLE Society for Tribologists and Lubrication Engineers

TSCT Technical Steering Committee on Tribology

TUT Tshwane University of Technology

UCT University of Cape Town

UFS University of the Free State

UJ University of Johannesburg

UJALA Affordable LEDs and Appliances for All

UK United Kingdom

UNEP United Nations Environment Programme

UP University of Pretoria

US United States of America

VITO Flemish Institute for Technology Research

Wits University of the Witwatersrand 


\section{FOREWORD}

The Academy of Science of South Africa (ASSAf) is mandated to provide evidencebased science advice to government on matters of critical national importance. The availability of energy is an important driver of a nation's development and recognised as such in South Africa's National Development Plan (NDP). It follows that energy efficiency is an area that warrants serious attention as it is a cost-effective means of reducing energy consumption. This study on The State of Research, Development and Innovation of Electrical Energy Efficiency Technologies in South Africa is both timely and important.

The study has followed the traditional Academy consensus study methodology, in which a panel of experts, guided by the panel chair, undertakes the study. The advantage of this multi-perspective approach based on volunteerism is that it is free of partisan interest. As a result, the findings and recommendations are the best considered outcomes in the circumstances.

This report provides valuable insights into the research strengths that exist in South Africa in the various sub-fields of energy efficiency and identifies research areas in need of strengthening. It concludes that the South African energy efficiency research community is small but that it has shown significant growth in terms of output over the past 20 years. Recommendations are made to support the progress that has been made.

While the report was commissioned by the Department of Science and Technology (DST), it will be useful to many other government departments, as well as being of value to the private sector.

The members of the study panel and the authors of the report, as well as the staff of the Academy, are acknowledged for the valuable work that they have done and for the care and attention with which they carried out their task.

\section{Professor Jonathan Jansen}

President: Academy of Science of South Africa 


\section{ACKNOWLEDGEMENTS}

This study was a collaborative effort involving many dedicated people. I wish to thank the following people and organisations for ensuring the success of the study:

- The Academy of Science of South Africa (ASSAf), the President of ASSAf, Jonathan Jansen, and the Council for their ongoing support throughout the project.

- The Department of Science and Technology (DST) for commissioning and funding the project, and in particular Ms Rebecca Maserumule, the Chief Director for Hydrogen and Energy, and Mr Mbangiseni Mabudafhasi, Deputy Director for Power, of the DST, for their guidance and support.

- The members of the consensus study panel for their commitment, time, effort and valuable contributions to the report.

- The authors, other than the panel members, who assisted by writing sections of the report. They include:

- Prof Xiaohua Xia, Director of the University of Pretoria's Centre of New Energy Systems and the National Hub for Postgraduate Programme in Energy Efficiency and Demand Side Management;

- $\quad$ Dr Willem de Beer an independent specialist in the energy industry;

- $\quad$ Prof Odireleng Martin Ntwaeaborwa of the School of Physics, University of the Witwatersrand;

- Mr Patrick Swan and Mr Thomas Surmon of the South African Institute of Tribology;

- $\quad$ Prof Philip de Vaal, Head of the Department of Chemical Engineering at the University of Pretoria.

- The peer reviewers who gave valuable input that allowed improvement of the report.

- The copy editor, Ms Patricia Scholtz, and LedCool for attention to detail and the production of the report.

- The staff of the Academy, in particular, Prof Roseanne Diab and Ms Nadia Algera for their contribution and support throughout the project.

\section{Prof Roelf Sandenbergh Chair of the Panel}




\section{EXECUTIVE SUMMARY}

The availability of appropriate, reliable and affordable energy is central to the sustainability and further development of modern societies. The field of energy efficiency aims to promote efficiency in the conversion, distribution and usage of energy technologies and products and provides an attractive methodology for managing growth in energy consumption.

The aim of energy efficiency is to reduce the energy intensity required to produce goods and services. South Africa is presently in a relatively unique position in terms of the energy intensity of its economy, with the per capita energy consumption as a function of per capita gross domestic product (GDP) at about twice the international average and with electrical energy consumption approximately $40 \%$ higher than the international average. There is thus significant potential for energy efficiency improvements to act as a virtual and relatively low cost fuel source to support poverty alleviation and job creation at a reduced environmental cost.

The focus of this report is on electrical energy efficiency, but it also provides some guidance on how an enhanced focus on tribology may contribute to energy efficiency. Since electricity production consists of a value chain (generation, transmission, distribution and end use), energy efficiency technologies and methods may be applied at each point, resulting in cumulative improvement in the efficiency of the energy system, with subsequently reduced losses and associated financial gains.

An overview of the current capabilities, and current and planned energy efficiency technology development and strategies in place in South Africa, enables effective coordination of efforts and improves progress toward mainstreaming energy efficiency in South Africa, whilst simultaneously avoiding duplication of efforts and maximising the use of limited resources.

The study aims to inform the Department of Science and Technology (DST) of opportunities for further development in terms of human capital development, intellectual property output and technology development and innovation, in order to promote the adoption of energy efficiency technologies in South Africa.

An overview of research productivity in various energy efficiency fields using the Scopus data base, is given for the 30-year period, 1986 to 2016 . The highest number of publications (3 872 papers over a 30 -year period) is in the area of industrial energy systems in mining, metallurgy and mineral processing (MMM), which is a traditionally strong South African research area, based predominantly at the University of Pretoria (UP) and the University of Cape Town (UCT). The second broad energy efficiency area is micro-grids, which includes the sub-categories of renewable energy, power systems, integrated building energy systems and energy storage. Again UP and UCT feature strongly, with Stellenbosch University (SU) showing strength in renewable energy, power systems and building energy systems, the University of KwaZulu-Natal (UKZN) in power systems, and the Council for Scientific and Industrial Research (CSIR) and the University of the Western Cape (UWC) in energy storage. The remaining energy efficiency areas are less well 
developed in terms of research outputs but there are indications of strength in solid-state lighting (SSL) research at the University of the Free State (UFS), tribology at UP, UCT and UKZN, smart grids at UP, UCT and the Cape Peninsula University of Technology (CPUT), and measurement and verification (M\&V) at North-West University (NWU).

It is concluded that South Africa has small but notable activities in energy efficiency. Research outputs increased markedly during the period 2007 to 2014 , but appear to have stagnated since then. The focused funding of the Energy Efficiency Demand Side Management (EEDSM) hub at UP contributed significantly to this growth in research but needs to be sustained and increased to maintain the momentum to guide and support energy efficiency interventions with linked research and development (R\&D) activities.

International cooperation agreements serve as conduits for South African participation in energy efficiency projects. One that is highlighted is the Brazil, Russia, India, China and South Africa (BRICS) Science, Technology and Innovation Framework Programme that is opening up opportunities for research cooperation on micro-grids and the related fields of integrated building energy systems, distributed generation systems, smart grids and SSL.

Energy efficiency is an economically and environmentally attractive way to meet growing energy demand but needs support to make a significant contribution as it may not be aligned with the aims of energy producers. As a country rich in mineral resources, South Africa should not try to move away from energy-intensive industries that offer significant downstream beneficiation opportunities, but should rather strive to make these industries more energy efficient and competitive through R\&D support.

Some of the key findings in specific fields are as follows:

Energy efficiency and demand side management: Energy efficiency offers many possibilities for enhancing competitiveness, reducing environmental impacts and stimulating social and industrial development. Energy efficiency is, however, typically not well aligned with the immediate interests of energy suppliers and needs policy supports to research, develop, implement and monitor energy efficiency interventions.

Smart grid technologies: There is significant potential for improving the efficiency of the electrical energy value chain by introducing smart technologies at all levels as well as to move away from production following user demand to one of rather synchronising availability and usage. R\&D of smart grid technologies with a focus on South Africa's developing energy supply mix, the diversity present in the distribution networks and emerging technologies could significantly improve electrical energy efficiency as well as open developmental opportunities. An overall integrated approach and enabling policies for the roll out of smart grids is required to ensure interoperability, upgradability, security, safety and affordability to achieve optimal results. 
Solid-state lighting: Advanced electrical to light conversion technologies offer major opportunities to improve energy efficiencies, as well as support development by offering affordable and enhanced lighting functionality. The opportunity for competitive local manufacturing of light-emitting diode (LED) devices is probably limited due to scale limitations and the availability of cheap imports from China. However, the development of luminaires offers significant potential and would build on existing capabilities. There is an opportunity for a R\&D programme on SSL that would improve the competitiveness of South Africa both on the fundamental research level, as a producer of luminaires, and as a smart user focused on the energy-efficient use of smart lighting devices.

Tribology: This wide-ranging interdisciplinary field offers significant prospects to increase efficiencies and reduce wastage over a broad range of activities. R\&D opportunities in tribology to improve energy efficiency should be focused on materials and lubricant development and evaluation, surface conditioning and finishing, and lubrication and maintenance practices.

The recommendations are:

1 Energy efficiency must be accorded the priority that it deserves in future iterations of the Integrated Resource Plan (IRP).

2 Compile a national Energy Efficiency and Demand Side Management (EEDSM) roadmap, in support of the IRP and the new National Energy Efficiency Strategy.

3 Strengthen research and training facilities in EEDSM.

4 Establish a national monitoring, evaluation and reporting framework on energy efficiency.

5 Strengthen the research and training facilities in smart grids at South African universities.

6 Ensure the development of a coherent policy on SSL and provide support for local manufacture of luminaires.

7 Consider the implementation of the energy efficiency aspects of the Tribology Roadmap as developed by the Technical Steering Committee on Tribology. 


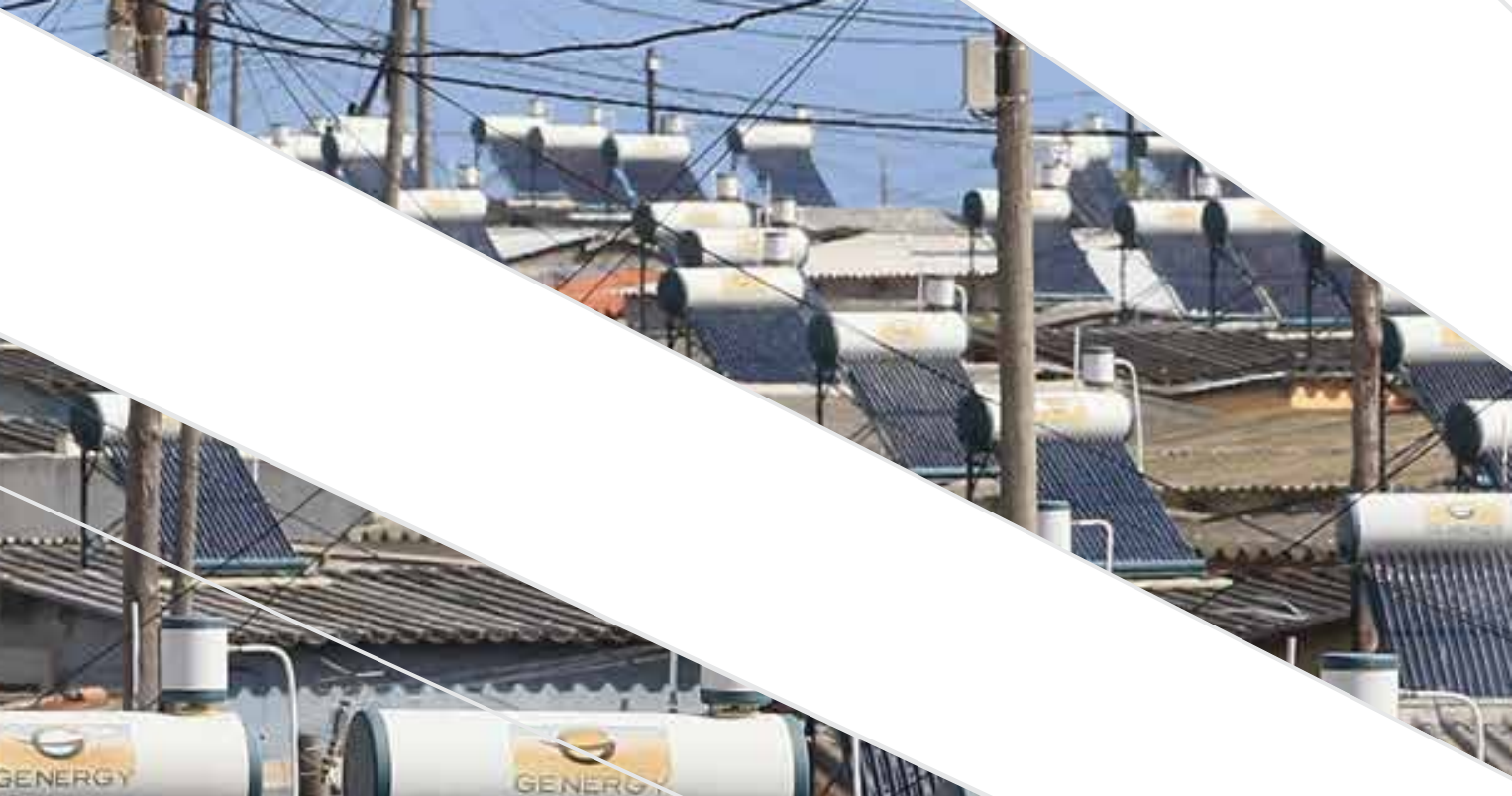

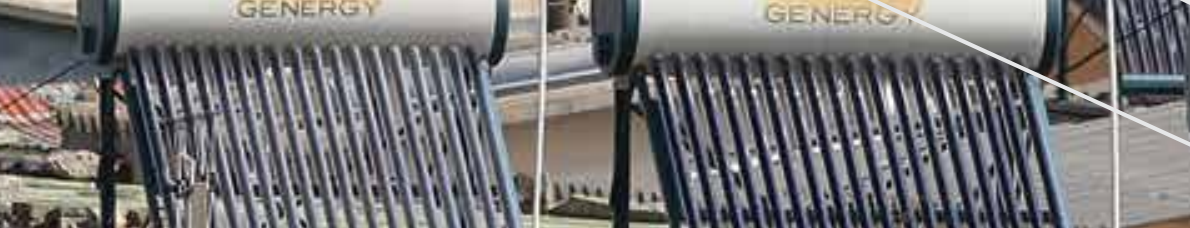
2515) 19.

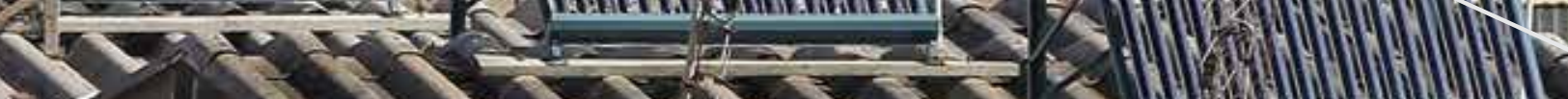

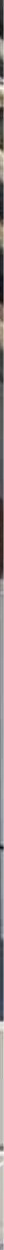




\section{INTRODUCTION}

\subsection{Background}

The availability of appropriate, reliable and affordable energy is central to the sustainability and further development of modern societies. The challenge is to structure the supply and usage of energy such that the maximum benefit is extracted at the lowest all-inclusive cost. The emerging field of energy efficiency strives to make contributions that will promote efficiency in the conversion, distribution and usage of energy in terms of policies, activities, technologies and products to achieve maximum benefits at acceptable costs. Energy efficiency also provides an attractive methodology for managing and restraining the growth in energy consumption. Something is more energy efficient if it delivers more services for the same energy input, or the same services for less energy input. Improvements in energy efficiency may be achieved by adopting a more efficient technology or production process or by applying specific methods to reduce energy losses.

The focus of this report is on electrical energy efficiency, but will also provide some guidance on how more focus on tribology may contribute to energy efficiency in a more general context. Since electricity production consists of a value chain (generation, transmission, distribution and end use), energy efficiency technologies and methods may be applied at each point, resulting in cumulative improvement in the efficiency of the energy system, with subsequently reduced losses and associated financial gains.

Technology research, development and innovation (RDI) related to, amongst others, smart grids, SSL and tribology are key to mainstreaming energy efficiency. Improving energy efficiency in the energy sector will have positive implications for the national economy. The major role that energy efficiency can play in stimulating economic growth, while also supporting energy security, competitiveness and environmental sustainability has recently been emphasised by the International Energy Agency (IEA) (IEA, 2014). The so-called 'rebound effect' in which energy efficiency gains are directed by users to access more services, and even more energy-intensive uses, can play a major role in South Africa to stimulate economic activity and job creation, and contribute to poverty alleviation and improved public health by allowing wider access to cleaner heating, lighting and refrigeration services.

While it is understood that the DST is working closely with the UP'S EEDSM hub, the department is aware of a number of other RDI initiatives in energy efficiency technologies taking place in South Africa, in addition to activities within the private sector and Eskom. An overview of the current capabilities, and current and planned energy efficiency technology development and strategies in place in South Africa, would enable effective coordination of efforts and improve progress toward mainstreaming energy efficiency in South Africa, whilst simultaneously avoiding duplication of efforts and maximising the use of limited resources. In addition, there are a number of international bilateral agreements in place, through which RDI-exchange is encouraged 
and an overview of the activities under these agreements would add to the understanding of RDI in energy efficiency technologies in South Africa.

\subsection{Scope}

The Academy of Science of South Africa (ASSAf) committed to undertake this study, the results of which could be used as a measure of the effectiveness and competitiveness of the national energy efficiency innovation system, and as a baseline that the DST could use to identify the appropriate energy efficiency RDI policy interventions for the next ten years and beyond.

This report comprises a review, assessment and analysis of the state of electrical energy efficiency technology RDI in South Africa. The study aims to inform the DST of opportunities for further development in terms of human capital development, intellectual property output and technology development and innovation, in order to promote the adoption of energy efficiency technologies in South Africa.

In particular, this study aims to provide:

- a comprehensive review, assessment and analysis of the current and historic energy-saving technologies, SSL technologies, tribology and smart grid technologies;

- $\quad$ an analysis of the landscape of institutions engaged in research in energy efficiency and technologies, such as smart grids, tribology and SSL, which contribute to the improvement of energy efficiency;

- $\quad$ benchmarking against other countries on how they ensure energy efficiency technology development;

- $\quad$ an outline of the progress of predetermined public and private economic sectors of South Africa in improving energy efficiency, and linking to additional existing studies in this regard;

- $\quad$ South African research and technology development opportunities in smart grids, tribology and SSL;

- $\quad$ the most appropriate institutional arrangements to enable energy efficiency technology RDI;

- $\quad$ an analysis of the impact of the uptake of locally and globally developed energy efficiency technologies;

- $\quad$ a review and high-level analysis of any bilateral agreements that include and/or promote energy efficiency technology RDI between South Africa and other countries;

- $\quad$ recommendations on the prioritisation of the proposed interventions. 


\section{METHODOLOGY}

A seven-member multi-disciplinary panel, under the chairmanship of Professor Roelf Sandenbergh, undertook the study. Membership of the panel is presented in Table 2-1, and member biographies are presented in Appendix 1.

\section{Table 2-1: Members of the panel including affiliations}

\begin{tabular}{|l|l|}
\hline Name & Affliation \\
\hline Prof Roelf Sandenbergh & University of Pretoria \\
\hline Prof Alex Quandt & University of the Witwatersrand \\
\hline Mr Barry Bredenkamp & South African National Energy Development Institute \\
\hline Dr Clinton Carter-Brown & Council for Scientific and Industrial Research \\
\hline Prof Kenneth Ozoemena & University of the Witwatersrand \\
\hline Prof Natasha Sacks & University of the Witwatersrand \\
\hline Ms Nelisiwe Magubane & Matleng Energy Solutions \\
\hline
\end{tabular}

The study was initiated in September 2016, with the first panel meeting held on 27 September 2016. Regular panel meetings were held throughout the duration of the study period to (1) initiate the study, (2) provide updates, feedback and to discuss report compilation, and (3) to finalise the report and closure of the study.

Notable experts were commissioned to undertake comprehensive assessments of the focus areas. Commissioned experts and panel members liaised to ensure assessments were inclusive and addressed the aims of the study.

Project activities included:

1 Consultation workshops with national stakeholders such as the Department of Energy (DoE) and the Department of Environmental Affairs (DEA)

2 Consultation workshop with other stakeholders from the public, private and academic sectors

3 Public questionnaire

$4 \quad$ Literature review

5 Personal interviews

The final draft report was submitted for peer review in April 2017 (the biographies of the reviewers selected and approved by the ASSAf Council appear in Appendix 2) and the ASSAf Council approved the publication at a Council Executive meeting in September 2017. 


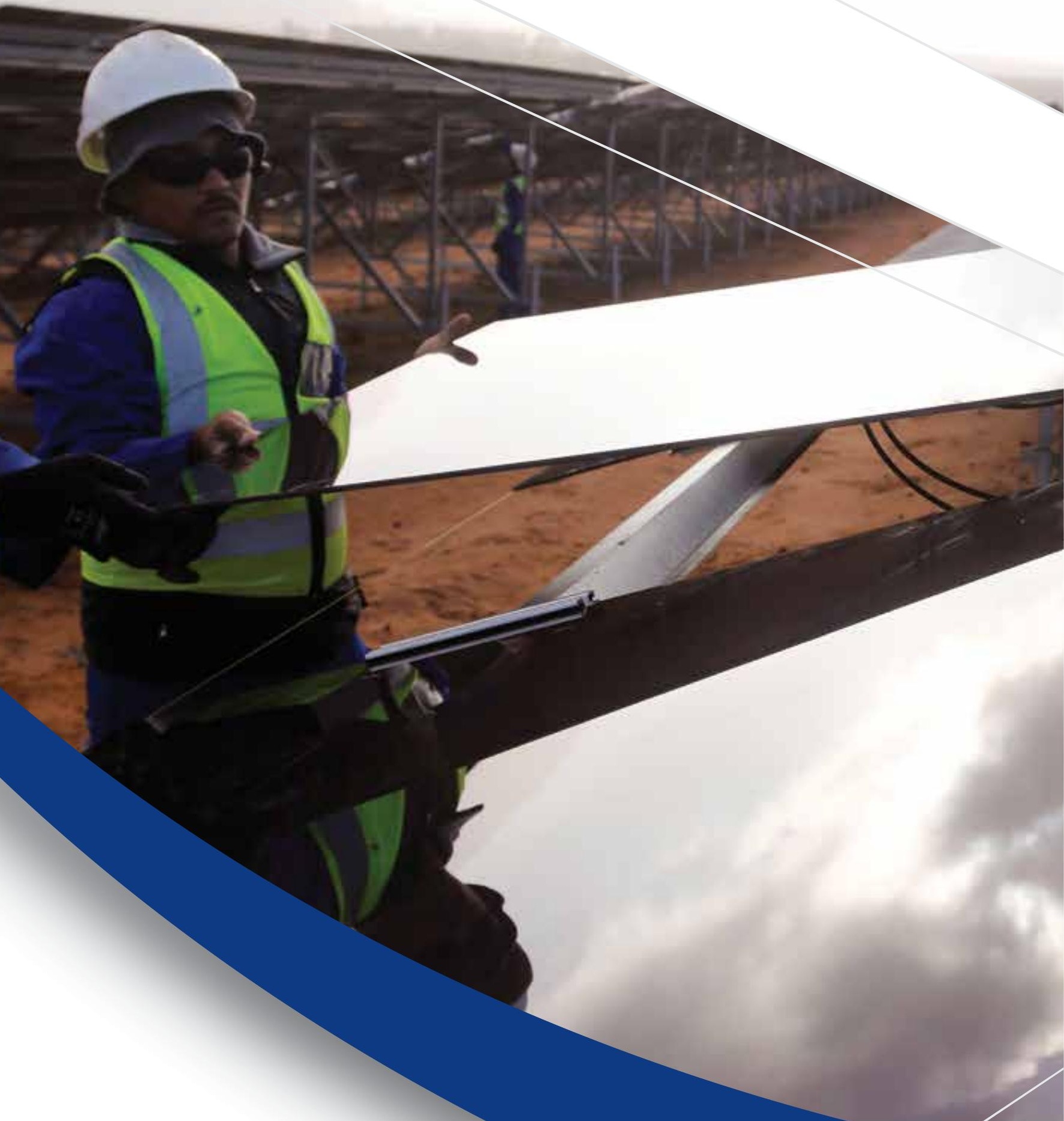




\section{OVERVIEW OF ENERGY EFFICIENCY TECHNOLOGIES}

\subsection{Introduction}

The aim of energy efficiency is to reduce the energy intensity required to produce goods and services. South Africa is presently in a relatively unique position in terms of the energy intensity of its economy, with the per capita energy consumption as a function of per capita GDP at about twice the international average and with electrical energy consumption approximately $40 \%$ higher than the international average (IEA, 2015). There is thus significant potential for energy efficiency improvements to act as a virtual and relatively low cost fuel source to support poverty alleviation and job creation at a reduced environmental cost. Many forms of energy are typically involved in the production of goods and the delivery of services. South Africa is again in a relatively unique position, with coal providing more than two-thirds of primary energy demand and with electricity providing only $24 \%$ of final energy consumption, based on 2012 figures (IEA, 2015). The focus of this report is mainly on the optimisation of electrical energy utilisation, i.e. electrical energy efficiency, but it needs to be emphasised that significant gains could also result from improving the efficiencies of the usage of oil, at $34 \%$, and of coal, at $24 \%$, of final consumption, based on 2012 figures (IEA, 2015).

Electrical energy is very attractive because of its ease of distribution and limited environmental impact at the point of consumption, but is most economical if production and consumption can be closely matched to limit additional expense of storage. Since electricity production consists of a value chain (generation, transmission, distribution, and end use), energy efficiency technologies and methods may be applied at each stage, resulting in a cumulative improvement in the efficiency of the energy system. Broadly speaking, EEDSM programmes, comprise the broad categories of conservation, load management, fuel switching, strategic load growth, and self-generation, but generally exclude large-scale renewable energy generation of the magnitude of the Renewable Energy Independent Power Producers Programme (REIPPP). These measures have proven to be effective in dealing with energy shortages by delivering the same service while consuming less energy. Improving energy efficiency in the electrical energy sector will have positive implications for the national economy since our economy is relatively energy-intensive and is currently heavily reliant on the reliability and efficiency of the national energy system. Improving energy efficiency would also have many social, economic and environmental benefits for South Africa.

South Africa is in the fortunate position that the state-owned electrical power utility (Eskom) included energy efficiency initiatives when it had to balance the electrical energy supply and demand in the short term, while 
additional generation capacity and a shift from predominantly coal to also include significant wind and solar-based generation capacity was being implemented. Eskom has administered the energy savings programmes since the mid-1990s. According to the Eskom Integrated Demand Management (IDM) annual report (Eskom, 2015), cumulative savings of about $4235 \mathrm{MW}$ have been achieved in the past 12 years through the establishment of its incentive programmes, at a cost of $R 2.38$ million/MW (peak demand reduction) and an energy saving of $\mathrm{R} 0.85 / \mathrm{kWh}$.

The International Energy Agency (IEA) estimates that the multiplier effect of investment in energy efficiency to the benefits gained is in the ratio of one to four (IEA, 2014). About two-thirds of these savings come from lighting where energy efficiency gains were obtained by replacing incandescent light bulbs with efficient lighting technologies. South Africa has also developed solid metrics to support its energy savings accounting, following the International Performance Measurement and Verification Protocol (EOV, 2012), and the first-ever national standard for Measurement and Verification, SANS 50010 (SABS, 2011). South Africa's progress in implementing EEDSM programmes has been reported in Eskom's IDM progress reports and in the South Africa country report on energy efficiency compiled by the Lawrence Berkeley National Laboratory in the United States of America (USA) (De La Rue Du Can et al., 2013).

Widespread rolling blackouts from 2008 to 2015 are, inter alia, attributed to Eskom's maintenance practices and its failure to convince its shareholder, i.e. the government, to invest in new generation capacity to enable it to balance electricity demand and supply. The government realised the importance of energy efficiency and has accelerated its adoption of the energy efficiency policy framework and its contribution towards energy efficiency research and development (R\&D). The reduction of South Africa's contribution to climate change, and the significant energy savings potential were contributing factors.

In its National Energy Efficiency Strategy (DoE, 2012), the government has identified the low price of energy in South Africa as one of the significant barriers to the investment in energy efficiency in the country. To remedy this specific market failure, the National Energy Regulator of South Africa (NERSA), the regulatory authority in charge of determining electricity tariff increases and energy efficiency goals, has taken bold actions to increase the retail price of electricity, with the goal to establish cost-reflective electricity tariffs by 2015. The government has also chosen to include an environmental levy on non-renewable generation capacity to fund the implementation of EEDSM programmes. Energy efficiency was included as a resource of choice in integrated planning for future energy resources (DoE, 2013a). South Africa is one of the first emerging economies to have established a transparent and systematic mechanism to fund energy efficiency. Much is to be learned from both the regulations surrounding the new policy framework and from the programme's implementation. 
In 2008, the then South African National Energy Research Institute (SANERI), supported by the DST, commissioned a five-year plan for the development of a research programme in EEDSM to facilitate the development of this critical field. RDI related to the most prominent areas of national strength and importance are key to mainstreaming energy efficiency, and much untapped potential still remains.

Drawing on this national context, the South African National Energy Development Institute (SANEDI), identified EEDSM as a short-term priority to address the constrained electricity reserve margin in South Africa. The development of human capital in the energy efficiency field was then identified as a key component to not only facilitate the management of the electricity crisis but also to position the country to more fully develop energy efficiency as an energy resource. In order to deepen knowledge in the field and to facilitate an increase in relevant skilled professionals, SANERI, with support from the DST, commissioned the development of a postgraduate programme in EEDSM in 2008. Following a competitive bidding process, UP was appointed by SANERI to establish the EEDSM hub within its Faculty of Engineering, Built Environment, and Information Technology. To provide an institutional base, the hub was housed within the university's existing Centre of New Energy Systems (CNES), as part of the Department of Electrical, Electronic and Computer Engineering. The overriding aim of the EEDSM hub is to:

"Lead and drive fundamental and applied research of energy efficiency and demand side management, with a strong focus on human capital development, vertical expansion of the knowledge base and to stimulate innovation and commercialisation of energy-efficient products and services" (DST, 2013).

However, an overview of the research and technology development in energy efficiency and demand side management in South Africa has not yet been undertaken. The EEDSM hub completed its first five-year programme in 2013, at which point a third-party review was undertaken. Camco Clean Energy ('Camco') was appointed by the DST to provide an independent review of the EEDSM hub at UP (Camco, 2013), focusing on its progress to date and to make recommendations with regard to future plans. In 2014, ASSAf compiled a report on the status of South African energy research (ASSAf, 2014), in which a brief summary was included for the research on energy efficiency and energy storage.

The focus of this chapter is to identify and report on the most prominent research areas in energy efficiency in South Africa, at a broad level. To this end, a review, assessment and analysis of the state of electrical energy efficiency technology RDI in South Africa was undertaken to inform the DST of opportunities for further development in terms of human capital development, intellectual property output, technology development and innovation, in order to promote the adoption of energy-efficient technologies in South Africa. 
The results of this study will be a measure of the effectiveness and competitiveness of the national energy efficiency innovation system and serve as a baseline for the DST to identify the appropriate energy efficiency RDI policy interventions for the next ten years and beyond.

\subsection{Scope and extent}

The review of the state of electrical energy efficiency technologies in South Africa will provide a broad overview of RDI in energy efficiency technologies in South Africa and, to a certain extent, internationally (mainly as an introduction). This will be followed by a focus on technologies of national importance and strength such as smart grids, solid-state lighting (SSL), and tribology.

The structure of this chapter is as follows: the methodology used to report on research outputs is described, followed by a balanced and representative classification of categories of South African research strengths, activities and opportunities in energy efficiency. A more in-depth account of each of the identified categories is given to benchmark the results against international trends. The national institutional strengths and local leading researchers are also identified. Finally, observations and recommendations are given.

\subsection{Methodology}

All the data collected and used in this report were gathered from published results reflected in the public domains of South African and international institutions, as well as in international peer-reviewed databases for country benchmarking purposes. Unfortunately, this report could not involve activities in all organisations and industry sectors since a reliable database from which to extract their achievements and the success of their research is not available.

Available searchable databases that can be used for this type of study include, but are not limited to, Scopus, Sciencedirect, Worldwidescience, Scienceopen and Pubget. However, not all of them have smart tools for tracking, analysing and visualising data in great detail. For instance, while Sciencedirect is a major database for this type of study, it lacks necessary filter and analytical tools. Scopus is the largest abstract and citation database of peer-reviewed literature, scientific journals, books and conference proceedings, delivering a broad overview of the world's research output in the fields of science, technology, social sciences, medicine, arts and humanities. One of the features that distinguishes Scopus from other search engines is the availability of smart tools to track, analyse and visualise research in granular detail (Elsevier ${ }^{1}$ ) and it was therefore chosen as the main research tool. A comparison of Scopus with a few other databases was given in Falagas et al. (2008). Most electronic search engines or database websites use a list of keywords to decide whether and when to display related articles 
to interested readers. To take advantage of this feature, the research part of this report is based on relevant keywords in energy efficiency. Scopus' built-in smart tools were used to isolate the results for each country. Another advantage of Scopus is that it can show the patents related to each research field as well.

The first step of this study was to assemble a comprehensive list of keywords in the fields related to electrical energy efficiency (Appendix 3). These keywords were chosen so that the entire field could be covered. The IEA (IEA, 2014; 2016), the National Energy Efficiency Strategy of South Africa (DoE, 2012) and the South African Energy document (RSA, n.d.) and academic keywords collected from various related professions were the main resources for the consolidated list.

The selection of keywords also took into consideration the international trend of energy efficiency practices in representative countries. The American Council for an Energy-Efficient Economy Biennial International Energy Efficiency Scorecard evaluates the energy efficiency policies and performance of the top energy-consuming countries of the world by using more than 27 metrics to evaluate each country's national commitment to energy efficiency, as well as its efficiency policies and performance in the building, industry and transportation sectors. The 2012, 2014 and 2016 International Energy Efficiency Scorecards analysed the world's 12, 16 and 23 largest economies respectively, covering more than $80 \%$ of global GDP and about $70 \%$ of global electricity consumption (Hayes et al., 2012; Young et al., 2014; Kallakuri et al., 2016). From the international scorecards over the years 2012, 2014 and 2016, the best performance sectors and top EEDSM technologies were identified. The top-scoring countries (Germany, Japan, Italy, France and the United Kingdom (UK)) have top-scoring sectors in industries, buildings, transportation and national efforts, with technologies and programmes such as tax credits and loan programmes, building labelling, mandates for energy audits, appliance and equipment labelling, and fuel economy standards for light-duty vehicles. The BRICS countries' top-scoring sectors are in buildings and transportation, with the main four means of EEDSM interventions being tax, voluntary manufacture agreements, use of public transit and energy management policies. It is also pointed out in the reports that South Africa's lowest scoring areas are in spending on energy efficiency, spending on energy efficiency R\&D, building retrofit policy, mandatory energy audits and fuel economy standards for light-duty vehicles.

After the keywords were selected, search results were obtained from Scopus for South Africa. A careful examination of the results revealed that further classification could be done by narrowing down the keywords into sub-lists. These are established field versus emerging field, restructuring field versus declining field, general area versus subject area, old versus new areas and, strong versus average areas.

After studying the general search results and re-organising the keywords, the following ten fields or areas were identified, broadly guided by the focus on 
electrical energy efficiency, as well as notable contributions in the fields of tribology and batch chemical processes:

- Smart grid

- Tribology

- $\quad$ Solid-state lighting

- $\quad$ Industrial energy systems in mining, metallurgy and mineral processing (MMM)

- Integrated building energy systems

- $\quad$ Energy storage

- $\quad$ Power systems

- Renewable energy

- $\quad$ Batch chemical processes

- Measurement and verification.

Some of the keywords are interrelated and cross fields, while others are less relevant to energy efficiency. These issues were resolved by restricting search results in relevant subject areas to energy efficiency. Batch chemical processes, industrial energy systems, integrated building energy systems, power systems, renewable energy and smart grids were limited to either the energy or engineering subject areas. Industrial energy systems in MMM were limited to either the energy, environmental science or engineering subject areas. Energy storage was limited to either of the energy, engineering, chemistry, or material science subject areas. SSL was limited to either the subject area of energy, chemistry, or material science. Tribology and M\&V were limited to the subject area of energy.

Technology develops rapidly, and as a result, old research results and technologies have the tendency to become obsolete quickly. In this study, a 30-year history of records was searched, up to and including the most upto-date results available at the time, i.e. November 2016. It should be noted that the figures for 2016 will change as further publications are captured in the data for the full year.

\subsection{Energy efficiency technology classifications for South Africa by keywords}

\section{Industrial energy systems in MMM}

The MMM industries constitute some of the important parts, if not the most important, of the industrial complex in South Africa. It is apparent from the general search results that this area represents the strongest presence of South Africa's technology contributions. It typically involves modelling, optimisation, and control of such industry energy systems from the equipment level, such 
as motors, pumps, fans, or conveyor belts, as well as the system and process integration levels in MMM for energy efficiency. The list of keywords to capture this area is given in Appendix 3-A.

\section{Micro-grids}

Recent technological advancements make it possible to redefine a number of traditionally established areas. One such field is micro-grids, also known as distributed energy systems or integrated energy systems. A micro-grid is a small-scale power and energy grid that can operate independently or in conjunction with a district's main energy grids. Even though its exact scope is still under debate, it is commonly believed that this is a restructuring field, arising from the following four traditionally strong research areas in which South Africa has shown great strength. In some sense, smart grids and SSL are believed to be sub-research areas of this broad research field.

\section{Renewable energy}

Renewable energy is generally defined as the energy harvested from replenishable natural resources such as solar, wind, rain, tides, waves and geothermal heat. According to the United Nations Environment Programme (UNEP), South Africa was one of the top ten countries in 2014 that invested in renewable generation capacity. In the same year, South Africa became the tenth biggest solar market in the world for installations sized $5 \mathrm{MW}$ and above (RSA, n.d.). The list of keywords to capture this area is given in Appendix 3-B.

\section{Power systems}

A power system can be defined as the combination of all the components used in the generation, transmission and distribution of electricity. The research area of power systems is broad and includes all aspects of electric power systems. The list of keywords to capture this area is given in Appendix 3-C.

\section{Integrated building energy systems}

In recent years, research into building energy systems has expanded into a multi-disciplinary field covering power engineering (power quality), computer and software engineering (ambient intelligence of appliances including LEDs, in particular smart grids and networks), energy engineering (energy balance and dispatching), and reliability and maintenance engineering (retrofitting and renovation). Many believe that this area itself is broader than microgrids, and in this sense, it should stand as an independent research area. In this report, it is placed here for its apparent relevance to micro-grids, and the interactions of the four subareas listed in Section 3.4.2. The list of keywords to capture this area is given in Appendix 3-D.

\section{Energy storage}

Electrical energy can be stored during times when production exceeds consumption, and it can be returned to the grid when production falls below 
consumption. Energy storage can decrease the need for significant new transmission grid construction upgrades, and also increases the efficiency of existing transmission and distribution assets. The list of keywords to capture this area is given in Appendix 3-E.

\section{Solid-state lighting}

A solid-state light is a type of lighting device that uses semiconductor light sources such as LEDs, polymer light-emitting diodes (PLEDs) or organic lightemitting diodes (OLED) as sources of illumination. These devices consume less energy than their incandescent or fluorescent counterparts and produce the same or significantly more illumination (Khanna, 2014; Yoshimura et al., 2016). The list of keywords to capture this area is given in Appendix 3-F.

\section{Batch chemical processes}

A batch process is a process which involves separate tasks being performed in accordance with a predefined sequence in a process that transforms raw materials into final products. Currently, batch chemical processes play an important role in the chemical processing industry, which comprises roughly $12 \%$ of the industrial energy demand in the European Union (EU) (European Commission, 2009). While fairly new to the energy efficiency considerations, batch chemical processes are an internationally accepted means to increase energy efficiency in manufacturing. The list of keywords to capture this area is given in Appendix 3-G.

\section{Emerging energy technologies}

The selection of research areas under emerging energy technologies was guided by the DST's prior knowledge and the distinctive features demonstrated in the Scopus search results. Many other potential topics are possible, but were omitted due to the time limitation of this study; topics omitted include electric vehicles, super-efficient equipment and appliances that allow reduction in the load of renewable energy needed, notably relevant in solar home systems, energy management, sensors (for lighting, heating, cooling, air quality/ventilation, etc.), and direct load control of water heaters.

\section{Tribology}

Tribology is the study of friction, wear and lubrication. A considerable amount of energy is lost to friction in machines, and significant energy efficiency improvements can be achieved by addressing these aspects (Stachowiak and Batchelor, 2005). The list of keywords to capture this area is given in Appendix 3-H.

\section{Smart grids}

A smart grid is a system that controls electricity demand in a reliable, sustainable and economical manner, built on an advanced foundation and 
tuned to reduce electricity waste and energy costs (Buchholz and Styczynski, 2014). A smart grid deals with electricity, while micro-grids deal with other types of energy as well. The list of keywords to capture this area is given in Appendix 3-I.

\section{Measurement and verification}

Before energy efficiency strategies can be devised, established energy systems must undergo tests and measurements. After implementation, M\&V is used to determine the true savings realised by the project (EOV, 2012; Zia and Zhang, 2014). The list of keywords to capture this area is given in Appendix 3-J.

\subsection{Results}

Energy efficiency technologies in each of the above fields and areas were investigated separately, with a brief review, assessment and analysis of the current and historic progression in South Africa, and an international benchmarking.

\subsubsection{National performance comparison in the selected areas}

Figure 3-1 shows the number of publications in South Africa per year in each area over the 30-year period from 1986 to 2016. The figure illustrates the relative size and performance of each category and shows the reasons for the classifications used in the previous section of this report.

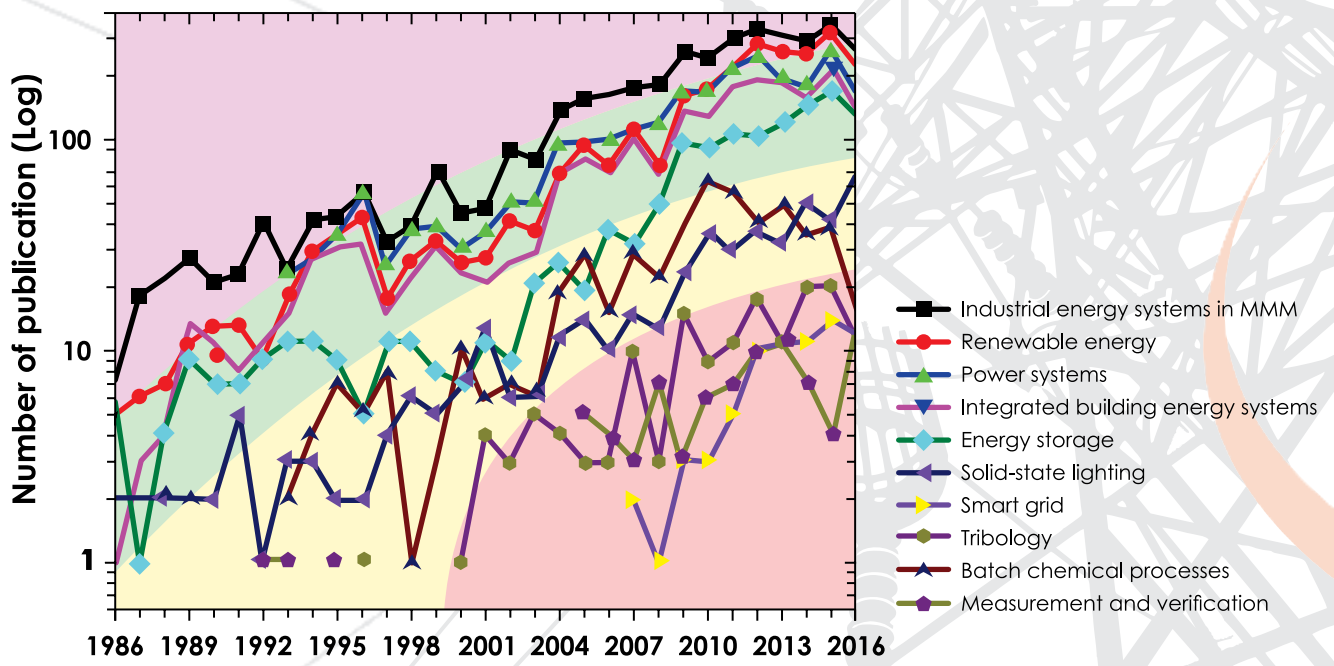

Figure 3-1: Number of publications originating from South Africa per year in each area 
The first category of industrial energy systems in MMM stands out as the largest and traditionally strongest South African research area. The second category is micro-grids, including renewable energy, power systems, and integrated building energy systems, which have grown concurrently, and energy storage which is gaining ground as these four areas converge in terms of output. There is significant potential for growth in this category. The third category comprises the areas with some research history in South Africa: SSL and batch chemical processes. SSL is growing, while the research in batch chemical processes has shown fluctuation and decline in recent years. The final category is emerging energy technology research areas: smart grids, tribology, and $M \& V$. These are very young fields in South Africa showing rapid growth, and which are yet to stabilise.

\subsubsection{International comparisons}

It is important to benchmark South African research outputs against international trends. The comparator countries considered in this study are divided into separate groups, namely: developed countries, BRICS countries, best-performing countries (China and Iran) and countries at the same development stage as South Africa (Egypt and Thailand). The selected countries are thus the US, China, Russia, India, Brazil, Australia, Egypt, Germany, Iran, and Thailand. This type of comparison assists in reaching a conclusion with regard to the relative strength and weakness of South Africa in the chosen areas.

Table 3-1 shows the number of publications and percentage contribution of South Africa to the world research output in each field in the recent 30 years (1986 to 2016). M\&V stands out as an area with the largest contributions, at roughly $1 \%$ of world's total output. Industrial energy systems in $M M M$, smart grids and power systems contribute around $0.59 \%, 0.52 \%$ and $0.5 \%$ respectively. It should not be concluded that the leading research area in South Africa is M\&V since the total number of publications in this area is very small (89), as is the case with smart grids too (73).

Table 3-2 shows the number of patents in South Africa in each area, as well as South Africa's percentage contribution to the global output. South Africa does not fare well in this regard, with a very small percentage contribution. Part of the reason for this might be that South African patents are not filed globally. 

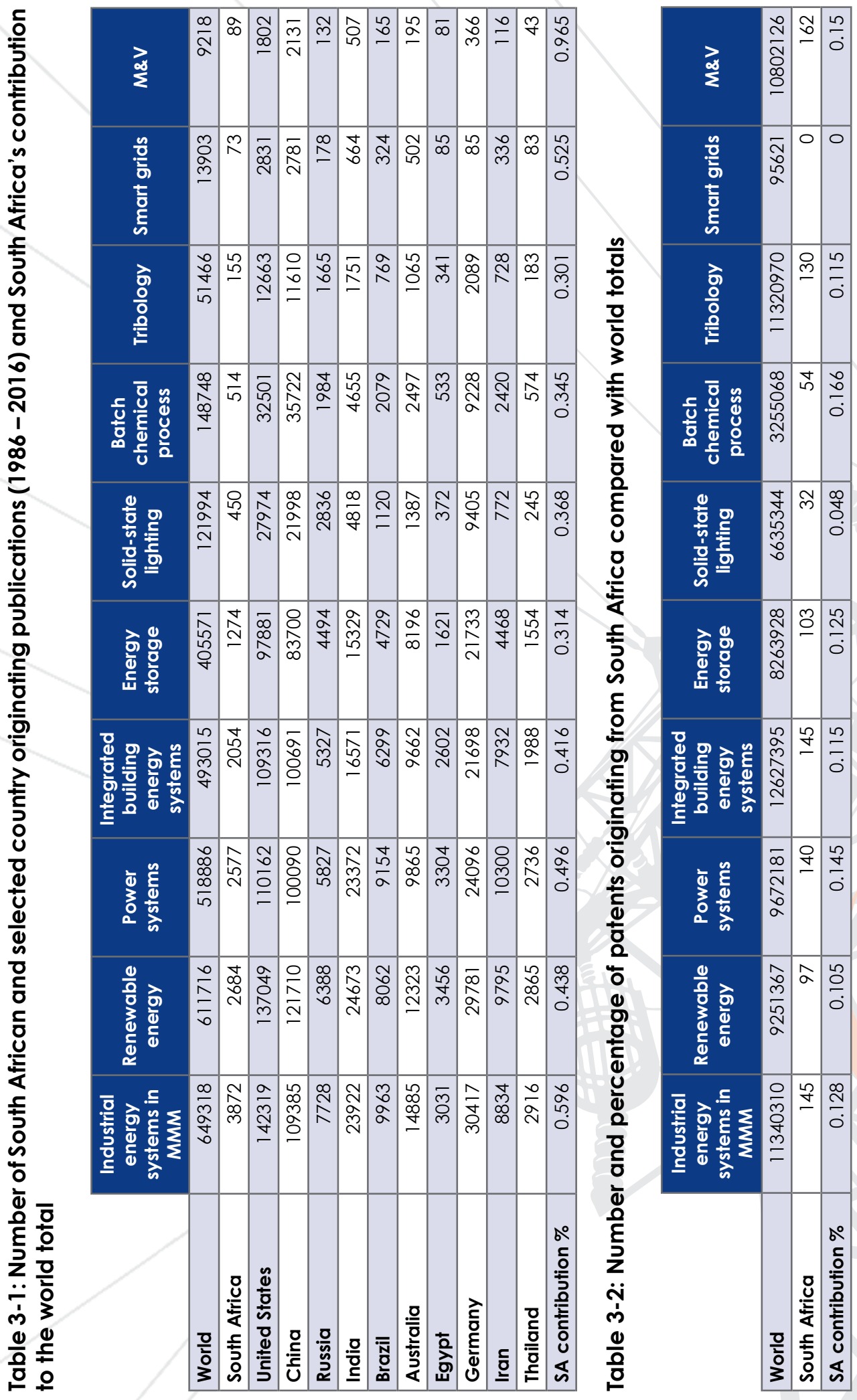


\subsubsection{Results in individual research areas}

\section{Industrial energy systems in mining, metallurgy and mineral processing (MMM)}

Figure 3-2 shows the institutions and researchers that are most active in the area of industrial energy systems in MMM in South Africa. This figure shows that UP leads with 561 publications, followed by the University of Cape Town (UCT) with 535 publications. ${ }^{2}$
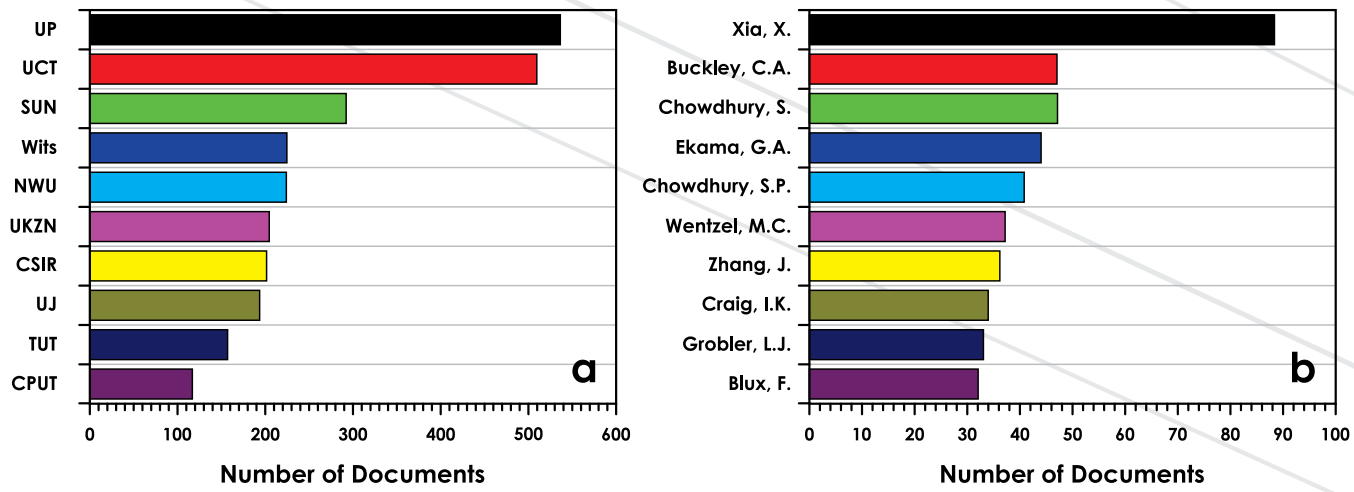

\section{Figure 3-2: Names of the most active (a) institutions and (b) authors in industrial energy systems in MMM}

Figure 3-3 (a) shows the number of publications in industrial energy systems in MMM in South Africa compared with selected countries over the period 1986 to 2016 . It can be seen that South Africa compares well with countries like Egypt and Thailand. Iran and China have increased their number of publications in this area more rapidly compared with the others. The US led the field until around 2009, when China surpassed it and produced the most publications. The sheer number of researchers in China has undoubtedly contributed to this growth. In Iran, international sanctions have likely forced the country into investing more resources into energy R\&D. The rapid growth in South African research output in this field after 2000 is noted (Figure 3-3 (b)) with the rising cost of energy and the increasing focus on reducing harmful emissions serving as the dominant drivers for this trend. 

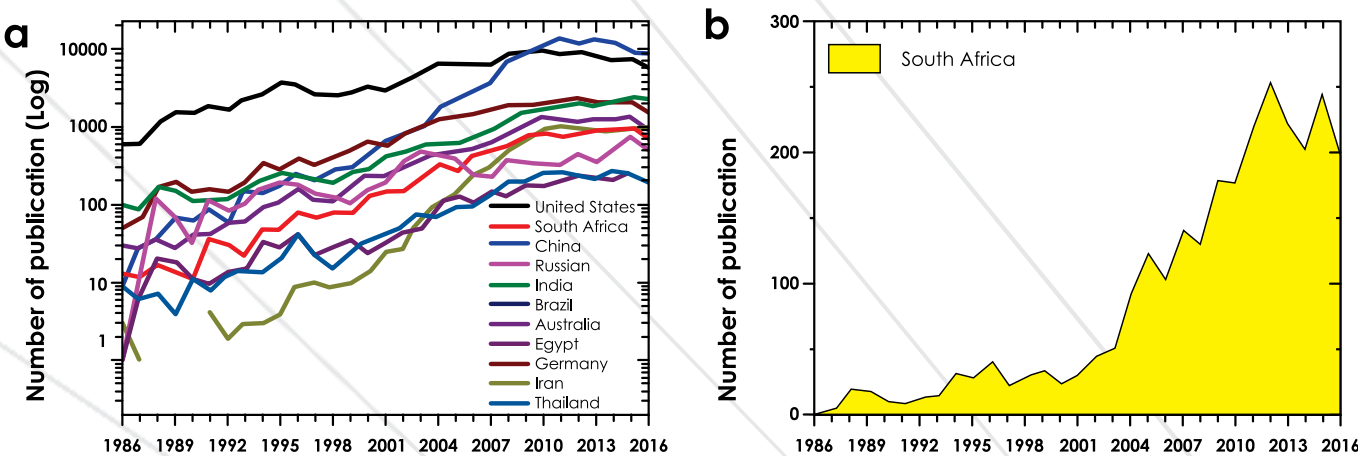

Figure 3-3: Number of publications in industrial energy systems in MMM per year originating from (a) selected countries and (b) South Africa

\section{Renewable energy}

Figure 3-4 shows the institutions and researchers that are most active in the area of renewable energy in South Africa. UCT leads with 396 papers, followed by UP with 306 papers. ${ }^{3}$
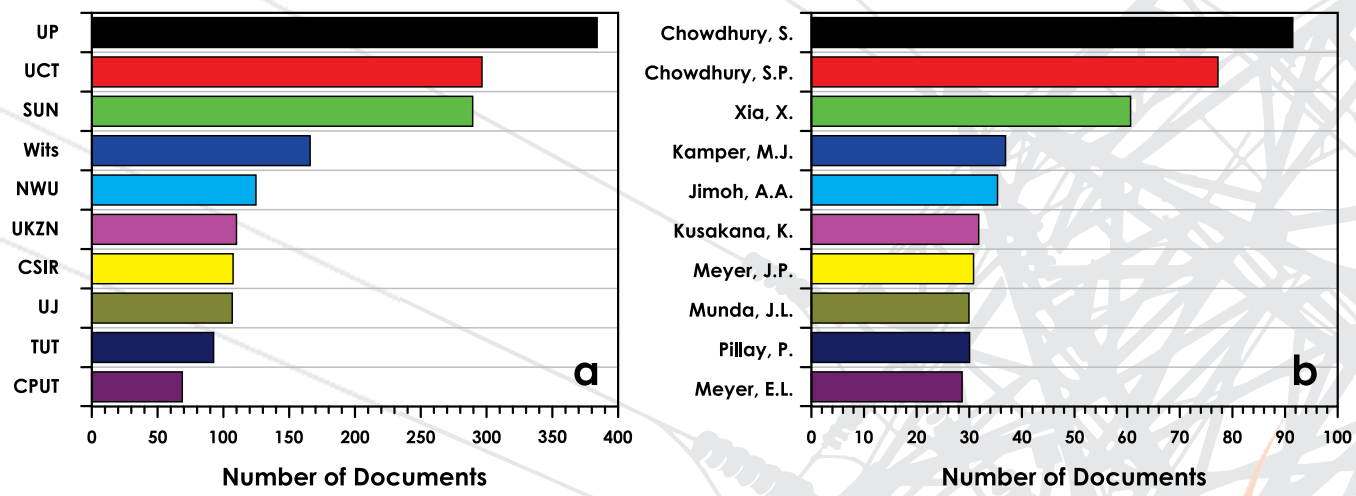

Figure 3-4: Name of most active (a) institutions and (b) authors in renewable energy in South Africa

Professor S. Chowdhury from UCT is leading with 92 papers, while Professors S.P. Chowdhury, X. Xia and M.J. Kamper follow with 78, 61 and 37 papers respectively. 
Figure 3-5 (a) compares South African research outputs in renewable energy with that of selected countries, while Figure 3-5 (b) shows only South African research outputs.
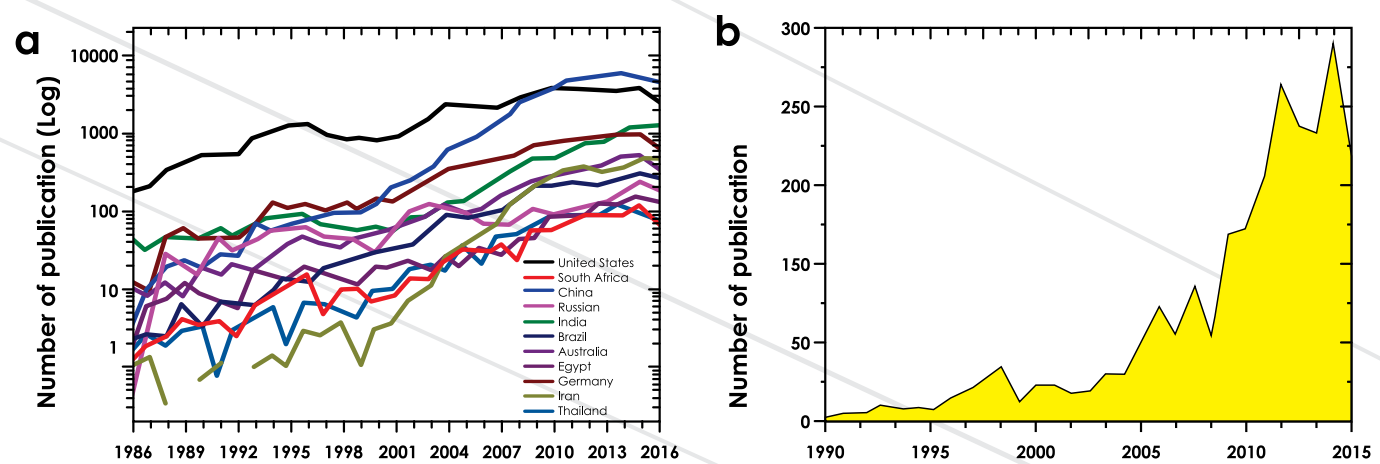

Figure 3-5: Number of publications in renewable energy per year originating from (a) selected countries and (b) South Africa

\section{Power systems}

In power systems, UCT leads with 478 papers according to Figure 3-6 (a). Figure 3-6 (b) identifies the most active authors in this area in South Africa. ${ }^{4}$
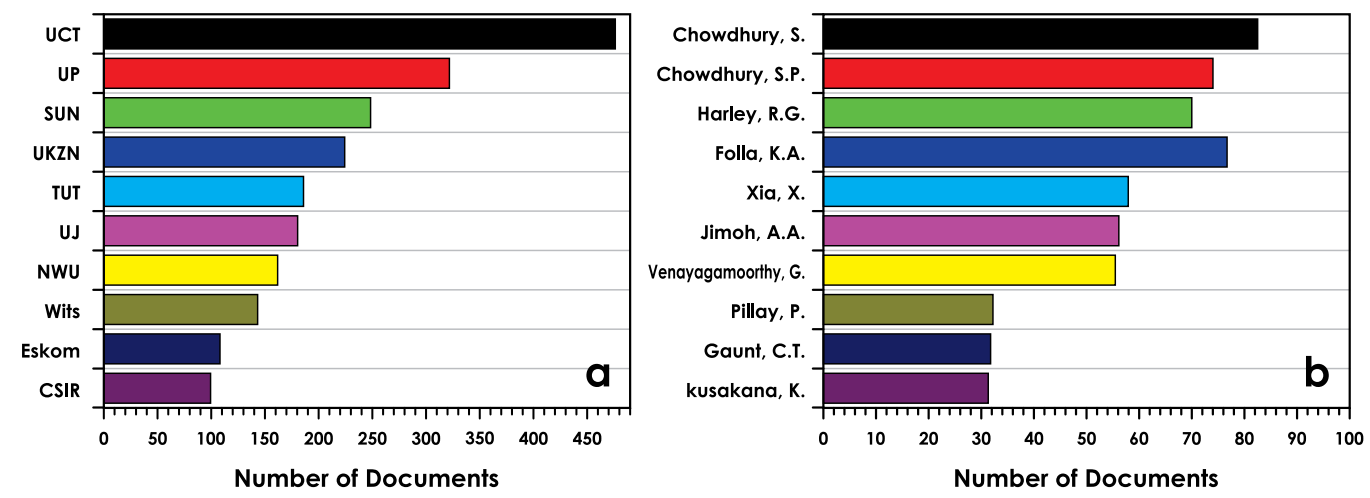

Figure 3-6: Names of most active (a) institutions and (b) authors in power systems in South Africa 
Figure 3-7 (a) compares South Africa research outputs, which are shown in

Figure 3-7 (b), with that of selected countries in the area of power systems.
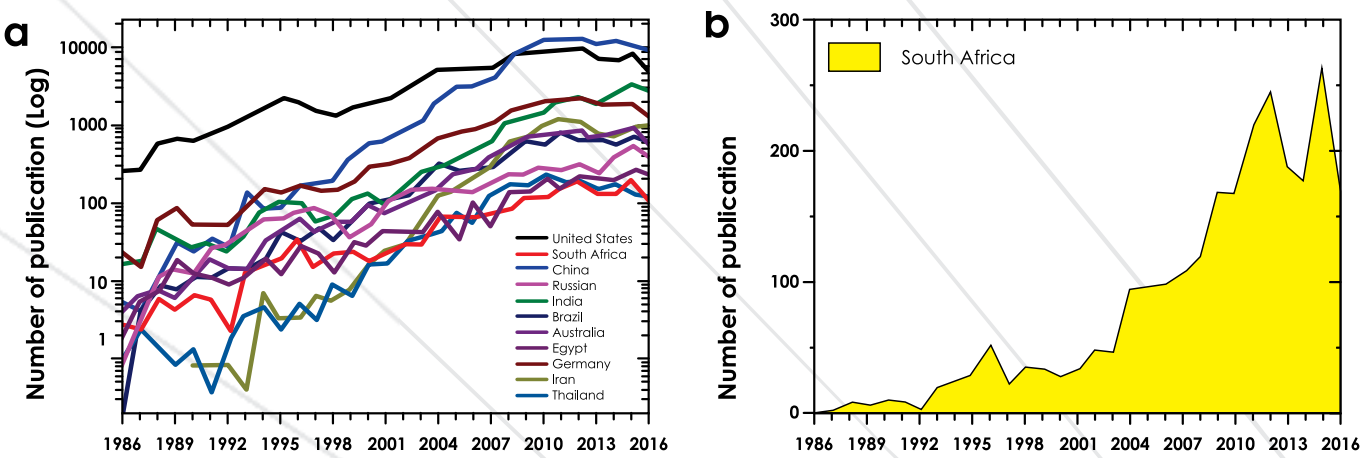

Figure 3-7: Number of publications in power systems per year originating from (a) selected countries and (b) South Africa

\section{Integrated building energy systems}

Figure 3-8 shows most active institutions and authors in the area of integrated building energy systems in South Africa. UP leads with 337 papers, followed by UCT with 332 papers. ${ }^{5}$
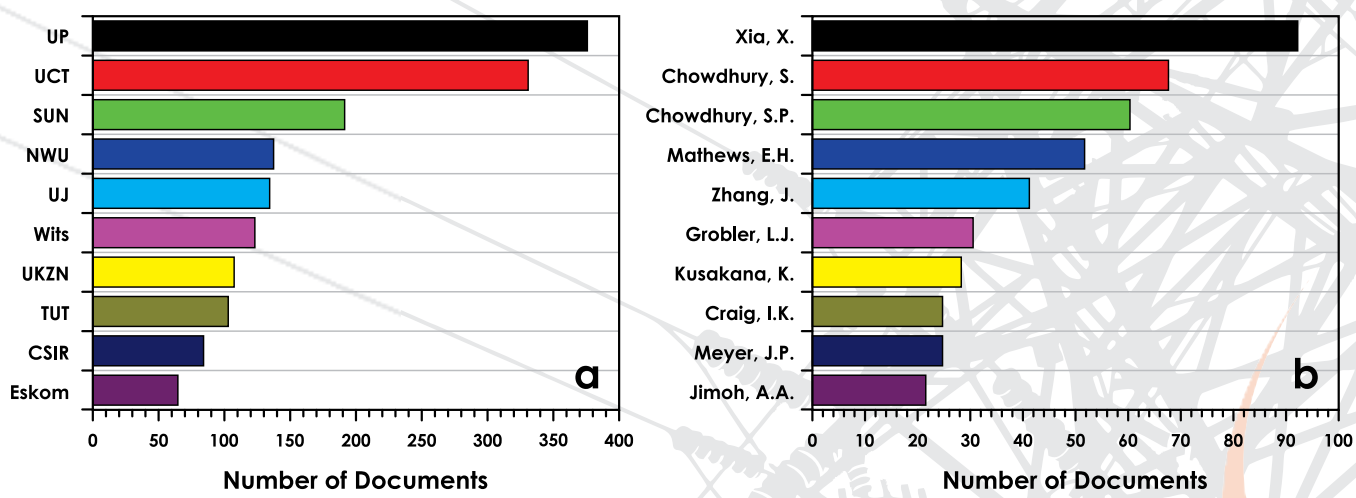

Figure 3-8: Names of most active (a) institutions and (b) authors in integrated building energy systems in South Africa 
Figure 3-9 (a) shows how South African outputs in integrated building energy systems, depicted in Figure 3-9(b), compare with other countries.

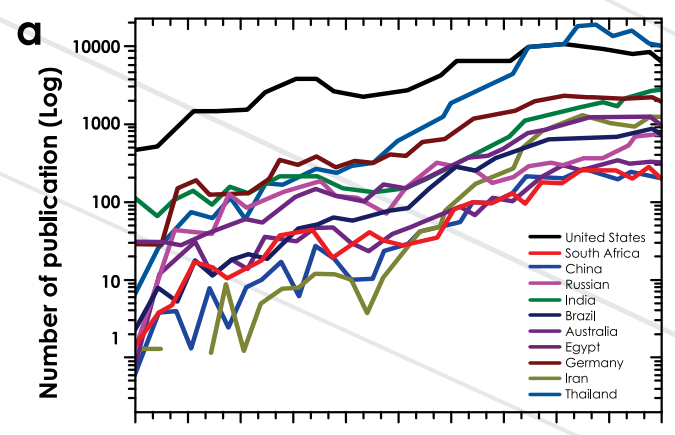

19861989199219951998200120042007201020132016

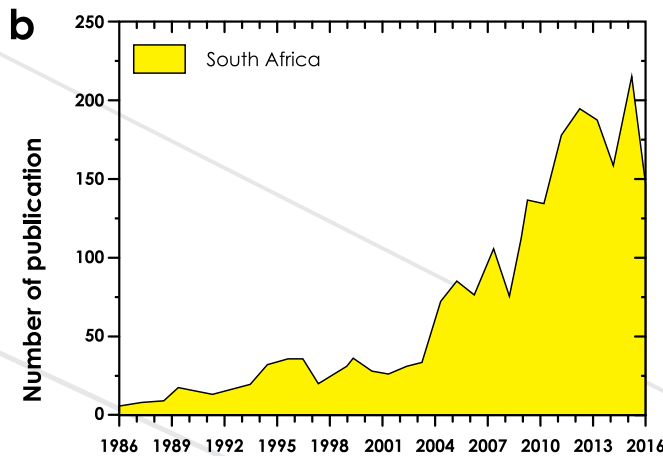

19861989199219951998200120042007201020132016

Figure 3-9: Number of publications in integrated building energy systems per year originating from (a) selected countries and (b) South Africa

\section{Energy storage}

Figure 3-10 shows the most active institutions and authors in the area of energy storage in South Africa. UCT leads with 168 papers, followed by UP with 161 papers. ${ }^{6}$
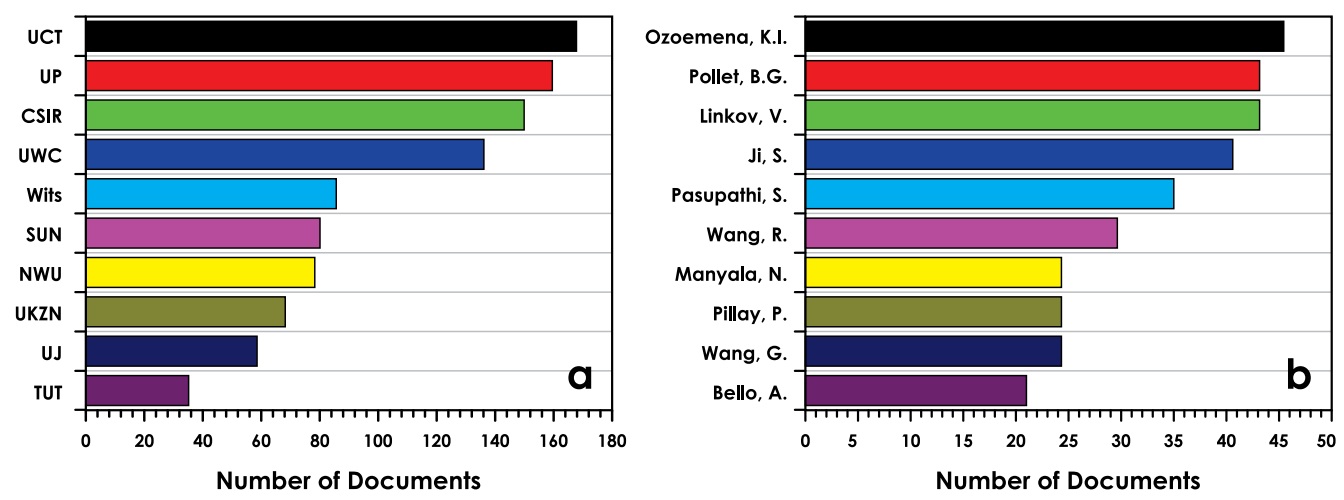

Figure 3-10: Names of most active (a) institutions and (b) authors in energy storage in South Africa 
Figure 3-11 (a) shows how South African outputs in energy storage, shown in Figure 3-11 (b), compare with other countries.
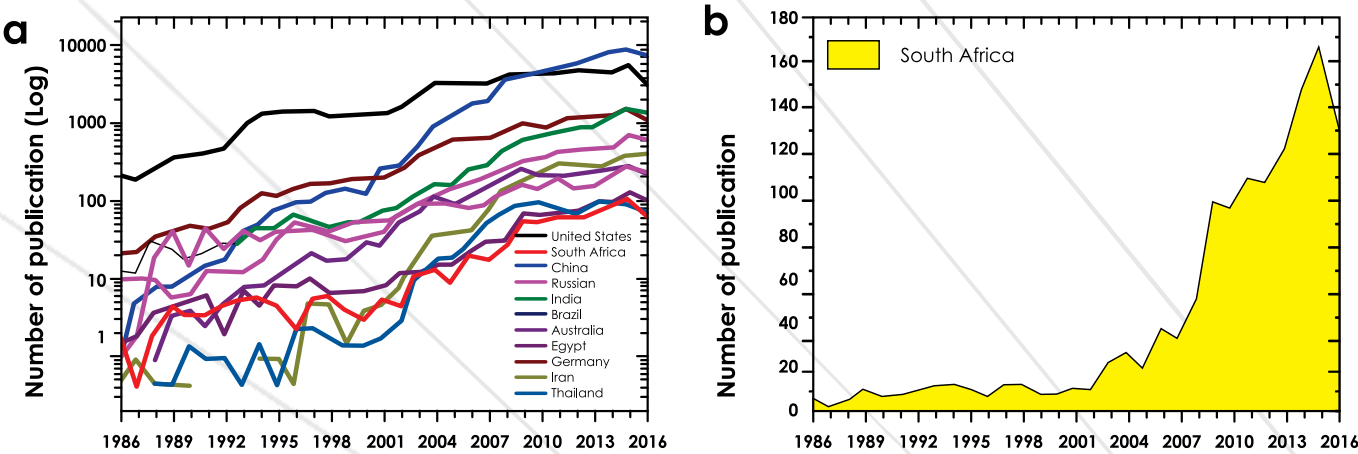

Figure 3-11: Number of publications in energy storage per year originating from (a) selected countries and (b) South Africa

\section{Solid-state lighting}

Figure 3-12 shows the most active institutions and authors in the area of SSL in South Africa. The University of the Free State (UFS) with 199 papers ranks highest and UP follows with 63 papers.?
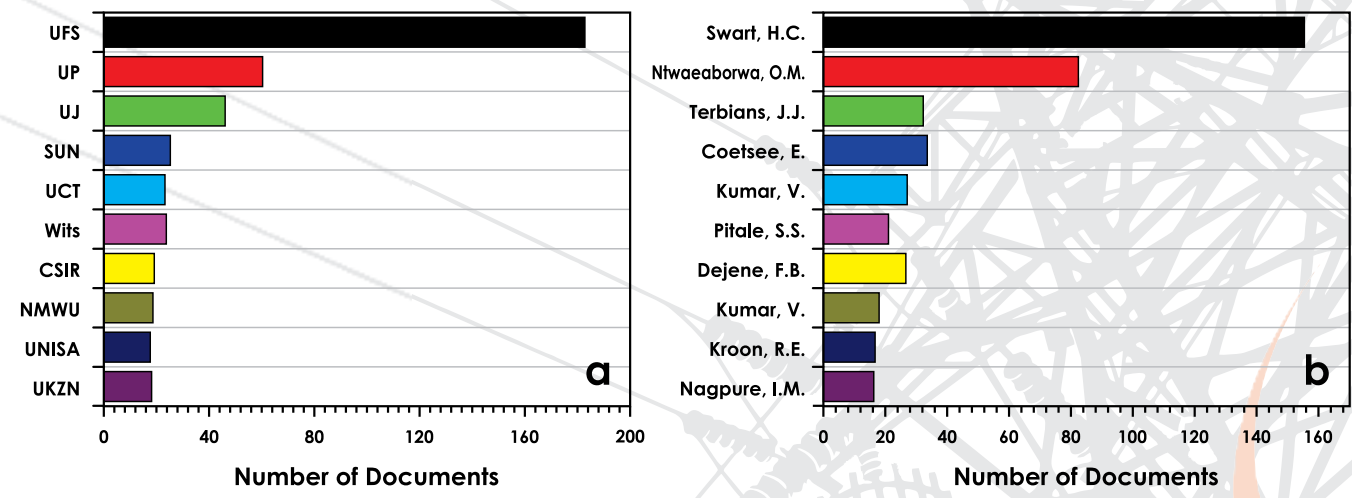

Figure 3-12: Names of most active (a) institutions and (b) authors in solidstate lighting in South Africa

Professor H.C. Swart from UFS with 162 papers is leading, while Professors O.M. Ntwaeaborwa, J.J. Terblans, and E. Coetsee follow with 84, 33 and 32 papers respectively. 
Figure 3-13 (a) shows how South African outputs in SSL, shown in Figure 3-13 (b), compare with other countries.

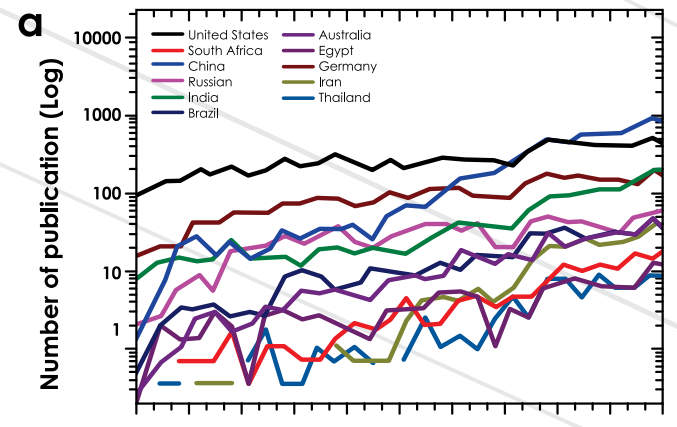

19861989199219951998200120042007201020132016

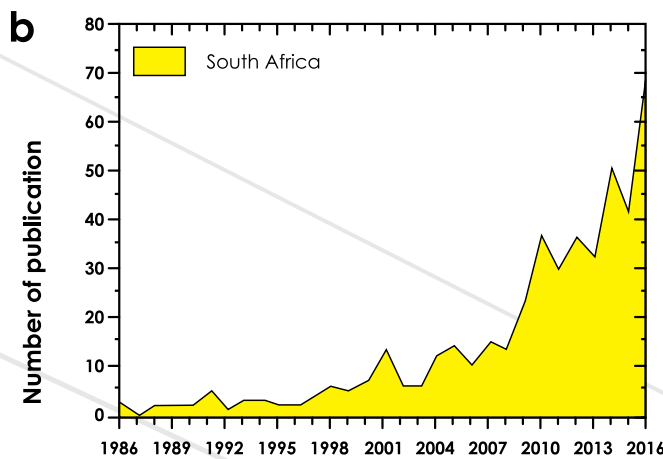

19861989199219951998200120042007201020132016

Figure 3-13: Number of publications in solid-state lighting per year originating from (a) selected countries and (b) South Africa

\section{Batch chemical processes}

Figure 3-14 shows the most active institutions and authors in the area of batch chemical processes in South Africa. UP leads with 92 papers and UCT follows with 70 papers. ${ }^{8}$
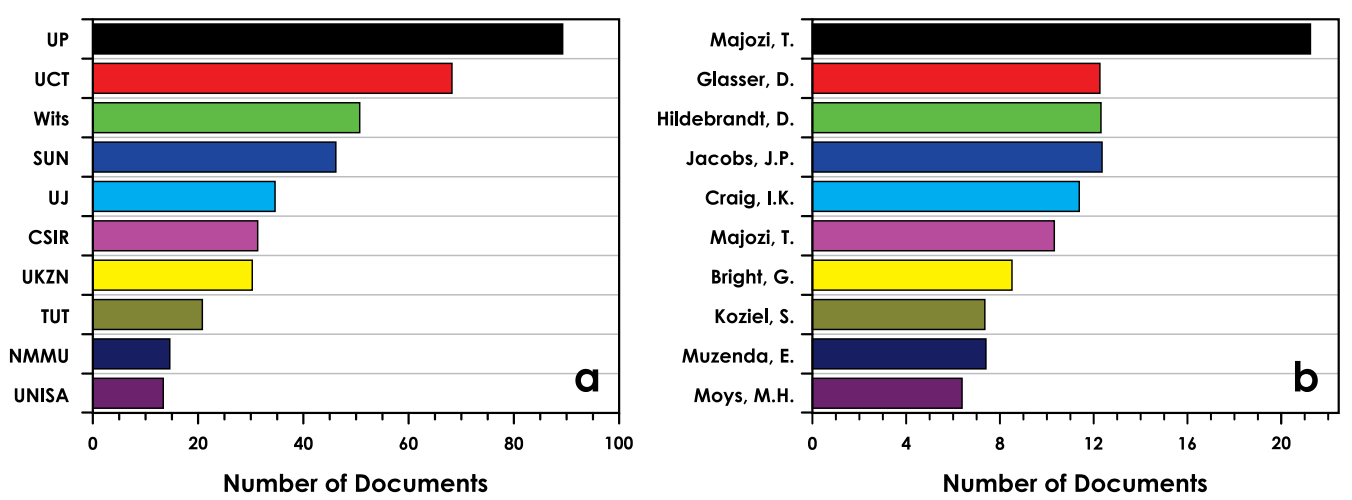

Figure 3-14: Names of most active (a) institutions and (b) authors in batch chemical processes in South Africa

Professor T. Majozi from the University of the Witwatersrand (Wits) is leading the area with 21 papers, while Professors D. Glasser, D. Hildebrandt, and J.P. Jacobs follow with 12 papers each respectively. 
Figure 3-15 (a) shows how South African outputs, shown in Figure 3-15 (b), compare with other countries.
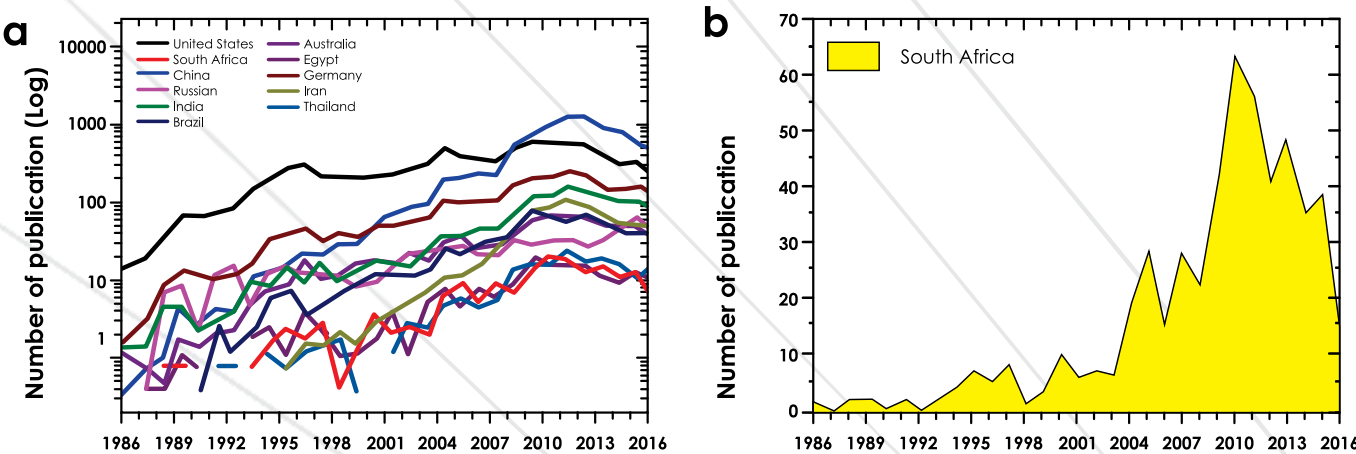

Figure 3-15: Number of publications in batch chemical processes per year originating from (a) selected countries and (b) South Africa

\section{Tribology}

Figure 3-16 shows most active affiliations and authors in the area of tribology in South Africa. UCT leads with 25 papers and UP follows with 18 papers.?
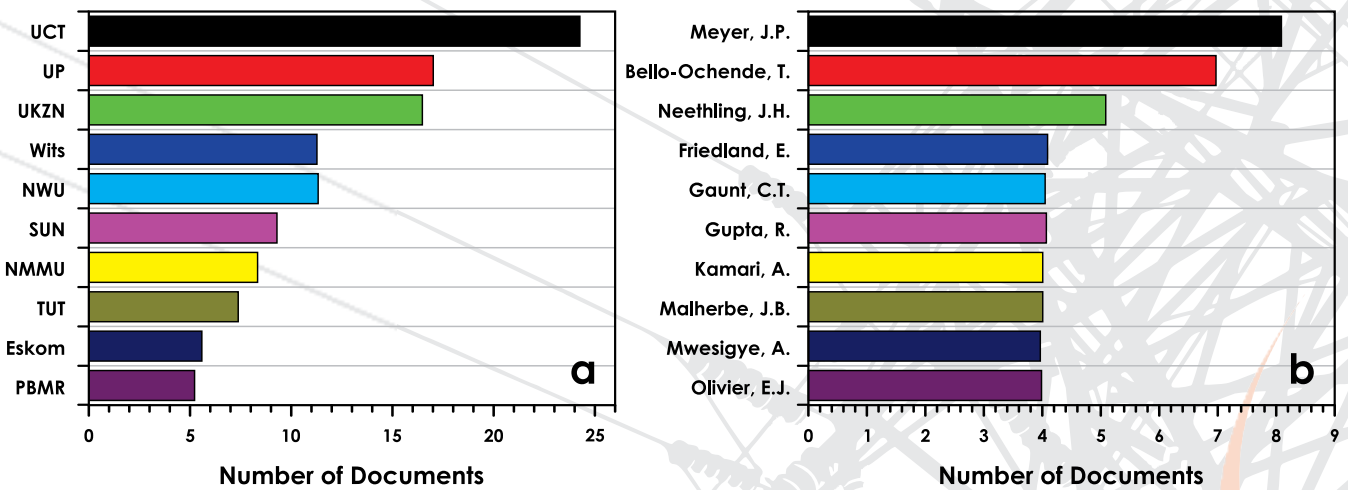

Figure 3-16: Names of most active (a) institutions and (b) authors in tribology in South Africa 
Figure 3-17 (a) shows how South African outputs, shown in Figure 3-17(b), compare with other countries.
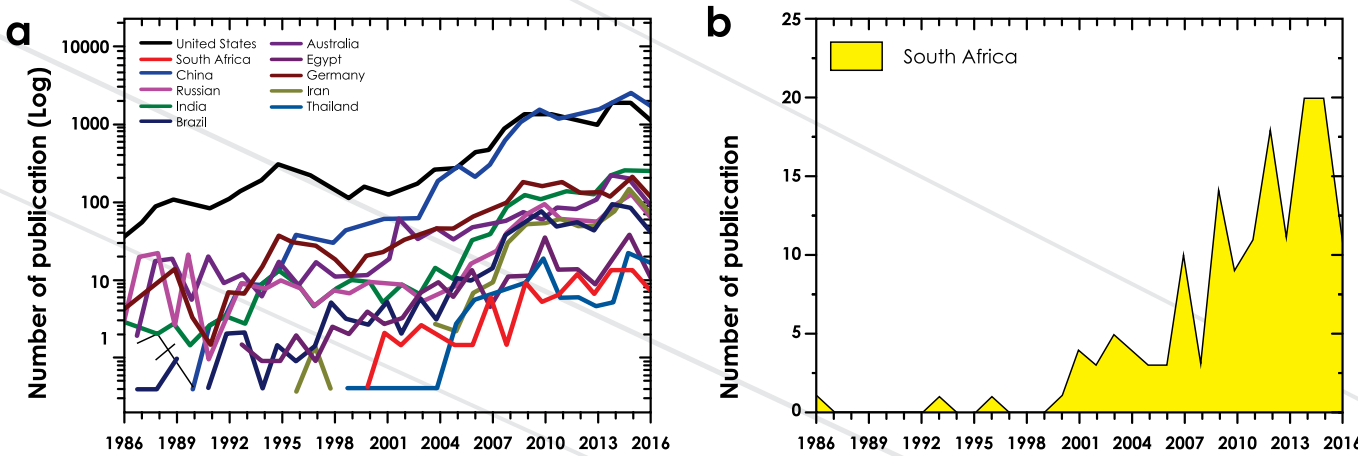

Figure 3-17: Number of publications in tribology per year originating from (a) selected countries and (b) South Africa

\section{Smart grids}

Figure 3-18 shows the most active institutions and authors in the area of smart grids in South Africa. UP leads with 15 papers, while UCT follows with 13 papers. ${ }^{10}$
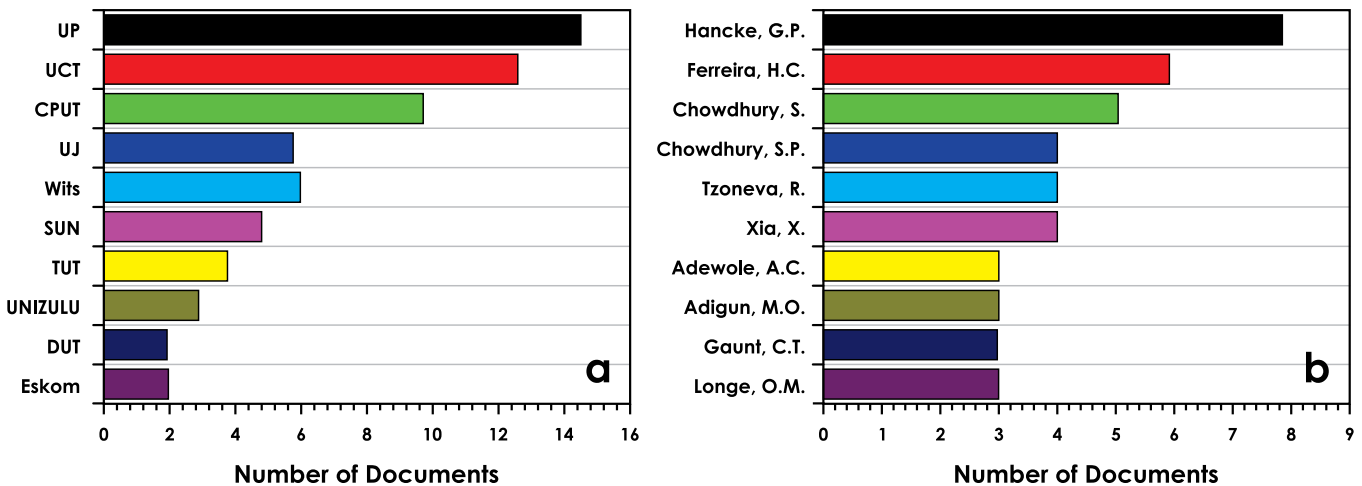

Figure 3-18: Name of most active (a) institutions affiliations and (b) authors in smart grids in South Africa

Professor G.P. Hancke from UP is the leading author with 8 papers, while Professors H.C. Ferreira and S. Chowdhury follow with 6 and 5 papers respectively. 
Figure 3-19 (a) shows how South African outputs, shown in Figure 3-19 (b), compare with other countries.
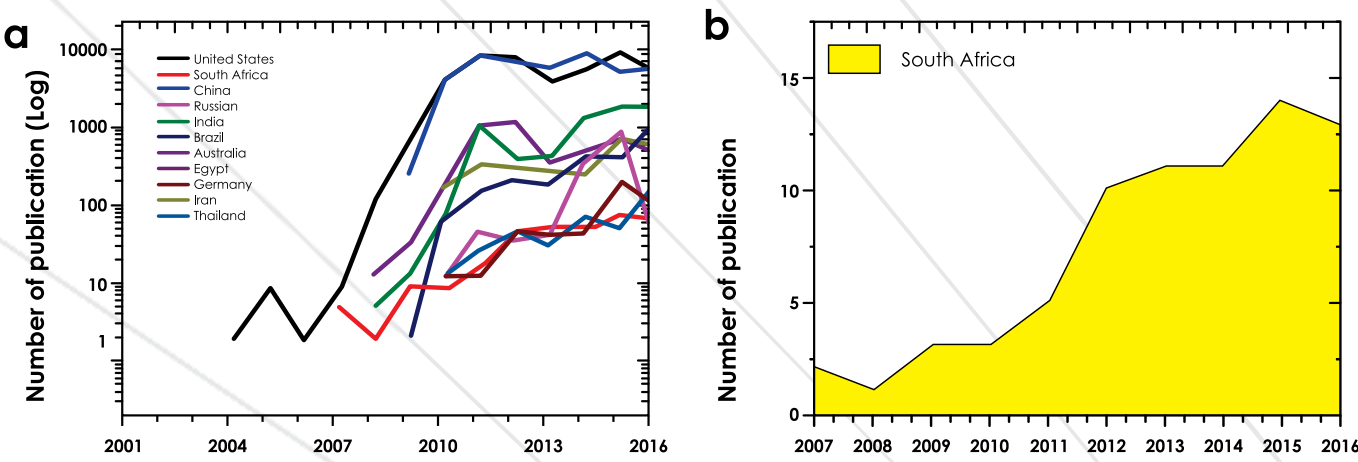

Figure 3-19: Number of publications in smart grids per year in (a) selected countries and (b) South Africa

\section{Measurement and verification}

Figure 3-20 shows the most active institutions and authors in the area of $M \& V$ in South Africa. North-West University (NWU) leads with 32 papers, while the University of Johannesburg (UJ) follows with 13 papers. ${ }^{11}$
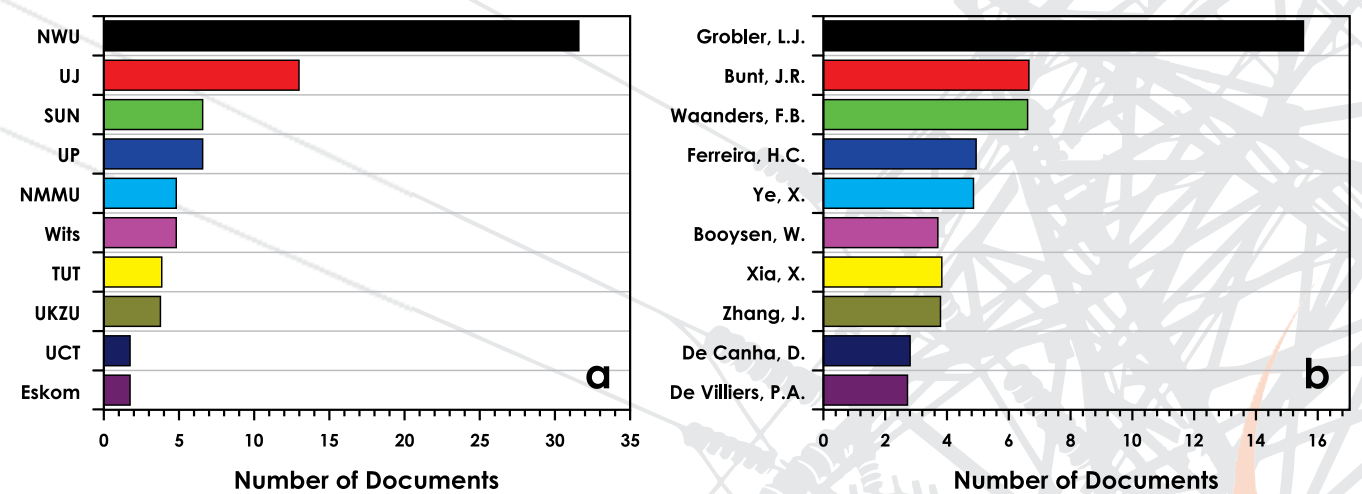

Figure 3-20: Names of most active (a) institutions and (b) authors in M\&V in South Africa 
Figure 3-21 (a) shows how South African outputs, shown in Figure 3-21 (b), compare with other countries.
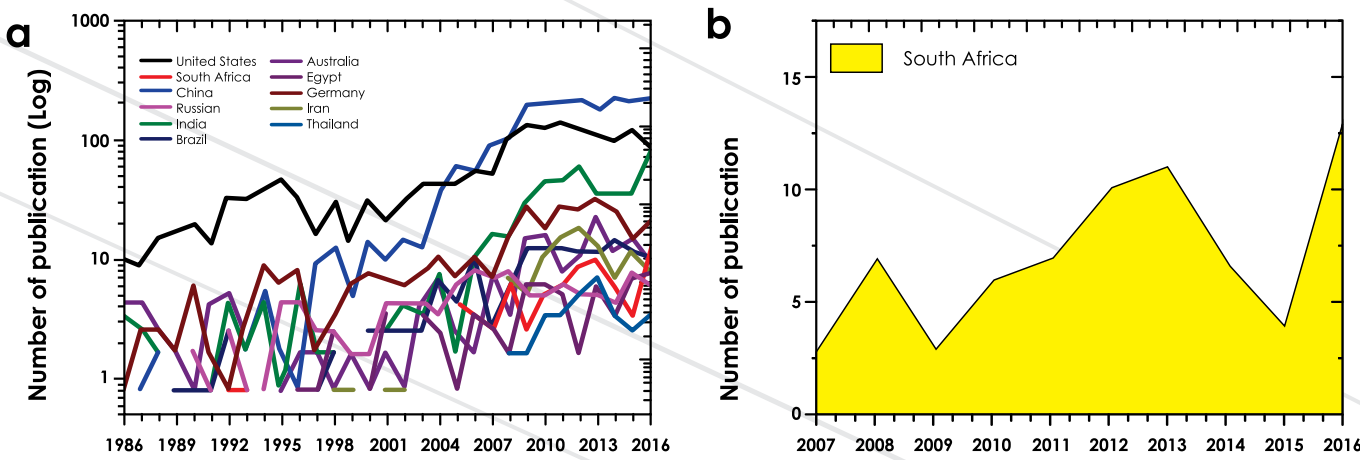

Figure 3-21: Number of publications in $M \& V$ per year originating from (a) selected countries and (b) South Africa

\subsection{Technology-enabled EEDSM options, implementation and potential}

EEDSM technologies are embedded in the vast literature, and when commercialised, are hidden in products and systems, and protected by the intellectual property framework. It is even more difficult, nigh impossible, in the modern era to attribute specific technologies to a country or an individual. However, the uptake and implementation of energy efficiency technologies are sometimes visible from various public sources, such as the aforementioned scorecards and the country specific case study (De La Rue Du Can et al., 2013). In South Africa, various technology-enabled EEDSM options were examined and implemented. This includes, but is not limited to, the following: load shifting, smart meter control of household appliances, time zones, switching off street lights during daytime, coal gasification, diesel generators, fuel switching to natural gas, solar water heating, photovoltaics, gas stoves, gas water heating, co-generation and energy efficiency lighting. In 2015, when the second large-scale load shedding happened nationally, the CNES released a report (CNES, 2015) evaluating the affordability, uptake timeframe and the savings potential as reflected in Appendix 4.

From the implementation side, the Eskom IDM funding allowed in the threeyear Multi-Year Price Determination (MYPD) phase 2 was R5.45 billion, with the goal of gross savings of $1037 \mathrm{MW}$ and a cumulative annualised total of 4055 GWh (about $0.67 \%$ electricity savings relative to retail sales per year) from 2011 to 2013. The MYPD 2 ended in March 2013 when MYPD 3 started. New funding of R5.183 billion for a period of five years, 2013 to 2018, was approved in the MYPD 3. During the MYPD 2, tariff increases by an annual average of $22.1 \%$ and annual increases of $8 \%$ have been approved in the MYPD 3, from $65.5 \mathrm{c} / \mathrm{kWh}$ in 2013/14 to $89.13 \mathrm{c} / \mathrm{kWh}$ in 2018. According to the statistics as reported in De La Rue Du Can et al. (2013), as much as $19 \%$ of IDM's savings are from industrial energy systems, with 5\% from compressed 
air and $10 \%$ from industrial process optimisation, and $76 \%$ from buildings and facilities in residential and municipalities, with compact fluorescent lamp (CFL) lighting rollout contributing up to $70 \%$. Yet, it was stated in the same report that very little was achieved in terms of technologies in the residential sector.

Energy efficiency is the 'first fuel'. This is however often forgotten. South Africa's Integrated Resource Plan (IRP) 2010-2030 update report (DoE, 2013a) took into consideration the EEDSM contributions as submitted by Eskom in its MYPD 2 and MYPD 3. According to this report it was stated that the market will drive energy efficiency for the next 30 years by itself on the one hand, but it also recognised the need for a centrally mandated entity to pursue national energy efficiency programmes whose costs and benefits were marked as "a high priority for the next full iteration of the IRP". In the final promulgated version of the IRP 2010-2030 (DoE, 2013b), the statement on the need for a centrally mandated entity and its priority recognition were removed. The Eskom IDM report (Eskom, 2015) showed first that the EEDSM market cannot sustain itself, yet with a minimal investment, EEDSM can achieve sustainable savings. The IDM performance indicates that with funding from MYPD 2 and MYPD 3, savings were quickly obtained in the first four to five years from 2005 and sustained for the next five to six years prior to 2014 with between $1 \%$ and $5 \%$ annual growth, but declined sharply when funding was discontinued from 2015. This experience provided the answer to the IRP 2010 (DoE, 2013a) priority question showing that EEDSM programmes offered the cheapest power at R2.38m/MW. Despite this, the new IRP (DoE, 2016) ignored energy efficiency completely for the period 2019 until 2050. A recent CNES (CNES, 2017) report indicated that increased energy efficiency should have a major impact on new generating capacity investment decisions and also offers significant developmental and competitive advantages.

Of course, a technology and implementation enabled EEDSM roadmap still needs to be compiled to clearly define the potential in this area, in particular, with respect to technology enabled options, sectorally and nationally.

\subsection{Observations and analysis}

The findings summarised in Section 3.5 form the basis of the analysis in this section.

- $\quad$ South Africa scores fairly well internationally in terms of research outputs. Relatively strong areas such as industrial energy systems in MMM and $M \& V$ are reflections of South African established research strengths. South Africa follows more or less the broad international trends in terms of restructuring and consolidation of cross-disciplinary fields for micro-grids, which consists of traditionally strong South African research areas in renewable energy, power systems, integrated building energy systems and energy storage. There is accelerated growth in SSL, and a slight decline in batch chemical processes, while emerging research areas such as tribology, smart grids and M\&V show rapid growth. 
- $\quad$ There seems to be a clear correlation between a country's research performance and the maturity of its technological status, economic development stage, policy support and R\&D investment (Figure 3-22). The countries under consideration can be divided into separate groups, namely: developed countries, BRICS countries, the bestperforming countries and countries at a similar developmental stage to South Africa. The fluctuations in the number of publications observed for developed countries are very small, as would be expected for a large system operating over a wide field. As for BRICS countries, each member state has chosen to support only certain areas and not all the relevant areas, and they perform quite differently. The best performing countries (China and Iran) have increased their number of publications quite rapidly, which shows that the dynamics of research output in energy efficiency is more complex. China and Iran have increased their number of publications in the general field of energy efficiency and in all selected specific areas they develop more rapidly compared with the rest of the developing countries. It can be expected that these two countries are best performing in further areas beyond energy efficiency. It is worth noting that this has happened over the past 30 years when both countries experienced rapid economic expansion from a low base. As was demonstrated in the international benchmarking section of the results, China as a country was below Australia between 2001 and 2003, but was able to become the leading country for energy efficiency research. On the other hand, Russia's contribution towards the world's research outputs has fluctuated in the last 20 years and has declined in relative terms. Countries with the same or almost the same development stage as South Africa showed similar trends in recent years, but South Africa and Egypt have dropped their rankings at historically important moments. 


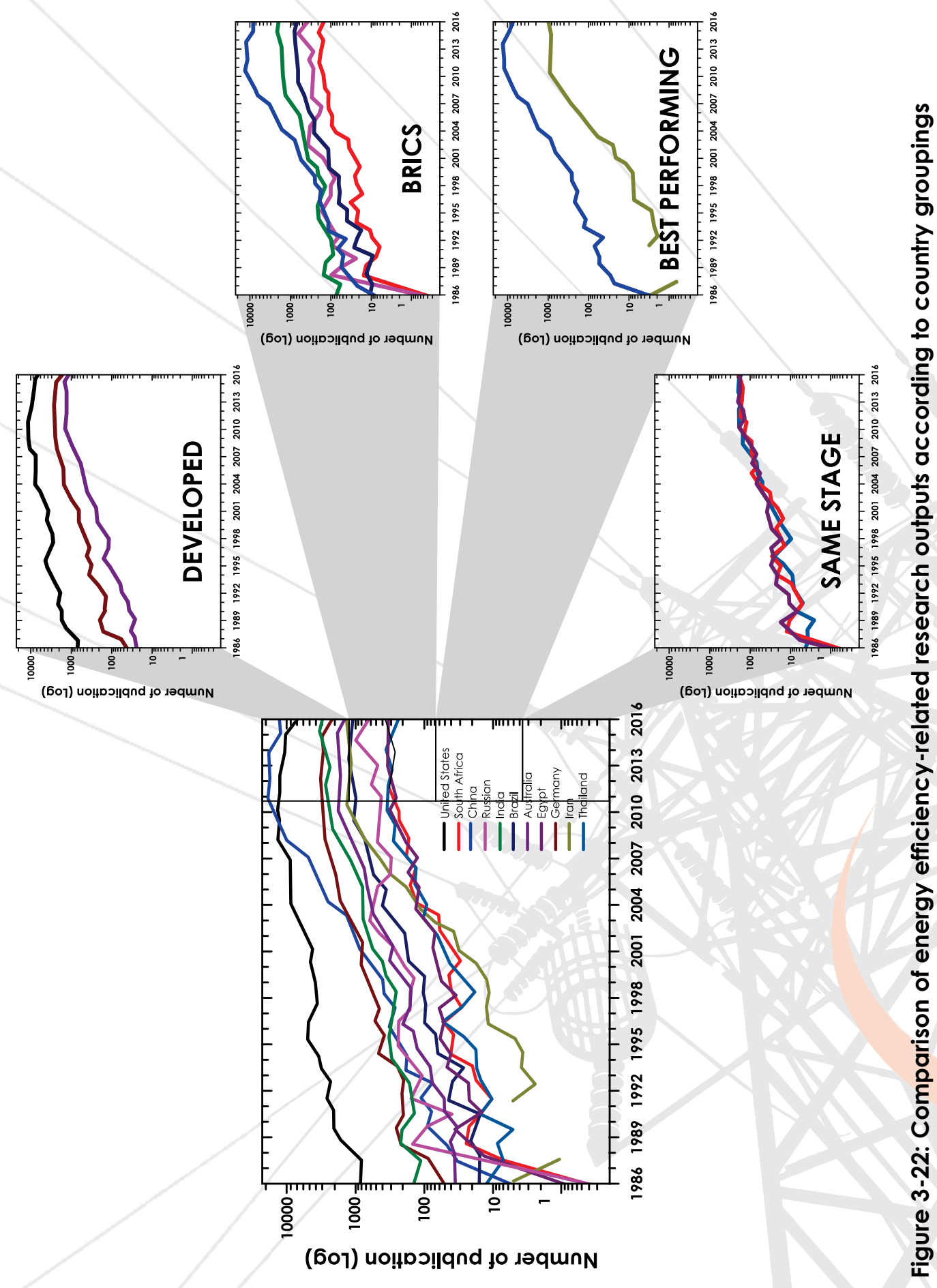


- $\quad$ From Figure 3-1 it is clear that the number of publications in South Africa in energy efficiency has been increasing steadily from 2007, peaking in 2013/4 in most of the energy efficiency areas in South Africa, and then stagnating, if not declining. This might be a global trend, but is also correlated to the trends in funding for energy efficiency research in South Africa. During the first funding cycle of $2008-2013$, the EEDSM hub at UP was supported with annually increasing funding, while it received a much reduced and flat funding level in the second funding cycle of 2015 - 2017, with a zero funding gap year in 2014. Internal factors could be another cause of these trends. For example, in the area of batch chemical processes, there is also a link with retirement and institutional relocation of leading researchers.

- Some institutions and authors have shown strengths with regard to scientific outputs. A recognisable trend is that when an institution and/ or an author show a leading contribution in one traditionally strong area, they tend to show the same leadership roles in other related research areas.

- $\quad$ There is a strong correlation between South African research strengths and the national uptake and impact of actual implementation of energy efficiency interventions. South Africa's strengths in implementation all lie in the above outlined areas of research strength, such as industrial systems, integrated building energy systems, and lighting technologies.

It is yet to be seen whether international cooperation and international agreements contribute to the research and technology establishment leading to contributions in energy efficiency, even though various studies indicate that they do, and that they are important as they help to explore new possibilities and build on what has already been done. South Africa is already part of the IEA's Technology Collaboration Programmes and participates in a total of seven IEA Technology Collaboration Programmes across the energy sector, as indicated in https://www.iea.org/media/impag/ Currentparticipants.pdf, and is also as a member of the international smart grid action network, as reported at http://www.iea-isgan.org/bbs/content. php?co_id=subl_4. There are further opportunities for South Africa to participate in more energy efficiency technology collaboration programmes such as: Demand Side Management, Buildings and Communities, Energy Efficiency End-Use Equipment, and Heat Pumping Technologies. The BRICS countries have recently established a Science, Technology and Innovation (STI) Framework Programme and issued a call for research proposals. The BRICS STI Framework Programme aims to support excellent research on priority areas which can best be addressed by a multinational approach. The initiative should facilitate cooperation among the researchers and institutions in the consortia, which consist of partners from at least three of the BRICS countries. New and renewable energy, and energy efficiency are part of the nine focus areas intended for joint funding. The call for proposals sent a strong signal in funding major research efforts in micro-grids, and as part of it, integrated building energy systems, distributed generation systems, smart grids and SSL. Many potential international collaborations to explore as typical examples of impetus to research include: South Africa is part of 
the Clean Energy Ministerial and has collaborated on Energy Management System, cool roofs and other topics; South Africa may want to consider exchange with universities or national laboratories. For example, Lawrence Berkeley National Laboratory (LBNL) would welcome, through its international exchange programme, students and visiting scholars to work on-site and gain access to the intellectual resources of LBNL to further their research and contribute to ongoing or emerging areas of research.

Some recommendations on EEDSM support mechanisms are appropriately based on the above observations and interpretations. Practically, both the design and implementation of national energy efficiency strategies require significant support from research activities. To name a few: technology transfer, localisation, innovation, investigations on market transformation, an improvement on energy efficiency programme and regulation design, programme impact and process evaluation, information and energy data gathering.

\subsubsection{Research, development, and innovation}

First, the RDI in EEDSM is applied in nature. It is different from basic research and isolated gadget-type development. Modern EEDSM RDIs call for integrated and systemic research efforts close to the market and society. EEDSM research activities are proposed to provide comprehensive evaluations of the national energy savings potential, design prioritised EEDSM policies and solutions, implement energy efficiency improvements in the field, and conduct accurate quantification of the EEDSM policy and programme impacts. This should be done with a well-documented survey of the market penetration and transformation and sufficient energy data. In the current situation, advanced energy efficiency technologies, such as those identified in this report have been transferred to South Africa gradually, but manufacturing capabilities of such devices with local materials have not been constructed, and no local technology innovation framework has been established thus far. RDI support from government has an important role to play to promote clean energy technology innovation and to bring emerging technologies to market. Research activities on evaluations and market transformation require strong information, data and budgetary support from the government. However, in the South African context, the EEDSM-related research activities conducted at several education and industrial institutions are indeed hampered by the limited budgets available. Moreover, an information and data-sharing platform has not been established and available energy efficiency-related data are either out-dated or kept as confidential in various governmental departments and private entities, and cannot be accessed for EEDSM research.

Given the current status of research in EEDSM, the following niche areas for RDI are readily identified:

- Integrated building energy systems

- $\quad$ Solid-state lighting 
- Micro-grids and distributed generation

- $\quad$ Energy storage

- Industrial energy optimisation.

\subsubsection{Policy}

In South Africa, the EEDSM programmes have been driving energy efficiency research and innovation. In parallel with the research developments for EEDSM, efforts are needed to bridge the gap between the national strategic energy efficiency target, and its implementation. Implementation models cannot simply be borrowed from the developed countries in view of discrepancies in knowledge, skills, capacity and culture. Therefore a need for operational units to fill these gaps exists. Under the current EEDSM framework, Eskom IDM has been taking the lead for EEDSM programme implementation over the past decades. Significant energy savings have been achieved by Eskom IDM with a budget of R3.75 million per MW savings, which indicates their strong technical and management skills in EEDSM programme design, implementation, and performance evaluation. Eskom IDM has also managed to open the energy efficiency service markets by offering a number of attractive EEDSM products, such as the ESCo model ${ }^{12}$, and standard product, standard offer and performance contracting. Since Eskom IDM's role in EEDSM is sometimes questioned, and is believed to be seriously undermined partly due to budget constraints, its contributions are commendable in building the knowledge, skills and capacity in EEDSM. It is essential that South Africa does not lose the momentum in knowledge, skills, capacity and even culture that has been accumulated in EEDSM over the past 20 years, so as not to leave a void in linking policy and implementation. Currently, there are several EEDSM programmes operating within municipalities and the private sector, although their effectiveness in managing costs and target adherence is yet to be proven.

The same is true of the RDI policy framework for EEDSM. There is a strong need for an 'operational' unit that bridges the gap between a national support policy and effective RDI platforms on the ground.

One of the most important energy efficiency programmes/policies that drives energy efficiency research are energy efficiency building codes and the adoption of energy efficiency standards for equipment and appliances, as companies have to innovate to meet high energy efficiency requirement (Kechichian et al., 2016).

The following four policy supports should be prioritised:

- $\quad$ Set up a national EEDSM roadmap, in support of the IRP and the new National Energy Efficiency Strategy. 
- $\quad$ Strengthen, through increased funding allocations, the research and training facilities in EEDSM.

- Mandate SANEDI, as an entity of the DoE, to provide ring-fenced, overhead funding to support the implementation of national programmes.

- $\quad$ Establish a national monitoring, evaluation and reporting framework. 


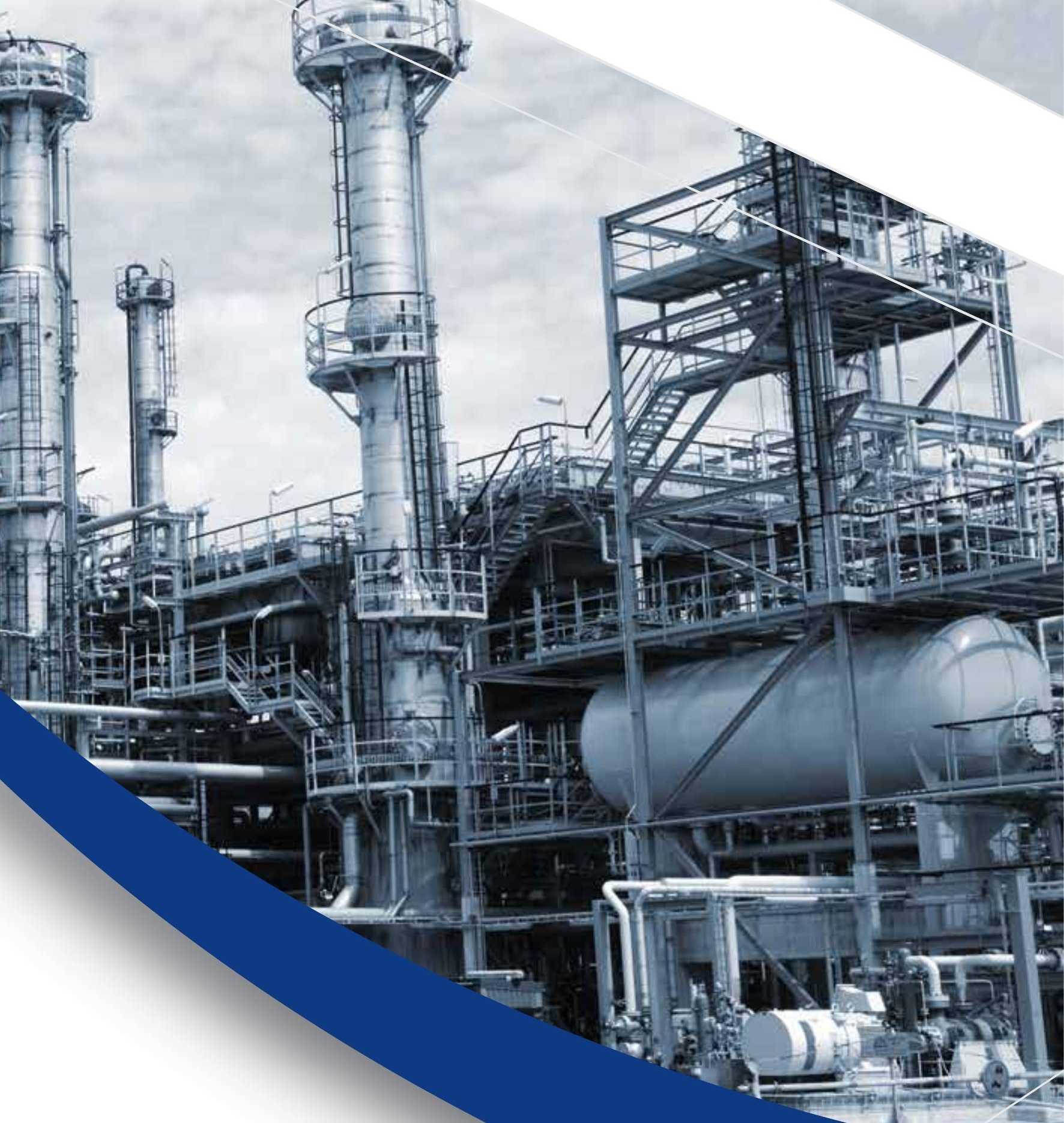




\section{IN FOCUS: SMART GRIDS}

\subsection{Introduction}

It is widely recognised that South Africa has an energy-intensive economy which enjoyed the benefit for many decades from relatively low cost electricity and high network/grid reliability. The historic energy saving strategies and technologies applied were not driven from an energy-efficient perspective. The initiatives pursued were mainly informed by the need to manage network loading and maximum demand reduction. Network loading refers to the impact on the infrastructure used to supply electricity to customers as a result of the real time electricity consumption of the customers supplied. Exceeding the ability of the infrastructure in question to supply the load could result in increased technical losses, network overloading and supply interruptions. Exceeding the maximum notified demand i.e. the contracted capacity to be made available through the bulk supplier of electricity (e.g. Eskom) results in penalties. The initiatives pursued therefore had an impact on the improvement of the power system efficiency and were not aimed at energy efficiency improvement from a customer perspective. Considering the risk to the network and the risk of financial penalties, the ability to manage the load and to interrupt the customer load through a controlled intervention, would therefore be the preferred option. To this end, the use of Ripple Control was found to be rather effective from a power system efficiency perspective, while power factor correction was also pursued to a certain degree. Power factor correction did contribute to the efficiency improvement of the end use loads. In most cases the key power factor correction driver was however the potential reduction in the electricity bill to be paid to the relevant utility. Ripple Control was deployed mainly in the larger municipalities, as well as some of the secondary municipalities targeting mainly geyser/electrical hot water cylinder-related loads. The Ripple Control load management initiatives mainly impacted on the commercial and domestic sector. The current status in the industry is that most of the installed Ripple Control-related equipment is not functioning. While the use of Ripple Control in load management might not be the 'smartest' technology available, it remains a relatively effective load management tool while also improving the efficiency of the power system. Some of the measures introduced by Eskom to manage network loading and energy consumption included load shedding, alternative tariff models, and specific contractual arrangements.

While the initiatives pursued should contribute to a change in the load profile and 'flattening' of the system demand, they will not necessarily result in improved network management, reduction of losses, improved business sustainability, energy portfolio optimisation, etc. It is important to note that improved matching of supply and demand may make the power generation system more efficient and result in overall energy efficiency improvements in terms of primary fuel consumption, even if end use energy consumption is largely unchanged. To be able to achieve the required balance from an energy-efficient perspective requires an integrated plan underpinned by $\mathrm{grid} /$ network/plant and customer-related intelligence, as well as real time system management capabilities. Reference to 'the system' includes the 
national electricity system, as well as the system under the control of the relevant utilities, e.g. municipalities. Any such plan will have to take the different sizes and capabilities of municipalities into account. Even without an integrated energy efficiency implementation plan, the $12 \%$ energy efficiency improvement target reflected in the Energy Efficiency Strategy of South Africa (DoE, 2005) was achieved (DoE, 2016) (Table 4-1).

Table 4-1: Energy efficiency targets and performance achieved (DoE, 2016)

\begin{tabular}{|l|c|l|}
\multicolumn{1}{|c|}{ Sector } & $\begin{array}{c}\text { 2015 target } \\
\text { (based on the } \\
\text { 2000 base line) }\end{array}$ & \multicolumn{1}{c|}{ Performance to 2012} \\
\hline Economy-wide & $12 \%$ & $23.7 \%$ \\
\hline Industry & $15 \%$ & $34.3 \%$ \\
\hline Residential & $10 \%$ & $28.2 \%$ \\
\hline $\begin{array}{l}\text { Commercial and } \\
\text { public }\end{array}$ & $15 \%$ & $\begin{array}{l}0.3 \% \text { (that is between } 2003-2013 \\
\text { electricity only) }\end{array}$ \\
\hline Transport & $9 \%$ & $14.1 \%$ in sector-wide energy intensity \\
\hline Power sector & $15 \%$ & $26 \%$ (as per Eskom estimation) \\
\hline
\end{tabular}

Managing energy efficiency effectively therefore implies a focus on the entire value chain, i.e. generation, transmission, distribution and the end customer - it cannot be an end customer/demand focus only. It is acknowledged that the generation of electricity and heat contributes to greenhouse gas emissions. It must also be appreciated that the electricity demand, the use of electricity and the managing of the network/grid directly contributes to the generation requirements. In the constant balance of production and consumption the efficient use of energy and the ability to leverage alternative energy options, inclusive of suitable storage capabilities, become mission critical. The various applications offered as an integral part of the smart grid solution provide the key to improved energy utilisation and to address the challenges reflected above.

Smart grid technologies fundamentally introduce a layer of digital intelligence to the grids and marry the interface between the classical grid infrastructure and the information technology capabilities. In this way the industry is enabled to respond to grid dynamics, restore power interruptions, accommodate alternative energy options, and facilitate demand response strategies. The importance of the interdependency between policy, standards and technology must be appreciated. Without an overall integrated approach and enabling policies the roll out of smart grids could result in less than optimal results.

While there are many ways in which a smart grid can be defined, the definition adopted by the South African Smart Grid Initiative (SASGI), as derived from the European Technology Platform Smart Grid (ETPSG), defines the smart grid as follows: - "A Smart Grid is an electricity network that can intelligently integrate the actions of all users connected to it-generators, consumers and those that do both - in order to efficiently deliver sustainable, economic and secure electricity supplies." 
Based on the ETPSG definition, the smart grid employs innovative products and services together with intelligent monitoring, control, communication, and self-healing technologies to:

- better facilitate and manage the connection and operation of all sources of energy;

- $\quad$ give consumers more choice so they can help to optimise their energy use;

- $\quad$ provide consumers with greater information and choice of supply;

- $\quad$ significantly reduce the environmental impact of the whole electricity supply system;

- $\quad$ deliver enhanced levels of reliability and security of supply.

In considering the objectives reflected above, it is clear that the smart grid will directly contribute to energy efficiency improvements. A smart grid provides the capability to manage the industry value chain in an integrated manner while visibility is enhanced which facilitates proactive decision-making and optimisation. The ability to introduce effective load management, demand response, real time pricing, etc. is dependent on effective customer interfaces, grid visibility and plant/network control. It is important to note that 'integrated' energy efficiency from a system perspective is impacted by, among others:

- $\quad$ The efficiency of power generation, as it links to load profile, variability and matching of supply and demand (e.g. using energy in periods of lower generation cost and resource availability, i.e. when renewable energy is abundant).

- $\quad$ The efficiency of the transmission and distribution grid, i.e. load and no-load technical loss reduction, reduction in line losses, transformer core losses, etc.

- $\quad$ The efficiency in the end use consumption of energy which is influenced by tariffs, load control, etc. Billing and revenue recovery is also core to this as users who do not pay for energy use are unlikely to use energy efficiently.

Table 4-2 represents a consolidated perspective of smart grid-related technology applications that could be pursued to enhance efficiencies in the electricity value chain. The functionalities contributing directly to energy efficiency include:

- Accurate loss management and loss reduction.

- Technical loss reduction, network optimisation and energy balancing.

- Capacity management and network loading. 
Table 4-2: Technology applications

\begin{tabular}{|c|c|c|c|}
\hline Business focus & Functionality & Enabler ${ }^{13}$ & Application \\
\hline \multirow[t]{3}{*}{$\begin{array}{l}\text { Revenue } \\
\text { management }\end{array}$} & $\begin{array}{l}\text { Accurate loss } \\
\text { management and } \\
\text { accounting }\end{array}$ & MDMS/NMS & AMI/Smart meters \\
\hline & $\begin{array}{l}\text { Targeted loss reduction } \\
\text { and greater network } \\
\text { visibility }\end{array}$ & MDMS/NMS & AMI/Smart meters \\
\hline & $\begin{array}{l}\text { Remote disconnect/ } \\
\text { reconnect }\end{array}$ & MDMS & AMI/Smart meters \\
\hline \multirow[t]{3}{*}{$\begin{array}{l}\text { Network } \\
\text { management }\end{array}$} & $\begin{array}{l}\text { Real time network } \\
\text { monitoring }\end{array}$ & NMS & Network sensors \\
\hline & $\begin{array}{l}\text { Fault location and } \\
\text { restoration management }\end{array}$ & NMS & Network sensors \\
\hline & $\begin{array}{l}\text { Technical loss reduction, } \\
\text { network optimisation, } \\
\text { energy balancing } \\
\text { and preventative } \\
\text { maintenance }\end{array}$ & $\begin{array}{l}\text { NMS/MDMS/ } \\
\text { GIS }\end{array}$ & $\begin{array}{l}\text { AMI/Smart meters/ } \\
\text { Network sensors }\end{array}$ \\
\hline \multirow[t]{2}{*}{$\begin{array}{l}\text { Network } \\
\text { planning }\end{array}$} & $\begin{array}{l}\text { Improved capacity } \\
\text { management, network } \\
\text { loading, loss reduction } \\
\text { and reliability }\end{array}$ & NMS/MDMS & $\begin{array}{l}\text { AMI/Smart meters/ } \\
\text { Network sensors }\end{array}$ \\
\hline & $\begin{array}{l}\text { Effective asset } \\
\text { management and } \\
\text { enhanced customer } \\
\text { connection }\end{array}$ & $\begin{array}{l}\text { NMS/GIS/ } \\
\text { MDMS }\end{array}$ & $\begin{array}{l}\text { NMS/MDMS/Network } \\
\text { sensors }\end{array}$ \\
\hline \multirow[t]{2}{*}{$\begin{array}{l}\text { Customer } \\
\text { service }\end{array}$} & $\begin{array}{l}\text { Improved customer } \\
\text { communication (e.g. } \\
\text { outage management) }\end{array}$ & $\begin{array}{l}\text { CIS/MDMS/ } \\
\text { NMS }\end{array}$ & $\begin{array}{l}\text { AMI/Smart meters/ } \\
\text { Network sensors }\end{array}$ \\
\hline & $\begin{array}{l}\text { Improved response time, } \\
\text { reduced outage time and } \\
\text { effective power quality } \\
\text { management }\end{array}$ & $\begin{array}{l}\text { CIS/MDMS/ } \\
\text { NMS }\end{array}$ & $\begin{array}{l}\text { AMI/Smart meters/ } \\
\text { Network sensors }\end{array}$ \\
\hline \multirow[t]{3}{*}{ Reporting } & $\begin{array}{l}\text { Regulatory, management } \\
\text { and operation reporting } \\
\text { (CAIDI, SAIDI, SAIFI, etc.) }^{14}\end{array}$ & NMS & $\begin{array}{l}\text { AMI/Smart meters/ } \\
\text { Network sensors }\end{array}$ \\
\hline & $\begin{array}{l}\text { Accurate fault reporting } \\
\text { and fault/equipment } \\
\text { history }\end{array}$ & NMS & $\begin{array}{l}\text { AMI/Smart meters/ } \\
\text { Network sensors }\end{array}$ \\
\hline & $\begin{array}{l}\text { Capture detailed network } \\
\text { information }\end{array}$ & NMS & \\
\hline
\end{tabular}

13 MDMS: Meter Data Management System.

NMS: Network Management System.

AIM: Advanced Metering Infrastructure.

GIS: Geographic Information System.

14 CAIDI: Customer Average Interruption Duration Index.

SAIDI: System Average Interruption Duration Index.

SAIFI: System Average Interruption Frequency Index. 
From the above it is clear that there are numerous opportunities to improve energy efficiency through the deployment of smart grid technology applications. Energy efficiency as a specific objective should however be included in the current assessment and benefit realisation criteria of smart grids in South Africa.

\subsection{Technology landscape}

\subsubsection{South African landscape}

The extent to which smart grids are deployed in South Africa should not be underestimated. In reality, from the transmission at the upper end of the distribution voltages, significant smart grid functionality is present. However, if we consider the distribution infrastructure in its broader context and in particular at lower voltages, very little and in some cases no advanced technology deployment is present. It is for this reason that the distribution industry is confronted with specific problems, such as extended outages, high losses (technical and billing/theft-related), inefficient energy utilisation and limited data which could be used to enhance decision-making and virtually no customer participation/communication. It is however important to keep in mind that most of the current distribution infrastructure was designed and built with a $20^{\text {th }}$ century point of reference. It is therefore important to enhance the grid intelligence in order to be able to facilitate aspects, such as demand response, energy conservation, the introduction of renewable energy options, outage management, grid self-healing (automatic network reconfiguration in response to grid faults), etc. In South Africa, a broad range of hardware, software, application and communication technologies that are part of the smart grid technology landscape are at various level of maturity. The Smart Grid Maturity Model is a management tool that municipality electricity distributors can leverage to plan their smart grid journey, prioritise their options and measure their progress as they move towards the realisation of a smart grid.

Utilities use the Smart Grid Maturity Model to assess their current state of smart grid implementation, define the goals for the future state, and generate inputs into their mapping, planning and implementation process.

The smart grid-related initiatives currently pursued in South Africa are mainly driven by the need to improve renewable energy integration, decarbonise the electricity generation, improve the ability to effectively manage the grid, improve the network reliability and availability, reduce operating costs and respond to national imperatives. Energy efficiency is not the primary driver. The transition towards smarter grids is slow since funding support is limited. Despite some pockets of progress, technology deployment in the form of smart grids is not leveraged to its full potential. Once the electrical systems are "enabled from a smart grid perspective", it will be much easier to accommodate the flexibility required in the management of renewable energy sources. Therefore, smart grids can directly contribute to the reduction in $\mathrm{CO}_{2}$ emissions, and address one of the main causes of climate change. 
The initiatives pursued by the utilities in South Africa can broadly be categorised according to the areas listed in Table 4-3.

Table 4-3: Energy efficiency-related initiatives by South African utilities

\begin{tabular}{|c|c|c|}
\hline Initiative & Focus & $\begin{array}{l}\text { Impact on energy } \\
\text { efficiency }\end{array}$ \\
\hline $\begin{array}{l}\text { Distributed power } \\
\text { generation }\end{array}$ & $\begin{array}{l}\text { Facilitate integration of } \\
\text { alternative energy options } \\
\text { harvesting clean energy } \\
\text { sources and move from } \\
\text { 'unidirectional' to 'bi- } \\
\text { directional' energy flow }\end{array}$ & $\begin{array}{l}\text { Directly contributes to } \\
\text { the optimisation of the } \\
\text { potential energy portfolio }\end{array}$ \\
\hline $\begin{array}{l}\text { Improved revenue } \\
\text { management }\end{array}$ & $\begin{array}{l}\text { Improved revenue } \\
\text { realisation }\end{array}$ & $\begin{array}{l}\text { Indirectly influences } \\
\text { energy consumption and } \\
\text { efficient use of energy }\end{array}$ \\
\hline $\begin{array}{l}\text { Energy efficiency } \\
\text { and demand side } \\
\text { management }\end{array}$ & $\begin{array}{l}\text { Loss reduction, network/ } \\
\text { plant loading and } \\
\text { demand reduction }\end{array}$ & $\begin{array}{l}\text { Direct focus on efficient } \\
\text { use of energy }\end{array}$ \\
\hline Outage management & $\begin{array}{l}\text { Reduce network down } \\
\text { time }\end{array}$ & $\begin{array}{l}\text { Indirect focus on efficient } \\
\text { use of energy }\end{array}$ \\
\hline $\begin{array}{l}\text { Improved grid/network } \\
\text { visibility }\end{array}$ & $\begin{array}{l}\text { Improved ability to } \\
\text { monitor plant/equipment, } \\
\text { to effectively deploy } \\
\text { resources and real time } \\
\text { optimisation of network } \\
\text { switches and voltage } \\
\text { control thereby reducing } \\
\text { line losses and energy } \\
\text { consumption }\end{array}$ & $\begin{array}{l}\text { Indirect contribution to } \\
\text { energy efficiency }\end{array}$ \\
\hline $\begin{array}{l}\text { Active network } \\
\text { management }\end{array}$ & $\begin{array}{l}\text { Improved ability to } \\
\text { manage grid/network } \\
\text { real time and to optimise } \\
\text { network loading }\end{array}$ & $\begin{array}{l}\text { Direct contribution } \\
\text { to energy efficiency, } \\
\text { e.g. flattening of the } \\
\text { load profile will reduce } \\
\text { technical losses and the } \\
\text { maximum demand }\end{array}$ \\
\hline $\begin{array}{l}\text { Advanced asset } \\
\text { management }\end{array}$ & $\begin{array}{l}\text { Reduce asset down time, } \\
\text { optimise operating costs } \\
\text { and extend asset life }\end{array}$ & $\begin{array}{l}\text { Indirect contribution to } \\
\text { energy efficiency }\end{array}$ \\
\hline
\end{tabular}

While the 'smartness' of a specific network must be defined by the asset owner, the development of a smart grid, inclusive of the required backoffice support, is a 'technology journey' and not a single event. While smart metering is pursued by most of the municipalities in South Africa, the following South African bodies/municipalities are making the best progress towards a smarter grid from a smart grid deployment perspective:

- $\quad$ City of Cape Town

- $\quad$ City Power, Johannesburg

- $\quad$ Eskom 
- $\quad$ eThekwini Metropolitan Area

- Nelson Mandela Bay Municipality.

Considering the energy challenges facing South Africa, there is an urgent need to enhance the efficient use of the available energy portfolio. The inability of utilities to effectively introduce energy efficiency and DSM in the context of IDM stems from the absence of effective grid/network visibility, active network management capabilities and/or remote switching capability. This implies that the larger percentage of bodies/municipalities in South Africa do not have the technology capability to manage their load profile and demand in real time. To facilitate effective energy management, smart grid capabilities are of critical importance. Furthermore, outdated plant and equipment in some cases compromise their ability to deploy near-real time network management practices. Numerous municipalities are confronted with exceeding their notified maximum demand, which results in network demand exceedance penalties. The more important challenge is however the negative impact on the national grid, inclusive of the inefficient energy utilisation and generation requirements. This is an area where applications within the suite of smart grid functionalities could be deployed to improve energy efficiency. This is an example of an initiative which could present substantial local and national efficiency improvement benefits.

In general, it is concluded that, among others, energy efficiency improvements in the electricity value chain can be achieved through smart grid deployment. It is however important to note that effective smart grid rollout starts with effective planning, followed by selecting applications within the suite of smart grid options, which will best serve the requirements of a specific utility. Therefore, it is important to evaluate the available options, and to subject the options selected to a pilot study, before embarking on a mass rollout. South Africa substantially lags behind the international smart grid leaders in respect of deploying smart grid applications to improve efficiency.

From a local perspective, entities/institutions conducting a level of research with some focus on smart grid applications were considered. Cases were not considered where smart grid applications were procured and implemented without a level of underpinning research.

In the case of South Africa, the available research reports are limited largely to SANEDI, Eskom, the National Cleaner Production Centre (NCPC) of South Africa and GreenCape. Through the SANEDI applied research programme, pilot sites were established in nine municipal areas to pilot smart grid-related applications in order to improve efficiency in the electricity value chain ${ }^{15}$. The pilot site selection was not driven from an energy efficiency perspective, but rather from a business sustainability and service delivery improvement perspective. The pilot sites and the relevant applications are reflected in Table 4-4.

5 Note from interview with Mr T. Yusuf, SANEDI. 
Table 4-4: Pilot sites for smart grids

\begin{tabular}{|c|c|c|}
\hline Site & Research objectives & Smart grid application \\
\hline eThekwini & $\begin{array}{l}\text { - To assess the readiness and } \\
\text { technology deployment } \\
\text { status of the business } \\
\text { - To enhance asset } \\
\text { management through a } \\
\text { smart grid }\end{array}$ & $\begin{array}{l}\text { - Smart grid maturity } \\
\text { assessment } \\
\text { - Advanced asset } \\
\text { management }\end{array}$ \\
\hline City Power & $\begin{array}{l}\text { - To assess the readiness and } \\
\text { technology deployment } \\
\text { status of the utility } \\
\text { - To evaluate the system } \\
\text { requirements when multiple } \\
\text { tariff options, inclusive of } \\
\text { the Inclining Block Tariff, } \\
\text { are made available to } \\
\text { customers }\end{array}$ & $\begin{array}{l}\text { - Smart meter deployment } \\
\text { - Load limiting through smart } \\
\text { meters } \\
\text { - Tariff switching through smart } \\
\text { meters }\end{array}$ \\
\hline Govan Mbeki & $\begin{array}{l}\text { - To assess the readiness and } \\
\text { technology deployment } \\
\text { status of the business } \\
\text { - Revenue enhancement }\end{array}$ & $\begin{array}{l}\text { - Smart grid maturity } \\
\text { assessment } \\
\text { - Smart meter deployment }\end{array}$ \\
\hline Nala & $\begin{array}{l}\text { - To assess the readiness and } \\
\text { technology deployment } \\
\text { status of the business } \\
\text { - Revenue enhancement }\end{array}$ & $\begin{array}{l}\text { - Smart grid maturity } \\
\text { assessment } \\
\text { - Smart meter deployment }\end{array}$ \\
\hline Naledi & $\begin{array}{l}\text { - To assess the readiness and } \\
\text { technology deployment } \\
\text { status of the business } \\
\text { - Revenue enhancement }\end{array}$ & $\begin{array}{l}\text { - Smart grid maturity } \\
\text { assessment } \\
\text { - Smart meter deployment }\end{array}$ \\
\hline $\begin{array}{l}\text { Nelson Mandela } \\
\text { Bay Municipality }\end{array}$ & $\begin{array}{l}\text { - To assess the readiness and } \\
\text { technology deployment } \\
\text { status of the business } \\
\text { - Smart grid enabled asset } \\
\text { management }\end{array}$ & $\begin{array}{l}\text { - Smart grid maturity } \\
\text { assessment } \\
\text { - Asset management }\end{array}$ \\
\hline Mogale City & $\begin{array}{l}\text { - To assess the readiness and } \\
\text { technology deployment } \\
\text { status of the business }\end{array}$ & $\begin{array}{l}\text { - Smart grid maturity } \\
\text { assessment } \\
\text { - Smart meter deployment }\end{array}$ \\
\hline Msunduzi & $\begin{array}{l}\text { - To assess the readiness and } \\
\text { technology deployment } \\
\text { status of the business }\end{array}$ & $\begin{array}{l}\text { - Smart grid maturity } \\
\text { assessment } \\
\text { - Asset management }\end{array}$ \\
\hline Thabazimbi & $\begin{array}{l}\text { - To assess the readiness and } \\
\text { technology deployment } \\
\text { status of the business }\end{array}$ & $\begin{array}{l}\text { - Smart grid maturity } \\
\text { assessment } \\
\text { - Smart meter deployment }\end{array}$ \\
\hline
\end{tabular}

SANEDI, in conjunction with DoE, is also involved in a project aimed at energy efficiency improvement in targeted government buildings through smart grid applications. While the required base line evaluations were conducted, the metering requirements addressed and the project governance established, reports on the success of these projects were not available to be considered for inclusion in this report. 
Eskom conducted smart grid-related research in the areas shown in Table 4-5 to improve efficiency in the electricity value chain ${ }^{16}$.

Table 4-5: Eskom smart grid-related research

\begin{tabular}{|c|c|c|}
\hline Research objectives & Smart grid application & $\begin{array}{l}\text { Potential impact on } \\
\text { energy efficiency }\end{array}$ \\
\hline $\begin{array}{l}\text { Improve generation black start } \\
\text { capability }\end{array}$ & $\begin{array}{l}\text { - Plant and } \\
\text { grid dynamic } \\
\text { management }\end{array}$ & $\begin{array}{l}\text { - No direct impact } \\
\text { on efficient use of } \\
\text { energy }\end{array}$ \\
\hline $\begin{array}{l}\text { Improved grid and equipment } \\
\text { visibility }\end{array}$ & $\begin{array}{l}\text { - Supervisory } \\
\text { Control And Data } \\
\text { Acquisition (SCADA) }\end{array}$ & $\begin{array}{l}\text { - Indirect impact } \\
\text { on efficient use of } \\
\text { energy }\end{array}$ \\
\hline $\begin{array}{l}\text { Improved remote plant and } \\
\text { equipment condition monitoring }\end{array}$ & $\begin{array}{l}\text { - Advanced asset } \\
\text { management }\end{array}$ & $\begin{array}{l}\text { - Indirect impact } \\
\text { on efficient use of } \\
\text { energy }\end{array}$ \\
\hline $\begin{array}{l}\text { Improve customer interface } \\
\text { and enhance revenue } \\
\text { management }\end{array}$ & $\begin{array}{l}\text { - Smart metering } \\
\text { - Metering Data } \\
\text { Management } \\
\text { System (MDMS) }\end{array}$ & $\begin{array}{l}\text { - Direct impact on } \\
\text { efficient use of } \\
\text { energy }\end{array}$ \\
\hline $\begin{array}{l}\text { Enhance system loading under } \\
\text { controlled conditions }\end{array}$ & - Grid sensors & $\begin{array}{l}\text { - Direct impact on } \\
\text { energy efficiency }\end{array}$ \\
\hline $\begin{array}{l}\text { Improve communication } \\
\text { reliability and capacity }\end{array}$ & $\begin{array}{l}\text { - Architecture } \\
\text { development }\end{array}$ & $\begin{array}{l}\text { No direct impact } \\
\text { on efficient use of } \\
\text { energy }\end{array}$ \\
\hline $\begin{array}{l}\text { Improved overhead line } \\
\text { visibility and enhance flexibility } \\
\text { in respect of managing line } \\
\text { thermal rating }\end{array}$ & - Line sensors & $\begin{array}{l}\text { - Direct impact on } \\
\text { efficient use of } \\
\text { energy }\end{array}$ \\
\hline $\begin{array}{l}\text { Improve efficiency of workforce } \\
\text { deployment }\end{array}$ & $\begin{array}{l}\text { - Active workforce } \\
\text { deployment }\end{array}$ & $\begin{array}{l}\text { - No direct impact } \\
\text { on efficient use of } \\
\text { energy }\end{array}$ \\
\hline $\begin{array}{l}\text { Improved customer } \\
\text { participation in energy } \\
\text { efficiency }\end{array}$ & $\begin{array}{l}\text { - Home energy } \\
\text { system/control }\end{array}$ & $\begin{array}{l}\text { Direct impact on } \\
\text { efficient use of } \\
\text { energy }\end{array}$ \\
\hline $\begin{array}{l}\text { Understanding the system } \\
\text { dynamics when disruptive } \\
\text { technologies are introduced } \\
\text { (PV Rooftop, etc.) }\end{array}$ & $\begin{array}{l}\text { - Advanced asset } \\
\text { management }\end{array}$ & $\begin{array}{l}\text { - Direct impact on } \\
\text { efficient use of } \\
\text { energy }\end{array}$ \\
\hline $\begin{array}{l}\text { Enhance ability to electrify } \\
\text { deep rural areas }\end{array}$ & - Micro-grids & $\begin{array}{l}\text { - Direct impact on } \\
\text { efficient use of } \\
\text { energy }\end{array}$ \\
\hline $\begin{array}{l}\text { Improve energy management } \\
\text { in the distribution component of } \\
\text { the ESI }\end{array}$ & $\begin{array}{l}\text { - Integrated demand } \\
\text { side management } \\
\text { - Energy trading }\end{array}$ & $\begin{array}{l}\text { - Direct impact on } \\
\text { efficient use of } \\
\text { energy }\end{array}$ \\
\hline $\begin{array}{l}\text { Optimise use of smart grid } \\
\text { related investment through } \\
\text { leveraging interoperability }\end{array}$ & $\begin{array}{l}\text { - Advanced } \\
\text { infrastructure } \\
\text { management }\end{array}$ & $\begin{array}{l}\text { - Indirect impact } \\
\text { on efficient use of } \\
\text { energy }\end{array}$ \\
\hline
\end{tabular}

16 Note from interview with Mr N. Singh, Eskom. 
The South African Industrial Energy Efficiency Project, hosted by the NCPC of South Africa, assisted industry in South Africa to reduce energy consumption and greenhouse gas emissions.

\subsubsection{International landscape}

Globally, smart grid deployment is pursued with great success to achieve the above stated objectives, among others. The objective to move towards a more intelligent and visible grid is fundamentally driven by the need to be more energy efficient. Due to the importance of energy efficiency and the role it plays in economic growth, attractive incentives were provided to move towards a smarter grid in the US, Europe and the UK.

The European Commission stated in 2011: "The European Union 2020 agenda comes across with a clear message for Europe. The EU's future economic growth and jobs will increasingly have to come from innovation in products and services for Europe's citizens and businesses. Innovation will also contribute to tackling one of the most critical challenges Europe is facing today, namely ensuring the efficient and sustainable use of natural resources. The development of our future energy infrastructure must reflect this thinking. Without serious upgrading of existing grids and metering, renewable energy generation will be put on hold, security of the networks will be compromised, opportunities for energy saving and energy efficiency will be missed, and the internal energy market will develop at a much slower pace." (European Commission, 2011) The report further states: "Smart grids provide a platform for traditional energy companies or new market entrants such as ICT companies, including SMEs, to develop new, innovative energy services while taking due account of data protection and cyber-security challenges. That dynamic should enhance competition in the retail market, incentivise reductions in greenhouse gas emissions and provide an opportunity for economic growth."

Miceli (2013) reflects on the benefits derived from the introduction of a smart grid and states: "Targeting environmental sustainability, energy efficiency and new power distribution, business models have to be evaluated. Moreover, innovative, energy-aware, flexible and user-centric solutions, able to provide interactive energy monitoring, intelligent control and power demand balancing at the home, block and neighbour level are needed. These solutions will interconnect legacy professional/consumer electronic devices with a new generation of energy-aware white-goods in a common network, where multi-level hierarchic metering, control and scheduling will be applied, based on power demand, network conditions and personal preferences. Moreover, renewable energy systems that will optimise and integrate, for example, an innovative combined photovoltaic/solar (CPS ${ }^{17}$ ) system can be used. These systems will provide hot water for white goods (such as a dishwasher and washing machine) in order to strongly decrease the energy consumption and the $\mathrm{CO}_{2}$ emissions at home by reducing/

Combined photovoltaic and solar-thermal systems (PV/T systems) join photovoltaic (PV) technologies and solar thermal technologies into one system with both electrical and thermal energy output. 
removing the heating operational cycles; electrical energy from renewable energy sources (RES), which can be utilised at home and during peak periods, even fed to the electricity network in a reverse power generation/ distribution business model. Information from CPS system will be shared in the management network and used for a new set of energy management rules in order to maximise energy savings and environmental savings at the home, block and neighbour level. In addition to the energy management methodology to be used at the load level, they are now emerging in smart grids in the vision of power system innovation."

The article further states: "Reliability, efficiency and safety improvements of power distribution networks are accomplished through communication and computing technologies. Smart grids can enhance the energy efficiency of the grid to the benefit of the end users by both coordinating and scheduling low priority home devices, so that their power consumption takes advantage of the most appropriate energy prices and/or energy sources at a given time. Furthermore, real time information transmitted over communication networks will allow power outage anticipation, as well as service perturbation detection. By rapidly detecting and analysing data coming from the distribution network, the smart grid will be in a position to take corrective actions, so as to restore power stability when needed. Harmonizing local distribution at the house level with energy distribution at a larger level can also reduce grid congestion. Last, but not least, an enhanced electrical grid is expected to lower $\mathrm{CO}_{2}$ emissions by reducing end-user energy consumption during peak hours, when electricity is generated through power plants that produce a lot of $\mathrm{CO}_{2}$ emissions."

A report by the Asia-Pacific Economic Cooperation (APEC, 2011) recognises the benefits to be derived through smart grid deployment in respect of energy efficiency. The report however also states: "The engagement of enduse systems in demand response through real time pricing signals or other incentives is low, with wealthier and more urban member economies showing the most activity in this direction. Of all smart grid technology deployments, advanced metering infrastructure is receiving the most attention. While this is a logical first step in a roadmap of smart grid deployments that will enable other capabilities, it is only a start and addresses a small fraction of the potential benefits from implementing smart grid capabilities. Even after measurement and communications systems, such as Advanced Metering Infrastructure, are installed, significantly more work will be needed to advance energy efficiency and support the integration of significant amounts of renewable resources."

An International Telecommunication Union (ITU) report, produced in 2012 , recognised the potential to improve efficiencies, manage the expected industry change and address climate change through the deployment of smart grids. However, it also emphasised the importance of following a systems approach, taking into account the entire value chain from generation to the end-customer. Furthermore, the report states: "In order to maintain the grid stability in the presence of great amounts of variable production from 
renewable sources, a large effort is required to control other generators and/ or the energy demand (loads) by actively involving the users to modify their consumption according to the current production. The actual electrical grid control method, with production that follows the "user demand", is expected to change towards a more flexible scheme, in which the "user demand" can be influenced or partially controlled depending on renewable production availability. This evolution will change the whole electricity supply chain, from generation, transmission and distribution to the customer side. The current system will progressively see an increasing number of "prosumers", namely, users that are both producers and consumers. The variable and unpredictable power production from renewable energy sources in different hours and seasons will require flexible dynamic loads and large storage capacity to keep an optimal balance between availability and demand of electric energy. Advanced types of control and management technologies for the electrical grid can also contribute to a more efficient operational running of the overall system. These technologies include devices such as smart electricity meters that show real time use of energy and that can respond to remote communication, enabling dynamic electricity pricing related to real production and distribution costs." (ITU, 2012)

Furthermore, the report states: "Distribution is the most affected domain by the Smart grid implementation. Indeed, the distribution grid has to integrate dispersed small/medium-size generators and manage bidirectional power flows on a grid designed for unidirectional flows. The distribution grid is where end users are connected and where advanced metering and new policies of demand management can be implemented. Widespread adoption of PEVs (plug-in electric vehicles) and PHEVs will bring additional and critical load to the grid.

The availability of distributed generators gives a real chance to have local production where electric power is needed. This approach can reduce the bulk of energy transferred by long transmission lines and bring more efficiency, due to less transmission losses. This can also increase the local reliability of the power systems and provide better efficiency by using local renewable resources (wind, water, sun, biomass).

The integration on the distribution grid of a great number of partially predictable variable sources and of new types of loads poses grid operation issues that require new control and protection schemes. One of the possibilities to balance generation and load in real time is to involve consumers, by asking them to modify their normal consumption patterns in response to a utility's need."

Internationally, substantial investments have been made in respect of smart grid-related research. As stated earlier, the smart grid was identified as a key enabler to enhance the ability of utilities to respond to the drive towards a more energy-efficient environment and improved customer service among others. The US DoE, the US DoE's National Renewable Energy Laboratory (NREL), the ElA's International Smart Grid Action Network (ISGAN) 
Technology Collaboration Programme, the National Institute for Standards and Technology (NIST), the European Commission, the Union of the Electricity Industry-EURELECTRIC and the Electricity Power Research Institute (EPRI) are among the leading international institutions devoting resources towards smart grid-related research.

\subsection{Research and development opportunities in South Africa}

While it is true that a substantial portion of the electricity infrastructure in South Africa is old and requires refurbishment or replacement, it is also true that this does not imply that a smarter grid cannot be pursued. The investment required in the electricity infrastructure actually presents the ideal opportunity to pursue the deployment of smart grid-related applications. The report entitled Approach to Distribution Asset Management (ADAM), (EDI Holdings, 2008) reflects the infrastructure investment requirements. The selection of the appropriate technology applications can assist the electricity supply industry in achieving the business objectives. It is however important to note that energy efficiency improvement might not be the core driver and rather a 'benefit by default'. From a South African perspective, smart grid deployment to date has been mainly considered from a business sustainability improvement and service delivery perspective. There is merit in evaluating the smart grid business case for South Africa, also from an energy efficiency perspective. Moving energy efficiency to the core of the smart grid deployment could enhance the benefit realisation and improve the return on the investment.

It is critical for the utilities in the energy sector to define the enterprise information technology (IT) architecture taking into account the technology deployment vision as well as the operational technology (OT) requirements to render an effective electricity value chain. If the IT and OT requirements are not well defined, it could lead to the wrong selection of the communication protocol and specification of the data transfer capability. Also accurate data are important to facilitate effective energy efficiency initiatives. Furthermore, it is essential in the selection of technology applications that aspects such as interoperability, upgradability, security, safety, cost and performance are addressed. The technology deployment must facilitate two-way digital communication, wide-area situational awareness, improve energy efficiency, improve network management, load management and improve customer interface. Without achieving the above, the smart grid will not produce the expected value.

In selecting technology, it must be kept in mind that the technology supplier and technology support provider will become a 'business partner'. Therefore, this relationship must be kept in mind when systems, application, business solutions, etc. are researched, developed and ultimately procured. It is therefore important to pursue smart grid-related technology research in an objective manner and to avoid 'dominant influence' from a small group of technology suppliers/developers. 
The study underpinning this report revealed that the current smart grid initiatives in South Africa are more focused towards the distribution business. The underlining objectives, as stated before, are to improve business sustainability and service delivery, while energy efficiency improvement for the electricity supply industry (ESI) is not a core driver. While the energy improvement efficiency potential to be derived through the smart grid is recognised, the overall potential has not been quantified. This is an area requiring further research with the objective to assess the energy efficiency potential associated with the various smart grid applications. Research in this regard will be of significant value in the compilation of an integrated smart grid plan for the ESI in South Africa.

Options which could also be explored to improve energy efficiency through smart grid deployment include, but are not limited to:

- Integrated demand management at utility level.

- $\quad$ Real time energy monitoring.

- $\quad$ Energy portfolio optimisation at utility level by embedding wind and solar.

- $\quad$ Embedding alternative energy options at utility level to defer network capital requirements and to improve network loading.

- $\quad$ Embedding rooftop photo-voltaic (PV) at utility level as part of the utility service offering.

- $\quad$ Energy storage within the distribution business to improve energy efficiency.

- $\quad$ Providing Wi-Fi over the utility network as a service to end customers while the network is energised, i.e. if the power is interrupted the Wi-Fi service is also interrupted.

- Metering standards and functionality to facilitate nett-metering and/ or nett-billing.

- $\quad$ Develop a model to define the minimum utility back-office support requirements.

- $\quad$ Development of an integrated smart grid plan aimed at energy efficiency improvement through appropriate technology deployment.

Selected South African universities listed in Table 4-6 have established specific competencies which could be leveraged from an energy efficiency and smart grid perspective ${ }^{18}$.

8 Note from interviews with Dr M. Bipath, Dr J. Rens, Mr P. Groenewald \& Mr N. Singh. 
Table 4-6: University smart grid-related research

\begin{tabular}{|l|l|}
\multicolumn{1}{|c|}{ University } & \multicolumn{1}{c|}{ Competency that could be leveraged } \\
\hline University of Cape Town & - Modelling \& simulation \\
\hline $\begin{array}{l}\text { Durban University of } \\
\text { Technology }\end{array}$ & - Real time simulator \\
\hline University of KwaZulu-Natal & $\begin{array}{l}\text { - Real time simulator } \\
\text { - High voltage direct current }\end{array}$ \\
\hline University of Pretoria & - EEDSM - National hub and smart grid laboratory \\
\hline Stellenbosch University & - Energy storage \& renewable energy technology \\
\cline { 2 - 2 } & - Power quality control \\
\cline { 2 - 2 } & - Solid-stator transformer \\
\hline
\end{tabular}

From a broader industry perspective, a number of international companies are investing in smart grid technologies to improve energy efficiency. These initiatives are mainly driven from a product development and marketing perspective. Smart grid application suppliers like ABB, General Electric, Siemens, Ventyx, Oracle, etc. are investing in smart grid RDI. Electricity distribution utilities are less committed to invest in technology RDI. However, most of them are willing to report back on their smart grid implementation experience. The results from three reports are reflected to illustrate the points made above. The Ventyx report (Lewis, 2013) indicated that efficiency improvement in the electricity value chain can be realised through a smart grid. In the following list the smart grid applications/initiatives that are highlighted reflect contributions (directly or indirectly) to energy efficiency improvement:

- Outage reduction

- $\quad$ Reduction in equipment operation

- More accurate grid/network calculations

- Improved capacity management

- Improved network predictions

- $\quad$ Accurate network loading estimations

- Improved mitigation plans

- $\quad$ Reduced peak demand

- Improved resource utilisation

- Improved resource dispatching

- Improved reporting and compliance

- Improved customer interface

- Confidence in grid/network status

- Efficient feeder topology

- Improved use of feeder capacity. 
A report produced by $A B B(A B B$, n.d.) indicated that the deployment of a smart grid is essential in providing data to power effective asset health management.

Maphumulo (2012) ${ }^{19}$ highlighted the following benefits/efficiencyimprovement which were derived from pursuing smart grid-related applications at the eThekwini Municipality: Efficient and cost-effective response to emergencies

- Improved load management

- Improved technical loss management

- Improved outage management

- Improved network reliability and availability

- Improved asset management.

From a South African perspective, SANEDI and Eskom are the leaders in respect of investing resources in smart grid-related research and associated efficiency improvement. Both organisations have agreements in place with the majority of the universities and universities of technology in South Africa. Through an industry partnership, the smart grid-related research is directed and mainly funded through SANEDI or Eskom. There are also cases where the DST are supporting energy efficiency research.

The only body in South Africa which is structured to engage with the ESI from an integrated smart grid perspective is SASGI. SASGI was established through SANEDI, with the primary objective to provide guidance in respect of the transition to a smarter grid. The SASGI membership is made up of utility representatives and various government bodies with a direct interest in the efficient and effective operation of the ESI, as well as smart grid deployment. The current smart grid approach is informed by the SANEDI, Smart Grid MultiYear Programme Plan (SANEDI, 2013) and the focus is predominantly on the distribution sector of the ESI. While the importance of climate change and energy efficiency is recognised in the plan, the plan is not driven from a national energy efficiency improvement perspective. Due to funding-related challenges, SANEDI is dependent on grant funding to complement their budget allocation. The funding constraints have resulted in SANEDI adopting an 'applied research' approach. In essence, the focus from a smart grid perspective is on research through the practical execution of defined projects. While this approach is yielding results, there is an urgent need to invest in fundamental research since this will pave the way to be more proactive in deploying appropriate technology which will best serve the South African requirements. Under the guidance of the DoE, SANEDI identified the piloting of various smart grid applications such as: (a) Distributed Power Generation (b) Revenue Enhancement (c) EEDSM (d) Advanced Asset Management and (e) Active Network Management will help to demonstrate the benefits of a smarter grid. Furthermore, the EU grant funding secured through SANEDI

http://www.sessionview.com/data/2012/01/54/pdf/Sandile-Maphumulo-LPPTILST-15520.pdf (Accessed on 10 March 2017). 
was earmarked in conjunction with DoE for this purpose. The donors made the funding available for technology deployment within the electricity utility businesses. Municipalities were invited to put forward specific technology deployment projects and to apply for funding support.

While the research being conducted in respect of improving energy efficiency technology development must be recognised, it is important to note that it is not informed by any defined national strategic plan. Therefore, it is reasonable to expect that the current research is driven by specific needs or areas of interest. Potentially the most obvious driver of the smart grid-related research and development must be the Integrated Energy Plan (IEP). It is advisable to establish an integrated smart grid energy efficiency technology development plan.

\subsection{Summary}

The need for South Africa to be more efficient in the use of energy resources is accepted in principle. The challenge however is to produce tangible results which will render a better environment and lead to improved sustainability of the ESI. Based on international best practices, the absence of largescale deployment of appropriate technology which could be leveraged to improve an integrated business approach becomes a major constraint. This also impacts on the efficient use of energy. Furthermore, in the context of a monopoly business, such as the ESI, effective regulation is required to instil the required high performance and compliance culture.

Internationally a combination of incentives (e.g. funding), penalties and enabling technologies are used to achieve energy efficiency objectives. The technologies developed and deployed are underpinned by sound research and in many cases by results obtained through technology deployment under laboratory conditions. The international success is further enhanced through the exchange of information and the participation in organisations, such as ISGAN, NIST and EPRI. In addition to the technology enablement it is essential that the market arrangement be such that it promotes transparency and facilitates a high performance business culture. The absence of a defined market arrangement/rules and the unwillingness to address it in South Africa, is not doing the country or the end customers any favours.

Furthermore, from an energy efficiency deliverable perspective, baselines are established and targets set against defined objectives/expected outcomes.

The operating environment of the electricity utility business has changed substantially over the past decade. It is clear that the traditional business of 'buying and selling' energy is under threat. This implies that new revenue streams must be identified, the business be aligned to accommodate the disruptive technologies and more efficient and sustainable practices be explored. The effective deployment of appropriate technology can significantly contribute to the improvement in business sustainability. In respect of achieving energy efficiency objectives, the following are some 
of the areas where technology deployment was leveraged to provide early results:

- $\quad$ Advanced energy balancing and introduction of real time statistical metering.

- Improved management of energy delivered at grid connection points.

- Deployment of smart meters as part of revenue management improvement.

- $\quad$ Reduction in network down time.

- Improved back-office functionality.

- Improved grid/network visibility.

- $\quad$ Integrated asset management.

The effective deployment of smart grids has significant potential to reduce outages by for instance $20 \%$, outage durations by $30 \%$, and peak loads relative to the loading on the distribution networks by $15 \%$, providing consumers with savings of up to $20 \%$ on their electricity bills (Dr De Beer, pers. comm. March 2017). The centralised Volt-Var control which in effect reduces energy waste by adjusting voltage and reactive power on distribution lines in response to demand from customers, presents a favourable option to network management and examples of voltage lowering of up to $3 \%$ was demonstrated. Field force automation results suggest that productivity improvements of up to $10 \%$ for office workers and as high as $18 \%$ for field workers can be achieved with eight months' improvement in inspection time.

While there are countries with substantial smart grid experience and numerous reports reflecting the potential benefits to be derived from smart grid deployment, it must be appreciated that this is a relatively new concept. Therefore, it is to be appreciated that detailed results in respect of the assessment of results from completed project and benefits realised are still in short supply. All indicators suggest however that the smart grid presents the potential to render a more effective industry, a more efficient energy utilisation and a significant contribution to the protection of the environment. 



\section{IN FOCUS: SOLID-STATE LIGHTING}

\subsection{Introduction}

Artificial lighting is an essential enabler for the development of modern societies. The challenge is to provide economic and efficient lighting with minimal light pollution and other impacts on the environment. Advanced electrical to light conversion technologies offer a significant opportunity to contribute to the efficient use of electrical energy while maintaining and even enhancing lighting functionality. The trend has been to replace incandescent devices with those based on fluorescent and solid-state light emissions. SSL development has recently significantly advanced from its earlier mainly visual indicator functionality to higher intensity lighting sources, with the promise of providing lighting in a more focused, cost effective and energy-efficient way. Today, the US, and many countries in Europe and Asia, are investing public funds in R\&D programmes to support implementation and advancement of SSL technology. For example, the US DoE has set aggressive and ambitious goals for SSL technology to save 217 terawatt-hours (TWh) by realising luminous efficacy ${ }^{20}$ of 200 lumen ${ }^{21}$ per Watt (Im/W) in 2025. However, many developing countries (especially in electrified urban and rural areas) still rely on traditional inefficient and expensive ways of lighting.

In South Africa, the residential and commercial sectors together consume about $21 \%$ of the country's electricity. However, like many other developing countries, South Africa is lagging behind in the development and implementation of SSL technology programmes aimed at improving energy efficiency. The primary objective of this review, therefore, is to investigate the state of energy efficiency in South Africa focusing on SSL technology. The investigation will reflect on, among other things, a review and assessment of the current and historic energy-saving technologies related to SSL, an outline of progress of SSL technologies in improving energy efficiency, South African research and development opportunities for SSL, an outline of institutions engaged in research on SSL and benchmarking of South African activities in SSL against those of other countries.

\subsection{Technology landscape}

\subsubsection{South African landscape}

Lighting accounts for $20 \%$ of the total consumption of electricity in South Africa (LEAP, n.d.). Very significant progress has been made to improve the energy efficiency of lighting in South Africa through the South African Municipal Energy Efficiency Demand Side Management Grant supported by the Deutsche Gesellschaft für Internationale Zusammenarbeit (GIZ) and the Department of Energy in which more than 900000 lamps were replaced

20 Luminous efficacy is a measure of how well a light source produces visible light. It is measured in lumens per Watt $(\mathrm{Im} / \mathrm{W})$.

21 Lumen is a unit of measurement for the brightness of light. 
with more energy-efficient ones over the six-year period ending in $2015^{22}$. However, like many other developing countries in the world, South Africa is still lagging behind the most developed countries in the implementation of SSL technologies. While many First World countries have already begun phasing out older lighting technology (incandescent and CFL bulbs), replacing it with SSL technology with specific set targets, South Africa does not yet have an overall and coherent policy on SSL. Eskom's Residential Mass Rollout Programme to replace incandescent bulbs with CFL bulbs and halogen downlighters with LED downlighters started in 2013, with the three-year sustainability period not extending beyond 2017 (De La Rue Du Can et al., 2013). Of over 65 million CFL bulbs that have been installed in South Africa since 2013 , only 4.5 million were installed across five provinces (KwaZulu-Natal, Free State, Eastern Cape, Western Cape and Northern Cape) between November 2015 and March $2016^{23}$. Although the application of LED technology is only starting in South Africa, a few LED outdoor lighting installations have already been implemented in certain provinces as indicated in Table 5-1.

\section{Table 5-1: Numbers of known presently installed LED street light points} (CLASP, 2013)

\begin{tabular}{|l|c|}
\hline \multicolumn{1}{|c|}{ Province } & Numbers of LED street light points \\
\hline Eastern Cape & 360 \\
\hline Free State & 201 \\
\hline Gauteng & 2060 \\
\hline KwaZulu-Natal & 6770 \\
\hline Western Cape & 250 \\
\hline
\end{tabular}

With regard to research in academic institutions, the Department of Physics at UFS has over the years contributed to fundamental research on the development of advanced light-emitting materials (phosphors) that could be used as sources of white light in both LEDs and OLEDs for application in SSL technology. Considerable progress has been made in developing single-host phosphors that emit white light upon excitation with ultraviolet light. Furthermore, the Department of Electrical, Electronic and Computer Engineering at UP houses a national hub that offers a postgraduate programme in EEDSM which was launched in 2008. In addition to conducting research in SSL to improve energy efficiency, the department is also offering a postgraduate module that covers fundamental topics in SSL.

\subsubsection{International landscape}

In 2009, UNEP established the "en.lighten" Global Efficient Lighting Partnership Programme aimed at accelerating a global market transformation towards environmentally sustainable, energy-efficient lighting technologies, as well as

2 http://dev.ssweb.co.za/sanedi/wp-content/uploads/2015/05/j-sdiemeep2-giz_Broschuere_ A5_S\%C3\%8E\%C2\%BF29.pdf.

$23 \mathrm{http}: / /$ www.eskom.co.za/sites/idm/Residential/Pages/CFLRollout.aspx. 
to develop strategies to phase-out inefficient incandescent lamps to reduce $\mathrm{CO}_{2}$ emissions and avoid the release of mercury from fossil fuel combustion ${ }^{24}$. In 2010, UNEP estimated that the use of lighting energy had risen to 2815 TWh, corresponding to $15 \%$ of the total global electricity use (US DoE, 2015), and predicted that this consumption would increase to 3575 TWh by 2030 if there are no measures in place to reduce the consumption. On the other hand, the adoption and implementation of accelerated and energy-saving lighting programmes could reduce the demand to 2366 TWh. Responding to this prediction, some countries spanning Africa, Asia, Europe, Latin America, The Caribbean and the Middle East have joined the "en.lighten" initiative of the UNEP to replace old lighting technologies with new SSL technology. The U4E country report for South Africa estimated that implementation of energy efficiency measures could save as much as $7 \%$ of future electrical energy usage with more than $40 \%$ being contributed by the implementation of advanced lighting technologies (http://united4efficiency.org/wp-content/ uploads/2017/05/ZAF-U4E-Country-assessments-saving-report_2016.pdf).

\section{United States}

The need to improve energy efficiency and to reduce electricity bills and maintenance costs is driving many countries in Europe, Asia and the US to install LEDs and to replace conventional sources of illumination such as mercury vapour, metal halide and sodium-based streets lamps.

In the past decade, the US DoE established a solid-state lighting programme aimed at supporting research and development and commercial application activities related to advanced solid-state lighting technologies based on white light-emitting diodes. The primary objective of the US DOE SSL programme is to save 217 TWh by realising luminaire efficacy of $200 \mathrm{Im} / \mathrm{W}$ in 2025 (US DoE, 2015). It is further forecast to increase to $395 \mathrm{~lm} / \mathrm{W}$ in 2030, equivalent to a $60 \%$ reduction of the cited electricity consumption (US DoE, 2015). The US began the phasing out of tungsten-based 100 and $75 \mathrm{~W}$ incandescent light bulbs in 2012 and discontinued the manufacturing of 40 and $60 \mathrm{~W}$ bulbs in 2014 because they did not meet the federal energy efficiency standards (US DoE, 2015). For example, over a five-year period (2009 - 2014) the City of Los Angeles embarked on a project to install over 150000 LED street lights to replace more than 209000 high-pressure sodium vapour street lights (US DoE, 2015). Figure 5-1 shows an aerial view of Los Angeles in 2008 when highpressure sodium street lights were still in use. The same aerial view in 2012 after replacing the high pressure sodium street lights with LEDs is shown on the right-hand side of Figure 5-1. This installation decreased the amount of light pollution significantly and reduced energy usage by $63 \%$, saving USD 8 million in annual energy costs (US DoE, 2016). Figure 5-2 shows how improved light utilisation of a parking lot lighting retrofitted using LED fixtures compares with high-intensity discharge (HID) fixtures. The retrofit programme has been reported to demonstrate a $66 \%$ reduction in energy usage due to improved efficiency and reduced total light generation (US DoE, 2016).

24 http://www.enlighten-initiative.org/About.aspx. 


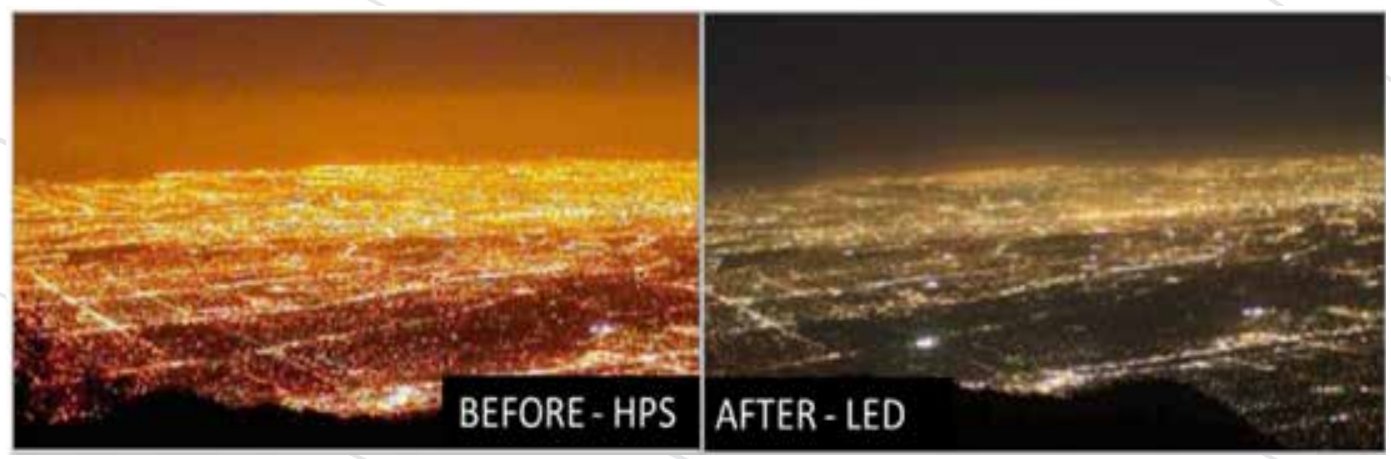

Figure 5-1: City of Los Angeles before and after LED retrofit programme (US DoE, 2016)
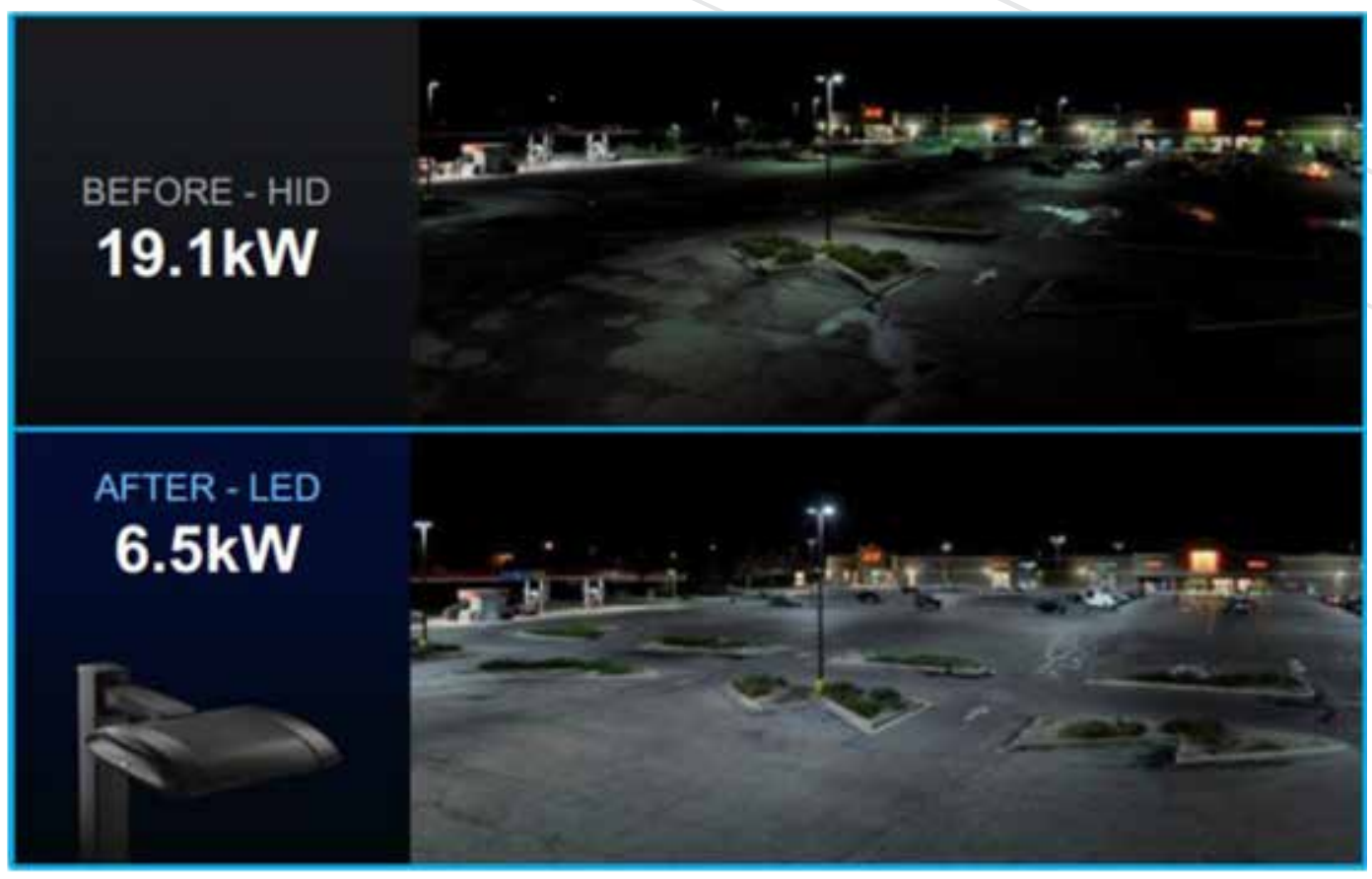

Figure 5-2: A parking lot of Edgewater marketplace (Colorado-USA) before and after lighting retrofit using LED fixtures (US DoE, 2016)

Asia

UNEP projects that $57 \%$ of the lighting energy demand in 2030 would come from Asia and is encouraging Asia to put new policy measures in place to improve energy efficiency and to reduce the lighting energy consumption ${ }^{25}$.

${ }^{25}$ http://www.enlighten-initiative.org/About.aspx 
Today, Japan is recognised as the world leader in the LED industry, both in production and in public funding for R\&D. The Vision 2020 for Lighting Business of the Japan Lighting Manufacturers Association projects that $100 \%$ shipments and $50 \%$ of the installed base of 950 million luminaires will be LEDbased by 2020. In China, the LED penetration increased from $2.4 \%$ in 2013 to $10 \%$ in 2014. The Chinese national goal of 2020 is to raise SSL penetration to $70 \%$, thereby saving 340 TWh of electrical energy. India has recently shifted its focus from CFLs to promote the installation of LED products through its Affordable LEDs and Appliances for All (UJALA) programme launched in 2015. It is focused primarily on retrofitting lamps, downlights and street lights, by providing LED lamps at the cost of incandescent lamps (http://www. eeslindia.org/writereaddata/EESL-Brochure.pdf). The goal for LED sales revenue in 2015 was USD 1.25 billion, representing over $80 \%$ of total lighting sales in India (Japan Lighting Manufacturers Association, 2015).

\section{Europe}

In Europe, lighting accounts for $14 \%$ of the total consumption of electrical energy (Japan Lighting Manufacturers Association, 2015). UNEP reported that lighting energy use in Europe was 480 TWh in 2010 and the Phillips Company estimated that complete replacement of the installed base with SSL sources would lead to savings of roughly 280 TWh (US DoE, 2016). The share of lumenhours produced by LED lighting has been forecast to reach $12 \%$ in 2020 and $67 \%$ in 2030 (CLASP, 2013). The Flemish Institute for Technology Research (VITO) estimated that 82 million LED lamps (equivalent to $5 \%$ of all lamps sales worldwide) were sold in 2013 in the European Union, and that this brought the total LED installation to 144 million units which represent $1.3 \%$ of the installed base (US DoE, 2016). Furthermore, VITO forecast that LED penetration will rise to between $70 \%$ and $86 \%$, with the average efficacy reaching between 113 and $169 \mathrm{~lm} / \mathrm{W}$ in 2025 (CLASP, 2013).

\subsection{Research and development opportunities in South Africa}

Although lighting consumes about $20 \%$ of the country's electricity (LEAP, n.d.) as mentioned above, there are very limited research and technology development programmes in South Africa to improve energy efficiency in lighting. Most energy efficiency projects are pilot projects run by Eskom. Furthermore, there is a very limited number of universities and research institutes in South Africa that are doing fundamental research in the development of advanced materials for solid-state lighting.

\subsection{Summary}

It is clear that South Africa should prioritise energy efficiency as an integral part of its economic and social agenda for the future, and that the country is already taking some action to realise its energy efficiency goals. However, South Africa does not have a general and coherent policy on SSL technology. Moreover, there is no well-established market for the sale of LED lamps and luminaires in the country and the rate of SSL penetration of the country's 
installed base is relatively slow. The slow replacement of incandescent bulbs with CFL bulbs, both of which are now being phased out and replaced by energy efficient and environment-friendly LED lamps and luminaires in many First World countries, is a clear indication that the country is lagging behind global developments. South Africa can make contributions to the development of solid-state light-emitting devices and should also position itself by providing education and training in the application of such devices. LED devices are not currently manufactured in South Africa but are imported, mainly from China. The prospect for the competitive local production of LEDs are limited and the focus should rather be on the utilisation of such devices in locally produced luminaires, as well as to develop capabilities in quality assurance, improvement of reliability and local manufacturing. This would then also open opportunities for after-sales support and maintenance of such devices. South Africa could learn much from the very successful UJALA programme in India that stimulated a switch to LED lighting by providing LED lamps at the same cost as that of incandescent lamps.

Furthermore, South Africa needs to establish a research programme on SSL, bringing together material scientists, electrical engineers, architects, economists and other stakeholders in order to guide and support the necessary change in lighting technologies with internationally competitive research done in South Africa. 


\section{IN FOCUS: TRIBOLOGY}

\subsection{Introduction}

Tribology is the science and technology of friction, wear and lubrication of interacting surfaces in relative motion and it has the potential to significantly reduce the energy requirements of society directly by reducing the energy losses associated with friction and indirectly by reducing wear with its associated decrease in functionality and the inherent energy requirements of repairs and replacement parts. Tribological problems impact every aspect of both our personal and societal lives in terms of electrical power supply, water supply, safety and security. Most gadgets and machines that we take for granted often had serious tribology problems to overcome before they were usable by society (Society for Tribologists and Lubrication Engineers, STLE, 2016).

Tribology as a wide-ranging interdisciplinary field thus offers significant prospects to increase efficiencies and reduce energy wastage and thus increase energy efficiency over a broad range of activities, specifically in electrical energy production and utilisation as will be highlighted in this section.

\subsection{Technology and research and development landscape}

\subsubsection{South African industry landscape}

From a historical perspective, energy saving due to a reduction of friction and wear as a result of more appropriate lubricants and lubrication, better choice of materials of construction and better equipment design has only in recent times been attributed to the collective role of tribology (STLE, 2014). In the local electricity generation environment, the following technologies have been applied and have collectively led to energy savings (South African Institute of Tribology, SAIT, 2011):

- Gear design - through suppliers of milling equipment, notably opengear drives.

- Gear surface preparation - close monitoring of gear surfaces, during running-in and during normal operation.

- $\quad$ Selection and use of correct lubricant through appropriate specifications - through constant development of appropriate specifications relevant to specific applications.

- Use of task-specific lubricants to ensure reduction in friction.

- Better maintenance practices.

As representative examples of efforts by industry, several extensive projects were successfully conducted in Eskom, as part of an internal goal to save 
1 billion kWh per year (Scott, 2011). In one such project, reduction in energy use was achieved by reducing friction in power generation with specific reference to changing lubricants used in helical gear drives on gearboxes for air condenser cooling fans at Matimba power station. Based on the known mechanical efficiencies of helical gearboxes, a saving of about $0.5 \%$ to $0.75 \%$ per gear stage was considered possible. Final results verified that synthetic gear oils lowered energy consumption by an average of $2.2 \%$. If all gearboxes were converted to use the same synthetic lubricant, potential energy savings at Matimba would be $1425 \mathrm{~kW}$, or roughly $11.5 \mathrm{Mwh}$ per annum. Converting all major gearboxes in Eskom to a suitable synthetic oil could conservatively provide savings as high as $20 \mathrm{MWh}$ or $140000 \mathrm{GWh}$. In the South African market, Eskom's oil usage is estimated at less than $0.5 \%$, while the mining industry alone accounts for at least 15 to $20 \%$. This makes the potential for energy savings approximately 30 times higher in the mining sector.

It is difficult to make the estimate for all sectors, but potential savings in gearing applications alone throughout industry, could exceed $200 \mathrm{MW}$ and be as high as $600 \mathrm{MW}$. It is not likely that all these applications would be converted, but even a low percentage uptake would have a significant impact in reducing power consumption. In another study by De Vaal et al. (2010), it was shown that Eskom's coal milling operations consume between 2000 and $2400 \mathrm{GWh}$ based on increased coal burning. The use of energyefficient gear oils can help reduce the power consumed by milling plants in their reducer gearboxes by a minimum of $1 \%$, with a figure of around $1.5 \%$ to $2.5 \%$ being more realistic. Therefore, a minimum of $24 \mathrm{GWh}$ can be saved from Eskom's milling plants alone. Again, if this was extended to milling operations in the mining sector, significant energy savings would be possible (SAIT, 2011 1). By making more efficient use of specialised applications of more efficient lubricating techniques like Minimal Quantity Lubrication in metalcutting operations, not only can substantial reduction in volumes of cutting oils be achieved, with the associated cost-savings, but this can in addition be achieved in an environmentally-friendly manner (De Vaal et al., 2012). The above examples serve to indicate how tribology serves as the common means through which energy usage can be optimised in a sustainable manner.

The DST-funded Tribology Project 2010 (SAIT, 2011) highlighted that when engine lubrication is considered from a South African perspective, the impact of one can of engine oil multiplied across a vehicle population becomes significant. The study states that "A large portion of the South African car fleet is considered to be relatively old, with $40 \%$ being older than ten years. It is assumed that the majority of these vehicles, as well as the taxi market, are currently using mono-grade SAE 40 engine oil. If it is assumed that these vehicles consume $30 \%$ of the petrol sales, changing them to multi-grade $15 \mathrm{~W}$ 40 engine oils would result in between 7 to 18 million litres of petrol savings".

As tribology impacts every economic sector it is worthwhile highlighting considerations in three important sectors which have a direct impact 
on the electricity generation chain, namely Energy, Manufacturing and Transportation.

\section{Energy}

- The economy is tied very closely to energy - a key input in all fields of production.

- $\quad$ Traditional fossil fuels have been the mainstay of energy. Alternative energy sources are needed in order to supplement and replace fossil fuels that have become increasingly difficult and costly to find and extract.

- $\quad$ The development of alternative energy technologies will eventually have a great impact on the field of tribology and lubrication engineering, but the future is uncertain.

- $\quad$ Fossil fuel-based natural gas will provide an important bridge to alternative energies of the future.

\section{Manufacturing}

- Manufacturing operations have traditionally followed a trend towards increasing the efficiency of production, which negatively impacts the operational lifetimes of machine components.

- Lubricants are a critical component to realising efficiencies, but are influenced by government regulation, advances in machinery and automation, the cost of energy, and the availability and location of raw materials and other resources.

- Materials for mechanical components used within the manufacturing industry, which offer increased operational lifetimes are also critical for improving energy and production efficiency; this is directly related to increasing the wear rates of the materials.

- $\quad$ The challenge is to find the right mix of location, technology and resources that result in the most efficient, lowest cost operations.

\section{Transportation}

- $\quad$ Transportation is strongly influenced by government emissions regulations, as well as fuel efficiency.

- $\quad$ The trend will be in producing ever more efficient vehicles - whether through traditional gas-powered engines or hybrid/electric motors.

- $\quad$ The demand for low-viscosity motor oil formulations that are capable of servicing long drain intervals, as well as increasingly advanced engines will remain.

- $\quad$ Electric motors of the future may sharply decrease the demand for lubricants and new lubricant formulations. 


\subsubsection{South African research and development landscape}

Research in tribology is conducted at several institutions in South Africa. Funding for research is obtained either via government funding bodies such as the National Research Foundation (NRF) or funded by industrial partners to undertake contract research within the academic environment. A brief overview of the tribology research and promotion at the different institutions is given.

\section{University of Cape Town}

The Centre for Materials Engineering functions within the Department of Mechanical Engineering. Tribology research focuses mainly on studies of wear of materials, notably light metals (titanium) and power plant materials.

\section{University of Pretoria}

Tribology research at UP is done through the Tribology Laboratory in the Department of Chemical Engineering. This laboratory focuses on the role of lubricants and the performance testing of lubricants. In the electricity generation sector, the efficient use of lubricants has played a consistently important role in applying tribological concepts to reduce energy usage and to reduce wear. Specialised work related to surface engineering and corrosion is performed in the Industrial Minerals and Metals Research Institute, in the Department of Metallurgical and Materials Engineering and hosts leading experts in the metallurgical engineering industry. The strong industrial focus, project-based approach provides leading research in especially the field of physical metallurgy, but the portfolio of the institute does include work in other fields as well.

\section{University of the Witwatersrand}

The tribology group at Wits is housed in the School of Chemical and Metallurgical Engineering. Research in the field of tribology is focused on investigating the wear mechanisms which components experience during industrial operation, with the aim of extending the lifetime of the component and/or improving operational efficiency. Emphasis is placed on materials research and development. Research includes designing new compositions, producing the materials and conducting materials property and wear tests. Optimisation of the production processes used to manufacture the wearresistant materials is also done. Tribology also forms part of the curriculum of the third year engineering students. Postgraduate courses in tribology are offered which may be taken by industry delegates on a short-course basis. The development of materials for wear applications is also done within the DST-NRF Centre of Excellence (CoE) in Strong Materials which has six major research thrusts namely, Ceramics, Carbides and Cermets, Strong Metallic Alloys, Carbon Nanotubes, Diamond and Thin Films, and New Ultrahard Materials. This CoE spans the Science and Engineering faculties at several universities in South Africa and includes researchers from chemistry, physics, metallurgical, materials, mechanical, industrial and chemical engineering. 


\section{Nelson Mandela University}

The InnoVenton Analytical facility is a unit within InnoVenton that serves industry, other research institutions and the public nationally and regionally, as well as supporting the R\&D activities of the institute. The focus areas related to tribology are on automotive components, fuels and coal analyses. The purpose of InnoVenton Analytical is to provide a comprehensive series of chemical and material testing and analysis services.

\section{Tshwane University of Technology}

Work on tribo-corrosion is the main focus at Tshwane University of Technology (TUT) where materials are investigated under simultaneous corrosion and wear testing. Materials of interest are coatings and ceramics, with some emphasis on metals.

\section{Stellenbosch University}

The tribology research at SU is centred on machining operations where optimisation from an industrial engineering perspective is emphasised.

\section{CSIR and Mintek}

Research into developing materials for tribology is also undertaken at the CSIR and Mintek. Materials of interest include metallic alloys, coatings, and the use of laser facilities at the National Laser Centre to produce wear-resistant materials.

\section{South African Institute of Tribology}

A professional society, known as the South African Institute of Tribology (SAIT) was formally launched on 29 March 1985. This society was founded after a group of industrialists and researchers, concerned with the extent of tribological wear in South Africa, convened and formed the 'Wear Society' in 1983. From these modest and early beginnings, the SAIT has grown into a significant and active member of the southern African engineering community. Having established technical transfer through technical meetings, mini-seminars and plant visits, the main objective of the SAIT was put into operation by the introduction of training courses on the principles and technology of lubrication and materials. The knowledge gained by over 3 500 students, who have attended the courses, has been put into practice back in industry. In addition to the training courses, the SAIT holds regular international tribology conferences, and also one-day seminars on topics of interest in the lubrication and materials fields. These seminars have proven to be of great interest and benefit to industry. The SAIT is a member of the world tribology body known as the International Tribology Council, based in the UK, and has a working agreement with the Society for Tribologists and Lubrication Engineers (STLE) of the US. The SAIT is committed to improving and expanding its services to meet the changing needs of southern Africa. 
In 2010, the SAIT, in collaboration with the DST, embarked on an intensive study to attempt to highlight the importance of tribology in South Africa and how investment in tribology research and industrial best practice could have a positive impact in aligning with the government's national priorities. Some of the findings from an initial short survey include the following:

- Tribology is a relatively unknown science in South Africa.

- Education is a priority, from the boardroom to labourer level.

- Tribologists are required in all industries, particularly in production and design, to ensure that equipment is correctly designed and produced. This will ensure that the benefits of correct tribology are considered and harnessed.

- $\quad$ Friction and wear are not sufficiently monitored at any level.

- Lubricants and lubrication need to be handled from a cradle-tograve perspective.

- $\quad$ Research and development in terms of application and implementation is required.

- $\quad$ Through ineffective maintenance training and practices and reduction in technical skills across industry, the average life of both rolling element and plain bearings has dropped by two-thirds and gearbox life to overhaul has dropped by $80 \%$ to $90 \%$ over the past 25 years.

- $\quad$ Overall, if industry was able to get back to basics and focus on tribology, energy costs could be reduced by between $8 \%$ and $20 \%$, and maintenance costs by $30 \%$ to $50 \%$.

In line with the South African Strategic Plan for the Fiscal Years 2015 - 2020 (DST, n.d.) and the South African Research Infrastructure Roadmap (DST, 2016) these can be addressed by enabling the application of tribological principles to ensure energy savings:

- $\quad$ Energy constraints are hampering both economic growth and access to the national electricity grid by the poverty-stricken. A lack of access to the national electricity grid has a negative effect on the development and opportunities of the poverty-stricken. A saving of $8 \%$ of the electric energy used by industry, with no effect on the production or output of industry, equates to a saving of many millions of Rand.

- $\quad$ Production costs can be reduced, both through a reduction in energy consumption and costs, and through a reduction of maintenance associated costs.

- $\quad$ Reduced production costs will stimulate industry in general and will increase employment.

- Increased employment and local production will increase GDP and will also have a calming effect on workplace conflict. 
- Industry that is more globally efficient will increase South Africa's potential for export which can improve the balance of payments and economic growth.

As part of this joint initiative, a Technical Steering Committee on Tribology (TSCT) was formed in 2013. The TSCT focused on the potential of tribology in South Africa and sub-divided into five Working Groups whose objectives were to work with representatives from specialist and interested parties in their respective fields to identify and resolve areas where tribology can make South Africa more globally competitive. The working groups were:

1 Education

2 Lubrication Selection, Standards Development and Quality Control

3 Materials

4 Mechanical Applications

5 Condition Monitoring and Maintenance Programmes.

From discussions of the TSCT, a Tribology Road Map was constructed in order to grow tribology into the future. Recommendations from this road map included:

- $\quad$ Establishment of appropriate research chairs at South African tertiary institutions according to similar guidelines as for the existing DST-NRF South African Research Chair Initiative (SARChI).

- $\quad$ Establishment of a CoE to promote human capital development in tribology.

- $\quad$ Expand knowledge gained and increase global competitiveness.

\subsubsection{International landscape}

The important role that tribology can play to improve the efficiency and competitiveness of societies was recently highlighted by several initiatives such as the US House of Representatives Resolution 916 tabled in September 2016, which called for increased research and development investments, and a report from the UK (Jost, 1966) that highlighted the role tribology can play to improve efficiencies and reduce wastage by its emphasis on both friction and wear. This led to the establishment of voluntary institutions in Europe, Asia, the US and Africa - often under the auspices of established institutions like the IMechE in the UK, but also through associations like the STLE in the US and the SAIT in South Africa, with the International Tribology Council in an international coordinating capacity.

Several surveys focusing on the status and role of tribology in various countries have been published as well. An overview of worldwide research in tribology was done by Elango et al. $(2015,2016)$. In the US, the STLE published a survey (STLE, 2015) in which the following major trends were identified:

"Tribology's economic and commercial impact is vast. The science reduces energy use, lowers the cost of maintenance and replacement, develops new technology, and solves resource 
problems, such as the lack of clean water. Proper tribological procedures save an estimated $1.3 \%$ to $1.6 \%$ of a nation's gross domestic product - a savings of hundreds of billions of dollars (US currency) in larger countries. Virtually every nation has realised it cannot afford to overlook the economic, industrial, and commercial advantages of tribology. Consequently, tribology is a science that is constantly being advanced by thousands of researchers around the world. Lubrication engineering is the practical application of that science, generally in the development of lubricants and their proper usage and maintenance."

A summary and analysis of the various trends and impacts of energy on tribology as published in STLE (2015) are:

- $\quad$ Energy is a critical input to the tribology and lubrication engineering field.

- $\quad$ Lubricants are required for the production and sourcing of energy las in the case of coal mines, oil drilling), as well as the usage of energy (as in the case of gas-powered engines, wind turbines).

- $\quad$ The cost of fossil fuels is likely to rise as current sources become depleted and new sources must be identified and developed at greater levels of effort and expense.

- $\quad$ Alternative energy offers a supplement and potential replacement to traditional fossil fuels. However, the uptake of new or alternative energy options is likely to be limited until advancements in science and engineering can remove important technological and safety barriers.

- $\quad$ As can be expected of such an important and interdisciplinary field there are numerous international academic, industrial and government research institutes with groups focusing on tribology research and development and the support of industry to limit the impact of friction and wear through the better characterisation of tribological processes, and the development of materials, lubricants and practices to limit the impact of friction and wear.

Global research in tribology appears to be largely encouraged and funded by governments. A recent example of such an initiative is the Chinese State Key Laboratory of Tribology at Tsinghua University that was founded in 1986 and officially certificated in November 1988. The laboratory focuses on fundamental research on theory and application of tribology and micro/ nano-manufacturing. It also carries out related technology development and consultation services. Its research areas cover inter alia friction, wear, lubrication, sealing, surface and interface, micro/nano-manufacturing, intelligent machinery, biomechanics and micro/nano-photonic devices. 


\subsection{Research and development opportunities in South Africa}

In the South African environment, several research and technology development opportunities in tribology that will directly contribute to improving energy efficiency can be identified. The main aims of tribology research are the reduction of friction and wear by:

1 Reducing surface roughness, and by surface patterning.

2 Optimum design of components taking into account operating conditions.

3 Designing, manufacturing and then employing the correct material for every component and application.

4 Lubrication engineering which includes development of new lubricants.

5 Development of standards and quality control policies for lubricants, condition monitoring, mechanical components, and maintenance practices.

An additional key initiative which contributes towards R\&D includes educational and skills development by, for example, including tribology education within curricula at educational institutions within key disciplines, as well as educating the existing industrial workforce. This could extend to providing research opportunities to existing workforce members based on current industrial problems which not only generate industrial solutions but also provide postgraduate qualifications to employees. 


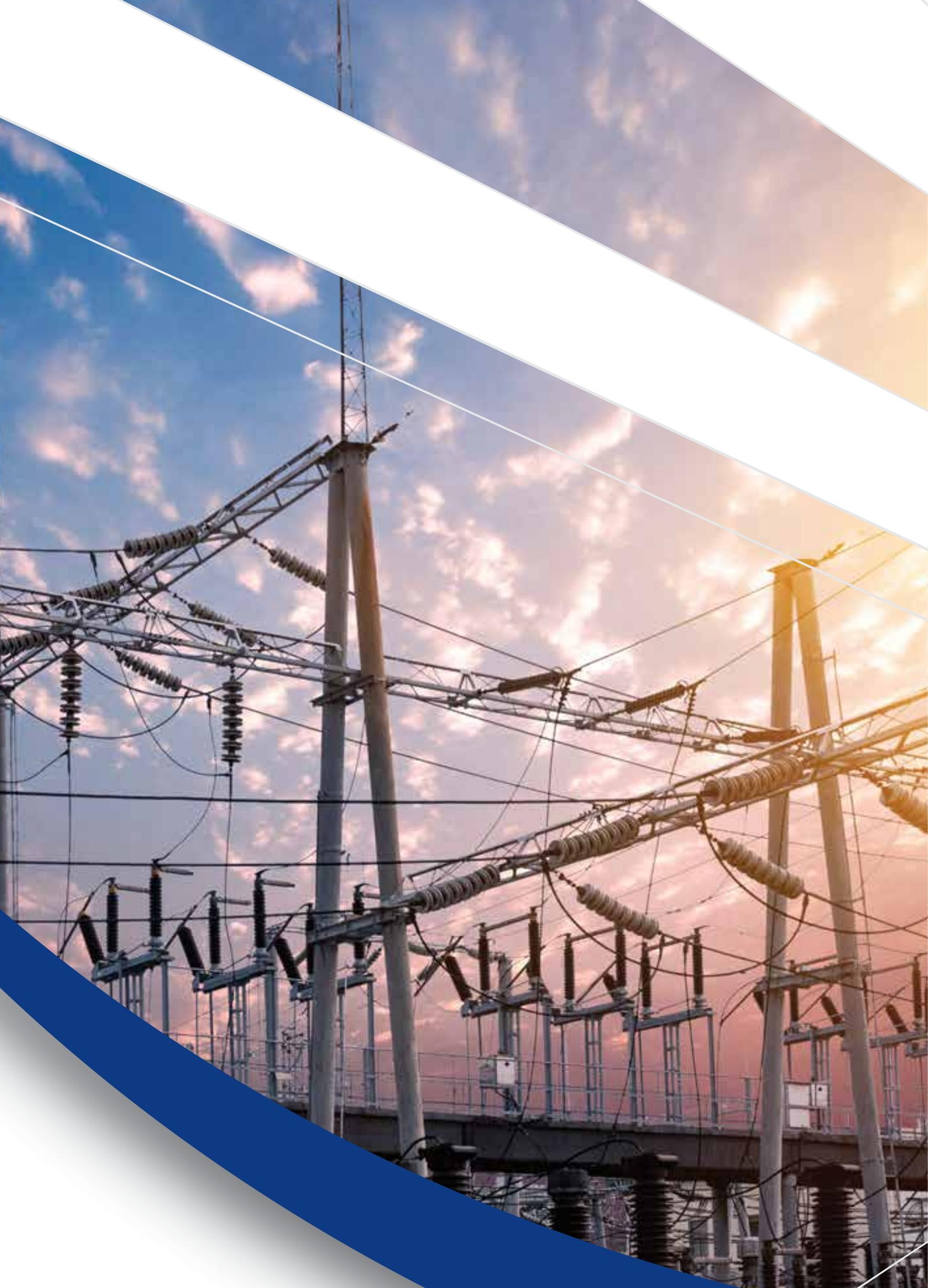




\section{KEY FINDINGS AND RECOMMENDATIONS}

\subsection{Findings}

\subsubsection{Energy efficiency}

South Africa has small but notable activities in energy efficiency, with significant contributions in industrial energy systems in MMM and with the $M \& V$ of energy efficiency initiatives. The traditionally strong research areas in renewable energy, power systems, integrated building energy systems and energy storage are converging on interdisciplinary topics such as smart and micro-grids. There is growing interest in emerging research areas sUch as SSL, smart and micro-grids, measurement and verification, and tribology. South African research outputs in energy efficiency increased from 2007 up to 2014, but have since then stagnated. The focused funding of the EEDSM hub at UP has contributed significantly to this growth in research but needs to be sustained and increased to maintain the momentum to guide and support energy efficiency interventions with linked R\&D activities.

International cooperation agreements serve as conduits for South African participation in projects best approached through multinational approaches. The BRICS STI Framework Programme is opening up opportunities for research cooperation on micro-grids and the related fields of integrated building energy systems, distributed generation systems, smart grids and SSL. South Africa is also participating in the Clean Energy Ministerial and has already collaborated on energy management systems and cool roofs. There are also significant exchange possibilities for developing and established researchers with a leading research institute, such as the Lawrence Berkeley National Laboratory.

Energy efficiency is an economically and environmentally attractive way to meet growing energy demands but needs support to make a significant contribution as it may not be aligned with the aims of energy producers. As a country rich in mineral resources, South Africa should not try to move away from energy-intensive industries that offer significant downstream beneficiation opportunities, but should rather strive to make these industries more energy efficient and competitive through R\&D support.

South Africa has made solid progress in energy efficiency over the past 20 years, with commensurate savings and increasing competitiveness. Policy interventions are required to consolidate and further develop these gains by ensuring that energy efficiency is a central part of the regulatory framework, by for instance establishing a national monitoring, evaluation and reporting framework for energy efficiency implementation. 


\subsubsection{Smart grids}

The operation of electricity distribution grids as smart grids is a relatively new concept that developed, inter alia, in response to a greater focus on energy consumption and its environmental impacts, and the emergence of renewable and alternative energy-based distributed generation systems, strongly enabled by advanced sensing, communication and computing capabilities. All indicators suggest that the smart grid presents the potential to facilitate a more effective industry, more efficient energy utilisation and a significant contribution to reducing the environmental footprint of energy production by enabling distributed generation and bi-directional flows of energy. In the South African context, smart grid technologies offer unique opportunities for effective distribution, revenue collection and the integration of newly developed generation capacity into a robust distribution network to optimally utilise existing and future infrastructure. The diverse nature and large differences in infrastructure and operational capabilities, and the very favourable conditions for renewable energy generation offer unique challenges and opportunities for the deployment of smart grid-based technologies to improve sustainable energy delivery.

There is a significant potential for R\&D of smart grid technologies with an energy efficiency focus, based on the existing research base and on the sound economic and environmental imperatives to utilise energy in a more efficient way rather than generating more electrical energy. Careful planning will be required to enable energy efficiency initiatives through appropriate communication and data transfer protocols in order to achieve interoperability, upgradability, security, safety and affordability. R\&D initiatives should deliver capabilities in terms of the local knowledge base, and also capabilities to sensibly interface with major industrial developers of technology to ensure localisation, interoperability and sustainability.

\subsubsection{Solid-state lighting}

Artificial lighting is an essential enabler for the development and sustainability of modern societies. The challenge is to provide economic and efficient lighting with minimal light pollution and other impacts on the environment. Advanced electricity to light conversion technologies, such as SSL, offer a significant opportunity to contribute to the efficient use of electrical energy, while maintaining and even enhancing lighting functionality at the same time. SSL has only recently become competitive, but is already being implemented on a large scale in advanced economies. South Africa has benefitted significantly in terms of energy efficiency from the implementation of more efficient lighting devices, such as CFLs, but is lagging in the implementation of the still more efficient SSL devices. It is important that the latest technologies be utilised and the focus on energy efficiency be retained. The implementation of LED lighting devices should be promoted as an energy efficiency and developmental instrument.

The opportunity for competitive local manufacturing of LED devices is probably limited due to scale limitations and the availability of cheap imports 
from China. However, the development of luminaires offers significant potential and would build on existing capabilities.

South Africa is contributing to R\&D of advanced light-emitting materials, and to the knowledge and application of these devices in luminaires through research and training. Both UFS and UP have ongoing research programmes and the latter offers postgraduate modules as part of its EEDSM. There is an opportunity for a R\&D programme on SSL that would improve the competitiveness of South Africa both on the fundamental research level, as a producer of luminaires, and as a smart user focused on the energy-efficient use of smart lighting devices.

\subsubsection{Tribology}

Tribology as a wide-ranging interdisciplinary field offers significant prospects to increase efficiencies and reduce wastage and thus increase energy efficiency over a broad range of activities and specifically in electrical energy production and utilisation. In the local electricity generation industry the application of tribology principles in gear design, gear surface preparation, the selection and correct application of lubricants, and better maintenance practices led to significant direct and indirect energy savings and thus overall energy efficiency. Increased energy efficiency in manufacturing through the use of efficient lubrication and minimal quantity lubrication in metal-cutting operations, as well as the use of more wear-resistant materials, contribute to the competitiveness and to reducing the environmental impact of industry.

Research and teaching in tribology are conducted at the leading South African universities, as well as at the CSIR and Mintek covering topics such as wear and materials development, corrosion and wear, lubricant development and evaluation to reduce wear and increase energy efficiency, coatings, the use of laser technologies to produce more wear-resistant surfaces, and conditioning monitoring and maintenance management. The international trend is for governments to encourage and fund interdisciplinary tribologyrelated research though initiatives such as the Chinese State Key Laboratory of Tribology at Tshinghua University. R\&D opportunities in tribology to improve energy efficiency should be focused on materials and lubricant development and evaluation, surface conditioning and finishing, and lubrication and maintenance practices.

\subsection{Recommendations}

Based on the findings of this study, the following recommendations, not in any order of priority, are proposed:

1 Energy efficiency must be accorded the priority that it deserves in future iterations of the IRP 
Energy efficiency should be regarded as the 'first fuel' to improve competitiveness and to create additional capacity in energy supply. This should be emphasised in policy development and implementation as it may not be aligned with the interests of the energy industry. Energy efficiency should be reinstated as a priority in future revisions of the IRP.

2 Compile a national Energy Efficiency and Demand Side Management (EEDSM) roadmap, in support of the Integrated Resource Plan and the new National Energy Efficiency Strategy

It has been shown that a focus on energy efficiency can achieve considerable savings and also create opportunities for innovation and growth. It is also clear, however, that the energy efficiency market cannot sustain itself without the support of a clear strategy and plan for monitoring and implementation. It is recommended that an EEDSM roadmap be developed to correctly position EEDSM in the IRP and the NEES.

\section{Strengthen research and training facilities in EEDSM}

The EEDSM hub at the University of Pretoria established by the DST in 2008 has shown the benefits in terms of research outputs of having critical mass in a focused area. Further investment in this facility, with consideration being given to establishing a Centre of Excellence, is recommended to support the implementation of national programmes.

4 Establish a national monitoring, evaluation and reporting framework on energy efficiency

Energy efficiency is an economically and environmentally attractive way to meet growing energy demands but needs support to make a significant contribution as it may not be aligned with the aims of energy producers. South Africa has made solid progress in energy efficiency over the past 20 years, with commensurate savings and increasing competitiveness. SANEDI should be mandated to develop appropriate policy interventions to consolidate and further develop these gains by ensuring that energy efficiency is a central part of the regulatory framework.

5 Strengthen the research and training facilities in smart grids at South African universities

Smart grid-related research in South Africa is concentrated in five universities (UCT, DUT, UKZN, UP and SU). Funding is derived mainly from SANEDI and Eskom and to some extent, DST. Research is informed by SANEDI's Smart Grid Multi-Year Programme Plan but due to funding constraints, the focus has been on applied research with practical outputs. There is an urgent need to enhance the depth of research undertaken, to improve research funding and to strengthen linkages 
with companies that are investing in smart grid technologies. Given the numerous potential benefits of smart grid implementation, a research chair in smart grid research that is co-sponsored by industry should be implemented and targeted postgraduate scholarships, co-sponsored by the private sector and the NRF, implemented to support the research chair. It is further recommended that smart grid research be framed within an energy efficiency framework to give it an overall purpose and vision.

\section{Ensure the development of a coherent policy on SSL and provide support for local manufacture of luminaires}

South Africa lags behind international trends to utilise SSL to improve lighting and energy efficiency while reducing light pollution. India in particular has been very sUccessful with its UJALA programme to move almost completely to LED lights for new and replacement sales. The South African market will most likely not be able to support LED manufacturing but there is considerable potential for locally produced luminaires. South Africa has established research activities on LED devices and it is recommended that support for that be continued, but also that the design and production of luminaires be promoted through policy and implementation initiatives.

\section{$7 \quad$ Implementation of Tribology Roadmap}

Tribology is a wide-ranging interdisciplinary field focusing on friction, wear and lubrication rather than directly on energy efficiency as such. Tribology research in South Africa has benefitted from the establishment of a Technical Steering Committee on Tribology (TSCT) in 2013 that has fulfilled a coordinating role and compiled a Tribology Road Map. Various recommendations contained therein relate to the strengthening of research through the establishment of research chairs and a centre of excellence in tribology. Specific recommendations stemming from this study are to strengthen education on tribology by including tribology in the curricula of appropriate disciplines at universities and educating the existing industrial workforce on tribology. It is further recommended that collaboration on tribology within BRICS be stimulated to leverage Chinese developments in this field. 



\section{REFERENCES}

\section{OVERVIEW}

ASSAf (2014). The State of Energy Research in South Africa.

https://www.assaf.org.za/files/2015/05/ASSAF-State-of-Energy-Research-

Consensus-Report.pdf.

Buchholz, B.M. and Styczynski, Z.A. (2014). Smart Grids: Fundamentals and Technologies in Electricity Networks. Springer.

Camco (2013). Review of the Energy Efficiency and Demand Side Management Hub at the University of Pretoria.

CNES (2015). EEDSM Options and Potentials as we stand in the 2015 of the RSA, Centre of New Energy Systems, University of Pretoria, Technical Report.

CNES (2017). Energy Efficiency, The First Fuel Forgotten in the IRP 2016. Centre of New Energy Systems, University of Pretoria, Technical Report.

DoE (2012). National Energy Efficiency Strategy - Second Review.

http://www.info.gov.za/view/DownloadFileAction?id=179403.

DoE (2013a). Integrated Resource Plan for Electricity 2010-2030 Update Report. http://www.doe-irp.co.za/content/IRP2010_updatea.pdf.

DoE (2013b). Integrated Resource Plan for Electricity 2010-2030. http://www.doe-irp.co.za/content/IRP2010_promulgated.pdf.

DoE (2016). Integrated Resource Plan, Update: Assumptions, Base Case Results and Observations. http://www.gov.za/sites/www.gov.za/files/40445_ gon 1431.pdf.

DST (2013). Terms of Reference: Review of Energy Efficiency and Demand Side Management Hub at University of Pretoria. Sub-Programme: Hydrogen \& Energy, Pretoria.

De La Rue Du Can, S., Letschert, V., Leventis, G., Covary, T. and Xia, X. (2013). Energy efficiency country study: Republic of South Africa, Lawrence Berkeley National Laboratory, LBNL Report 6365E. http://ies.lbl.gov/sites/all/ files/south_africa_country_study_lbnl_report_final.pdf.

EVO (2012). International Protocol of Measurement and Verification Professionals. http://evo-world.org/en/.

Eskom (2015). Eskom Integrated Report.

http://integratedreport.eskom.co.za/par-keeping.php.

European Commission (2009). High Level Group on the Competitiveness of the European Chemicals Industry - Final Report. http://www.cefic.org/ Documents/PolicyCentre/HLG-Chemical-Final-report-2009.pdf. 
Falagas, M.E., Pitsouni, E.I., Malietzis, G.A. and Pappas, G. (2008). Comparison of PubMed, Scopus, Web of Science, and Google Scholar: Strengths and Weaknesses. Federation of American Societies of Experimental Biology Journal, 22 (2), 338 - 342.

Hayes, S., Young, R. and Sciortino, M. (2012). The ACEEE 2012 International Energy Efficiency Scorecard, Report E12A, American Council for an Energy-Efficient Economy.

IEA (2014). Africa Energy Outlook, https://www.iea.org/publications/ freepublications/publication/WEO2014_AfricaEnergyOutlook.pdf.

IEA (2015). Energy Efficiency Outlook for South Africa - Sizing up the opportunity. https://www.iea.org/media/topics/energyefficiency/ EnergyEfficiencyPotentialinSouthAfrica_FINAL.pdf. [Accessed: 02/12/2016]

IEA (2016). Key World Energy Trends. Excerpts from World Energy Balances. http://www.iea.org/publications/freepublications/publication/ KeyWorldEnergyTrends.pdf.

Kallakuri, C., Vaidyanathan, S., Kelly, M. and Cluett, R. (2016). The 2016 International Energy Efficiency Scorecard, Report E1602, American Council for an Energy-Efficient Economy.

Kechichian, E.R., Pantelias, A., Reeves, A., Henley, G. and Liu, J. (2016). A greener path to competitiveness: policies for climate action in industries and products. Washington, D.C.: World Bank Group. http://documents. worldbank.org/curated/en/835691472028683380/A-greener-path-tocompetitiveness-policies-for-climate-action-in-industries-and-products.

Khanna, V.K. (2014). Fundamentals of Solid-State Lighting : LEDs, OLEDs, and Their Applications in Illumination and Displays. CRC Press.

NCPC (n.d.). Industrial Energy Efficiency Project in South Africa, http://ncpc.co.za/about-the-iee-project.

RSA (n.d.). Energy, http://www.gov.za/about-SA/energy.

SABS (2011). South African Standard of Measurement and Verification, SANS 50010. https://www.sabs.co.za/.

Stachowiak, G.W. and Batchelor, A.W. (2005). Engineering Tribology. Elsevier Butterworth-Heinemann.

Xia, X. and Zhang, J. (2012). Energy Efficiency Measurement and Verification Practices in South Africa. Media Africa.

Yoshimura, K., Annen, K., Fukunaga, H., Harada, M., Izumi, M., Takahashi, K., Uchikoshi, T., Xie, R-J. and Hirosaki, N. (2016). Optical properties of solidstate laser lighting devices using SiAION phosphor-glass composite films as wavelength converters. Japanese Journal of Applied Physics, 55 (4), 42102.

Young, R., Hayes, S., Kelly, M., Vaidyanathan, S., Kwatra, S., Cluett, R. and Herndon, G. (2014). The 2014 International Energy Efficiency Scorecard, Report E1 402, American Council for an Energy-Efficient Economy. 


\section{SMART GRIDS}

$A B B$ (n.d.), Asset management. The next generation maintenance strategies. http://www.tdworld.com/white-papers/asset-management-nextgeneration-maintenance-strategies-0. [Accessed: 30 March 2017]

Africa Utilities Technology Council (2016). Telecoms \& ICT - The Essential Ingredients to Create Energy Networks of the Future in Africa.

APEC (2011). Using Smart Grids to Enhance Use of Energy-Efficiency and Renewable-Energy Technologies. Asia-Pacific Economic Cooperation. Pacific Northwest National Laboratory 902 Battelle Boulevard Richland, WA 99352 USA. Available at: http://www.pnl.gov/main/publications/external/ technical_reports/PNNL-20389.pdf. (Accessed on 10 March 2017).

Carnegie Mellon (2016). Smart Grid Maturity Model.

http://www.sei.cmu.edu/smartgrid/tools/. [Accessed: 1 December 2016]

DoE (1998). The White Paper on Energy Policy - South Africa (1998).

Department of Minerals and Energy, Pretoria.

DoE (2005). Energy Efficiency Strategy of the Republic of South Africa.

Department of Minerals and Energy, Pretoria.

DoE (2016). Draft post-2015 National Energy Efficiency Strategy.

Department of Energy, Pretoria.

EDI Holdings (2008). Approach to Distribution Asset Management (ADAM) Report. http://www.infrastructuredialogue.co.za/wp-content/uploads/2012/10/ ApproachtoAssetDistributionADAM.pdf.

European Commission (2011). Smart Grids: From Innovation to Deployment.

European Commission (2013). Incorporating Demand Side Flexibility, in Particular Demand Response, in Electricity Markets.

European Commission (2014). Benchmarking Smart Metering Deployment in the EU-27 with a Focus on Electricity.

Lewis P. (2013). Smart Grid 2013 Global Impact Report. San Francisco, CA: VassaETT. https://www.smartgrid.gov/files/global_smart_grid_impact_ report_2013.pdf.

Miceli, R. (2013) Energy management and smart grids. Energies, 6, 2262-2290.

SANEDI (2013). Smart Grid Vision 2030. South African National Energy Development Institute.

ITU (2012). Boosting energy efficiency through Smart Grids. International Telecommunication Union. Available at: https://www.itu.int/dms_pub/itu-t/ oth/4B/01/T4B010000050001PDFE.pdf. [Accessed on 10 March 2017] 


\section{SOLID-STATE-LIGHTING}

CLASP (2013). Estimating Potential Additional Energy Savings from Upcoming Revisions to Existing Regulations Under the Ecodesign and Energy Labelling Directives. http://kms.energyefficiencycentre.org/publication-report/ estimating-potential-additional-energy-savings-upcoming-revisions-existing. [Accessed: 30 March 2016]

De La Rue Du Can, S., Letschert, V., Leventis, G., Covary, T. and Xia, X. (2013). Energy Efficiency Country Study: Republic of South Africa, Lawrence Berkeley National Laboratory, LBNL Report 6365E. http://ies.lbl.gov/sites/all/ files/south_africa_country_study_lbnl_report_final.pdf.

Japan Lighting Manufacturers Association (2015). Growth Strategy 2020. http:// download.taiwantradeshows.com.tw/2015/TILS/seminar_ppt/20150325-1. pdf. [Accessed: 16 December 2016]

LEAP (n.d.). Energy efficient lighting implementation. http://www.energycommunity.org/documents/SEA5.Energy\%20efficient\%20 lighting\%20implementation.pdf. [Accessed: 30 March 2016]

SANEDI (2013). Smart Grid Vision 2030. South African National Energy Development Institute.

US DoE (2015). Solid State Lighting Program, R\&D plan. https://energy.gov/eere/ssl/downloads/solid-state-lighting-2015-rd-plan.

US DoE (2016). Solid State Lighting Program, R \& D plan. https://energy.gov/sites/prod/files/2016/06/f32/ssl_rd-plan_\%20jun2016_0. pdf

\section{TRIBOLOGY}

Burger, N.D.L., De Vaal, P.L. and Meyer, J.P. (2007). Failure analysis on retrieved ultra high molecular weight polyethylene (UHMWPE) acetabular cups. Engineering Failure Analysis, 14, 1329-1345.

De Vaal, P.L., and Barker, L.F. (2010). Quantifying friction-reducing properties of gear oils at constant temperature with a modified FZG Test. $14^{\text {th }}$ Nordic Symposium on Tribology, Nordtrib 2010, Storforsen, Sweden.

De Vaal, P.L., Barker, L.F., Du Plessis, E. and Crous, D. (2012). Chapter 20: Biorefining - a green tribological perspective. In M. Nosonovsky and B. Bhushan (eds.), Green Tribology, Green Energy and Technology, DOI: 10.1007/978-3-64223681-5_20, Springer-Verlag Berlin Heidelberg.

DST (n.d.). Strategic Plan for the Fiscal Years 2015 - 2020. http://www.dst.gov.za/ images/Attachments/DST_Strategic_Plan_2015-2020_web_pdf.pdf.

DST (2016). South African Research Infrastructure Roadmap.

http://www.eresearch.ac.za/sites/default/files/image_tool/images/140/ DIRISA_Roadmap.pdf.

Elango, B. and Rajendran, P. (2015). Global tribology research output (19982012): a macro level scientometric study. Journal of Information Science Theory and Practice, 3 (4), 35-48. 
Elango, B. and Kannan, G. (2016). Modern tribology research: identificaton of seminal publications. Journal of Mechanical Engineering, 1, 1 -15.

Gresham, D. (2016). A vote for tribology. Tribology and Lubrication Technology, November 2016, 2-4.

Harvey, T., Walker, J., King, S. and Wood, R. (2012). Results of a UK industrial tribological survey. National Centre for Advanced Tribology at Southampton (nCATS), Faculty of Engineering and the Environment, Highfield Campus, University of Southampton.

Jost, H.P. (1966). Lubrication (Tribology), Education and Research: A Report on the Present Position and Industry's Needs. Her Majesty's Stationery Office, London.

Massinga, P.H., Focke, W.W., de Vaal, P.L. and Atanasova, M. (2010). Alkyl ammonium intercalation of Mozambican bentonite. Applied Clay Science, 49, 142-148.

SAIT (2011). Tribology Project 2010. South African Institute of Tribology.

Scott, D. (2011). Conserving current - switching gear oils to save electricity; Lubes \& Greases EMEA, 20-26.

STLE (2015). Trends in Tribology and Lubrication Engineering: Industry Leader Predictions Report; Published by the Society of Tribologists and Lubrication Engineers (STLE), USA. 



\section{APPENDICES}

\section{APPENDIX 1: BIOGRAPHIES OF PANEL MEMBERS}

\section{Roelf Sandenbergh (Panel Chair)}

Prof Sandenbergh was the Dean of the Faculty of Engineering, Built Environment and Information Technology at the University of Pretoria. He started his career as technical assistant at the Hartebeestfontein Gold Mining Co. in South Africa before joining the University of Pretoria in 1974 as lecturer in the Department of Materials Science and Metallurgical Engineering. He became Head of the Department in 1996, as well as Chairman of the School of Engineering in 2001 and Dean of the Faculty of Engineering, Built Environment and Information Technology in 2001. He contributes to teaching, research and consulting in the fields of extractive metallurgy and corrosion on an ongoing basis. Prof Sandenbergh is a Registered Professional Engineer, fellow of the South African Academy of Engineering, Member of ASSAf, honorary life fellow of the South African Institute of Mining and Metallurgy, and member and former President of the Corrosion Institute of Southern Africa. He holds the degrees: BEng and MEng in Chemical Engineering from the University of Pretoria (1972 and 1975 respectively) and DEng from the University of Pretoria in 1983.

\section{Barry Bredenkamp}

Mr Bredenkamp is a General Manager at the South African National Energy Development Institute (SANEDI), responsible for the energy efficiency portfolio. He worked in the distribution, customer service, marketing and Demand Side Management areas of Eskom for a period of 27 years, before being seconded to the Central Energy Fund to establish the National Energy Efficiency Agency in South Africa. While at Eskom, he helped develop and implement the first Energy Efficiency Schools Programme and this led to the formation of a Special Purpose Vehicle - BONESA, which set the scene for the roll-out of efficient lighting in the country. He is acclaimed locally and internationally for contributions to the general market transformation to efficient lighting in South Africa and presents papers on energy efficiency at numerous conferences. He currently represents South Africa on the Global Superior Energy Performance (GSEP) Work Group of the Clean Energy Ministerial (CEM) and has served as President of the Sustainable Energy Society of Southern Africa (SESSA), the southern African affiliate of the International Solar Energy Society (ISES), as well as serving on various committees of the Illumination Engineering Society of South Africa (IESSA) and Technical Committees of the South African Bureau of Standards (SABS) and the NBI's Steering Committee responsible for implementing and monitoring the national Energy Efficiency Accord, which was succeeded by the Energy Efficiency Leadership Network.

\section{Clinton Carter-Brown}

Dr Clinton Carter-Brown is a Chief Engineer - Grid Design in the CSIR Energy Centre. He is focused on the smart grid enablement of the CSIR campus grid, and the related development of an energy autonomous campus and virtual 
power plant. He joined the CSIR in July 2017 and was previously a Technical Director in Aurecon (April 2014 - June 2017). Prior to Aurecon he spent 18 years with Eskom, where he was a corporate specialist in the utility provider's technology division. Regarded in the industry as an expert in his field, he has received numerous awards and has authored more than 15 conference and journal papers.

He has BSc (Cum Laude), MSc and PhD degrees in Electrical Engineering. He is a Registered Professional Engineer with the Engineering Council of South Africa, and is the recipient of the South African Institute of Electrical Engineers (SAIEE) Young Achievers' Award for 2003, and the 2003 Eskom Chairman's Award for Technical Excellence and Innovation. He was awarded the 2012 specialist of the year in the Eskom Technology Group.

\section{Nelisiwe Magubane}

Ms Nelisiwe Magubane obtained a BSc in Heavy Current Electrical Engineering from the former University of Natal and a postgraduate diploma in Business Administration from the University of West London. Her career in engineering started at Eskom and, in 1996, she became the founder and Managing Director of Magubane Isibonelo Projects in KwaZulu-Natal. She held various influential senior positions in the South African energy sector, including being appointed the first Director-General of the Department of Energy (DoE) in 2009, when the department split from the former Department of Minerals and Energy (DME). Some key achievements during her term of office at the DoE included the development of the Integrated Resource Plan for 2010 and the Renewable Energy Independent Power Producer Procurement Programme (REIPPPP). In 2000, she was appointed Chief Director for electricity for the $\mathrm{DME}$, where she was instrumental in developing the electricity pricing policy and the electricity supply industry reform strategy.

A former member of the Engineering Council of South Africa and chairperson of the Council's Audit, Risk and Compliance Committee, she has also held nonexecutive directorships with NERSA, Electricity Distribution Industry Holdings and the South African National Energy Research Institute. She currently serves on Aurecon South Africa's, State Information Agency' (SITA's) and Matleng Energy Solutions board of directors.

\section{Kenneth I. Ozoemena}

Prof Kenneth Ozoemena is Chief Research Scientist at the CSIR. After eight years at the CSIR where he successfully led the interdisciplinary research programme on electrochemical energy technologies (focusing mainly on advanced lithium-ion batteries, super-capacitors and fuel cells) he recently joined the School of Chemistry of the University of the Witwatersrand as full Professor of Materials for Energy and Electrochemistry. He holds BSc (Hons) degree in Industrial Chemistry from Abia State University, Nigeria (1992); double MSc degrees (Chemistry \& Pharmaceutical Chemistry) from the University of Lagos, Nigeria (1996 and 1998); and a PhD (Chemistry) degree from Rhodes University (2003). 
Prof Ozoemena is recognised as one of the most productive South African authors of energy papers. He has published over 150 peer-reviewed articles, three edited books, ten book chapters and has five patent (PCT) applications. $\mathrm{He}$ is a fellow of the African Academy of Sciences (AAS), fellow of the Royal Society of Chemistry (FRSC) and a Member of ASSAf. He holds an extraordinary Professorship at the University of Pretoria. He serves on the editorial boards of several leading science journals, including the Electrochemistry Communications (Elsevier) and Scientific Reports (Nature Publishing).

\section{Alex Quandt}

Prof Quandt received his doctorate in physics from the Eberhard-Karls University of Tuebingen, Germany, in 1997. In 2001, after postdoctoral fellowships at Cornell University and Georgetown University, he joined the Physics Department of Greifswald University, Germany, as an assistant/ associate Professor. Since 2010, he has been an associate and now full Professor of Theoretical Solid - State Physics at the School of Physics, Wits, where he also acts as focus area coordinator at the DST/NRF Centre of Excellence in Strong Materials (COE-SM), and as Director of the Materials for Energy Research Group (MERG). His research interests are computational materials science, photonics/plasmonics, nanotechnology and materials for energy. He is one of four members of the CoE-SM, who together won the 2017 NSTF-South32 Award for Science Communication.

\section{Natasha Sacks}

Prof Natasha Sacks has been employed as a lecturer in Metallurgical and Materials Engineering at the University of the Witwatersrand since June 2004. She received her BSCEng and MScEng degrees in Materials Engineering from UCT and her Drlng degree in Engineering from the Friedrich Alexander University in Germany. Prof Sacks is the focus area coordinator of the Carbides and Cermets research group within the DST-NRF Centre of Excellence in Strong Materials, and serves on the editorial board of the International Journal of Refractory Metals and Hard Materials. She is an adjudicator for the UNESCO/L'Oreal Women in Science sub-Saharan Africa fellowships, and serves on the Technical Programme Committee for the International Conference on Tungsten, Refractory and Hardmaterials hosted in the US every threeyears. Prof Sacks is a member of the South African Institute of Mining and Metallurgy (SAIMM) and the South African Institute of Tribology (SAIT). She has established a tribology laboratory at Wits that is capable of testing a range of wear mechanisms and her main research foci include tribology, powder metallurgy, cemented tungsten carbides, coatings, and physical metallurgy, She has authored more than 50 scientific conference and journal papers, and her research group has received several awards including the 2015 Louw Alberts Award from the SAIT in recognition of her advancement of tribology both locally and internationally, including her liaison with industry in the field of tribology. 

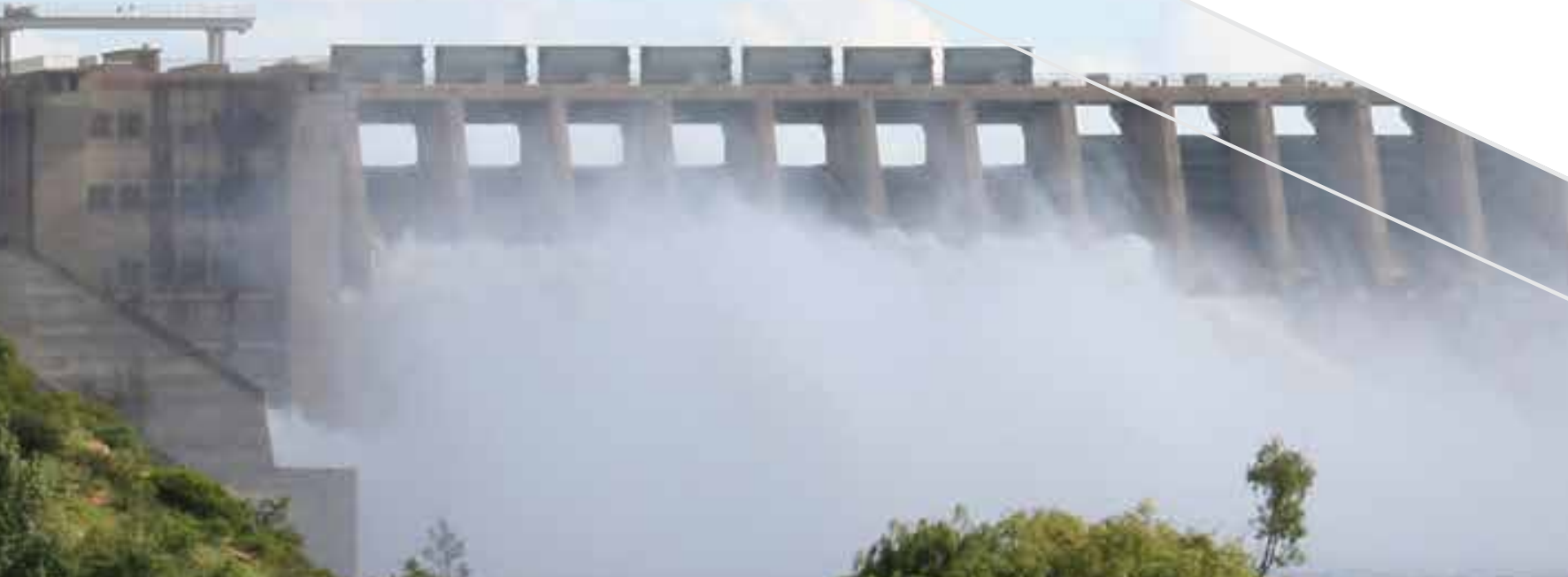

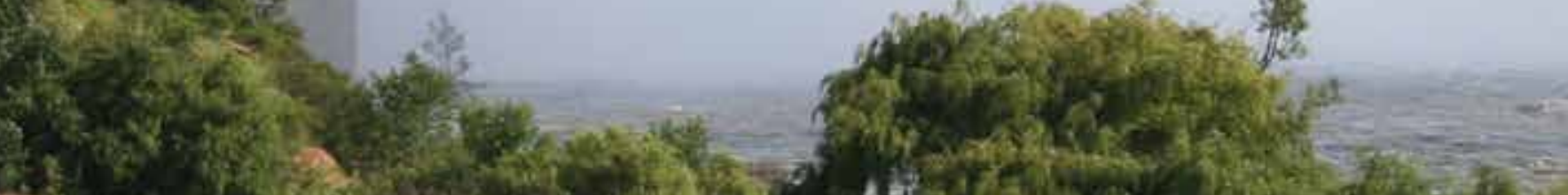

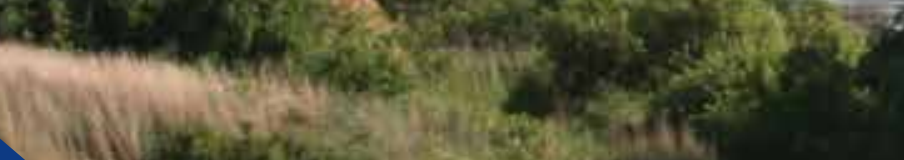

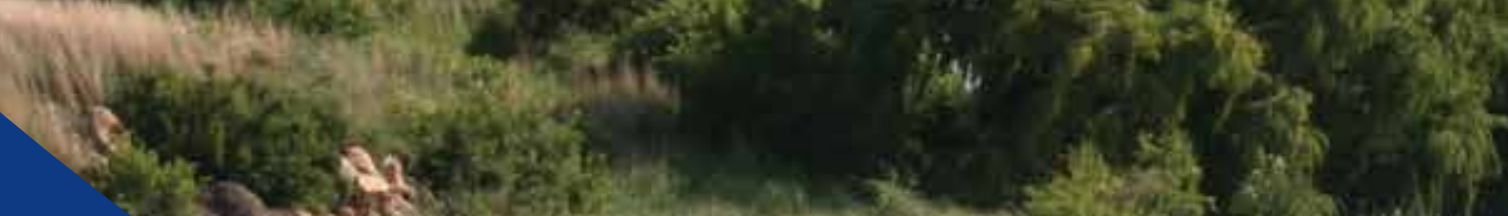

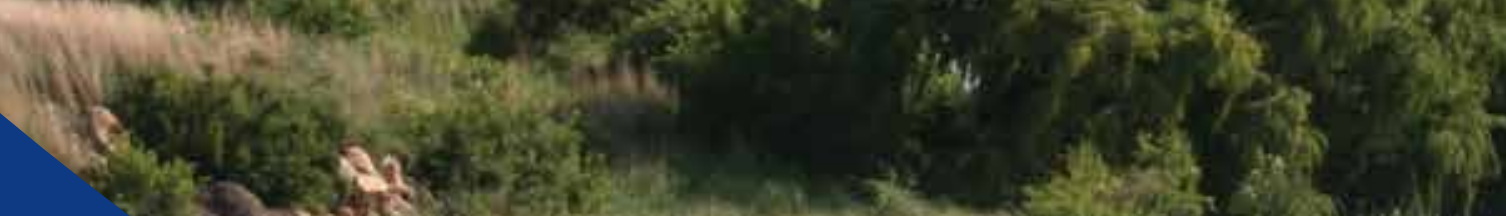

Whe

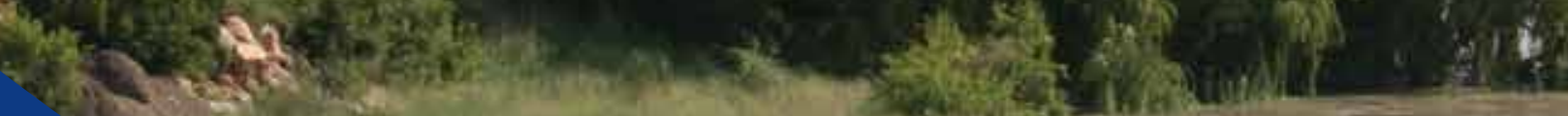

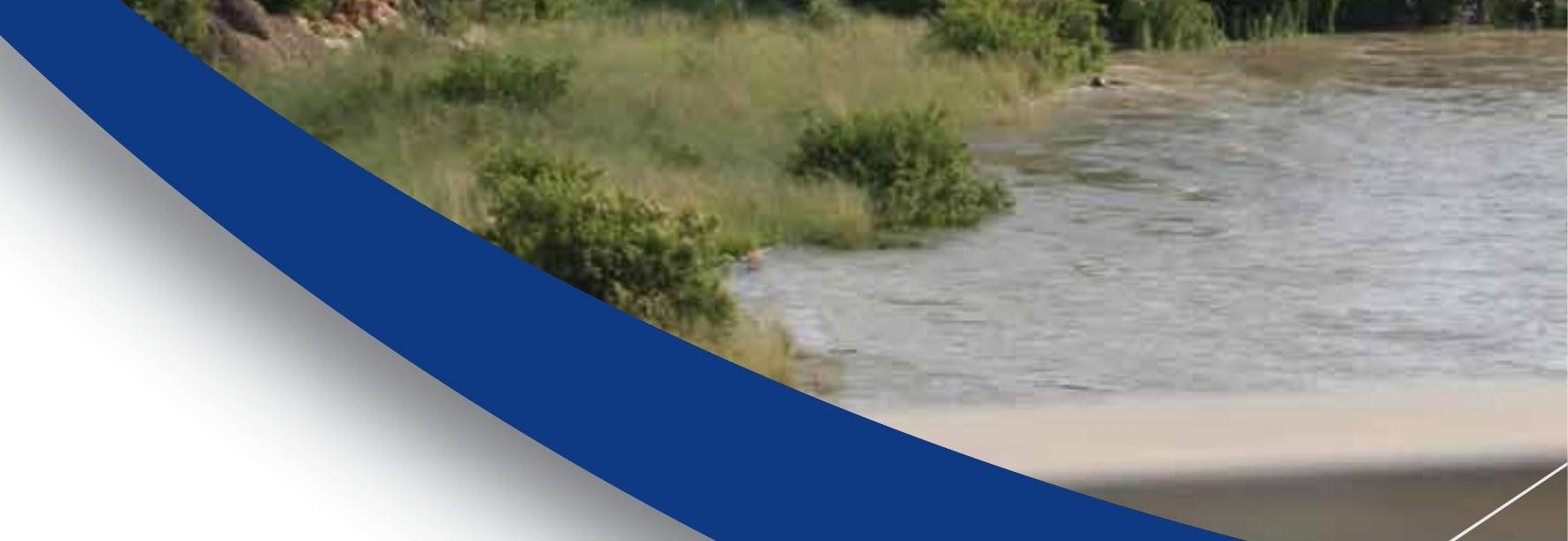




\section{APPENDIX 2: \\ BIOGRAPHIES OF REVIEWERS}

\section{Kevin Bennett}

Prof Kevin Bennett was the Director of the Energy Research Centre, UCT until 2013 and a Professor in the Department of Mechanical Engineering at UCT. After working as a turbine engineer with Eskom, he returned to UCT where he joined the Energy Research Institute. He completed his PhD in 1977 in the general area of energy utilisation in South Africa and was subsequently involved in research projects that included alternative liquid fuels and renewable energy. He joined the Department of Mechanical Engineering as an associate Professor and was subsequently promoted to Professor in 1992, lecturing in the areas of thermodynamics and fluid mechanics. In 2000, he took over as Director of the Energy Research Institute and after the merger between the ERI and the Energy for Development Research Centre, he was appointed as the Director of the newly formed Energy Research Centre. Prof Bennett retired in 2014.

\section{Brian Motherway}

Dr Brian Motherway is Head of Energy Efficiency at the International Energy Agency in Paris, leading a team focused on supporting the global implementation of energy efficiency actions. The IEA acts as a global hub of analysis, policy support and knowledge exchange for energy efficiency. Prior to joining the IEA, he was Chief Executive of the Sustainable Energy Authority of Ireland. Motherway holds bachelors and Masters degrees in engineering, and a doctorate in sociology.

\section{Jamal Saghir}

Jamal Saghir is an expert in infrastructure, energy, water, international finance, economic development, and policy with over 25 years of experience at the World Bank Group. From 2010 to 2016, he was Director of Sustainable Development and Senior Regional Adviser at the World Bank. He held directorships in agriculture and rural development, energy and infrastructure, environment, climate change, water, transport, and sustainable development. He provided intellectual and operational leadership and managed one of the largest departments of the World Bank Group. From 2000 to 2010, he was Director and Chair of the World Bank Group's Sector Boards for Energy, Transport, and Water. During this period, the World Bank strongly increased its engagement in infrastructure investments. From 1990 to 2000, Mr Saghir served in senior management and leadership roles in a variety of private-sector development organisations, restructuring operations in Africa, Latin America, Central and Eastern Europe, the Middle East and North Africa. He has deep experience in infrastructure project finance, as well as implementing high-profile infrastructure investments, public-sector policy, and private-sector development. In 2016, Mr Saghir was appointed Professor of Practice at the Institute for the Study of International Development at McGill University in Montreal, Canada. He is also Senior Associate at the Centre for Strategic and International Studies, Washington DC. He serves on 
the Advisory Board of MAN Holding SAL, Inventis Corporation and is special adviser to the Executive Committee of Bolloré Group Transport and Logistics. He holds a BA and MA in Economics from Laval University. 


\section{APPENDIX 3:}

\section{KEYWORDS USED IN THE ENERGY EFFICIENCY OVERVIEW}

A KEY(Industrial energy systems) OR KEY(Batch plants) OR KEY(Belt conveyor) OR KEY(Bulk Air Coolers) OR KEY(Cement plant) OR KEY(Coal beneficiation) OR KEY (Coal gasification) OR KEY(Conveyor belt) OR KEY(Conveyor belt system) OR KEY(Cooling system energy efficiency) OR KEY(Crushing process) OR KEY (Deep mines) OR KEY (Demand management) OR KEY (Demand response) OR KEY(Demand-side management) OR KEY(Dense Media Separation) OR KEY (Diesel generator) OR KEY (Dispatch strategy) OR KEY (Doubly fed induction generator) OR KEY(Energy management) OR KEY(Energy-water nexus) OR KEY(Facilities maintenance) OR KEY(Heat Integration) OR KEY (Hybrid energy system) OR KEY(Industrial energy systems) OR KEY(Industry) OR KEY(Jaw crushing process) OR KEY(Life cycle cost analysis) OR KEY(Load curtailment) OR KEY (Load management) OR KEY (Load profiles) OR KEY (Load scheduling) OR KEY(Load shifting) OR KEY(Maintenance Planning) OR KEY(Maximum demand) OR KEY(Measurement and Verification) OR KEY(Mine ventilation) OR KEY(Model predictive control) OR KEY(Operation cost minimization) OR KEY(Operation efficiency optimization) OR KEY (Optimal maintenance) OR KEY(Optimal planning) OR KEY(Parallel HPGR crushing process) OR KEY(Peak times) OR KEY(Permanent magnet synchronous generator) OR KEY(POET framework) OR KEY (Pumping station) OR KEY (Pumping system) OR KEY(Pump-storage system) OR KEY(Reliability) OR KEY(Solar water heaters) OR KEY(Temperature set point) OR KEY(Time-Of-use) OR KEY(Variable speed drive based optimal control) OR KEY (Variable water flow) OR KEY(Ventilation on demand) OR KEY(Vertical Roller Mill) OR KEY(Vertical shaft impactor) OR KEY (Wastewater) OR KEY(Water network synthesis) OR KEY (Water pumping) OR KEY(Water Supply Optimisation) AND (LIMIT-TO/ AFFILCOUNTRY, "SOuth Africa")) AND ( LIMIT-TO (SUBJAREA, "ENGI") OR LIMIT-TO (SUBJAREA, "ENER" ) OR LIMIT-TO ( SUBJAREA, "ENVI" )) AND PUBYEAR > 1985 AND PUBYEAR < 2017

B KEY(Renewable energy) OR KEY(Biomass) OR KEY(Demand management) OR KEY(Demand response) OR KEY(Demand-side management) OR KEY(Dispatch strategy) OR KEY(Distributed energy resource mix) OR KEY(Distributed generation) OR KEY(Energy management) OR KEY(Hybrid renewable energy system) OR KEY(Hydrokinetic) OR KEY (Hydrokinetic energy) OR KEY(Hydrokinetic systems) OR KEY(Integration of Renewable Sources) OR KEY(Life cycle cost analysis) OR KEY(Low-cost water heating system) OR KEY(Maintenance Planning) OR KEY(Operation cost minimization) OR KEY(Operation efficiency) OR KEY(Optimal maintenance) OR KEY(Optimal planning) OR KEY(Peak times) OR KEY(Photovoltaic) OR KEY(Photovoltaic system) OR KEY(Photovoltaic cells) OR KEY(Photovoltaic energy) OR KEY(Photovoltaic power generation) OR KEY(Photovoltaic--diesel--battery) OR KEY(Photovoltaics) OR KEY(POET framework) OR KEY(Pump-storage system) OR KEY(PV system) OR KEY(Reliability) OR KEY(Renewable and Sustainable Energy) OR KEY(Renewable energy sources) OR KEY(Renewable Energy Systems) OR KEY (Renewable energy technologies) OR KEY (Renewable 
hybrid system) OR KEY(Residential demand response) OR KEY(Small-scale energy generation) OR KEY(Solar energy) OR KEY(Solar Power) OR KEY(Solar water heaters) OR KEY(Solar water heating) OR KEY(Time-of-use) OR KEY(Wind) OR KEY(Wind farm) OR KEY(Wind solar) OR KEY(Wind system) OR KEY(Wind turbine) AND PUBYEAR > 1985 AND PUBYEAR < 2017 AND (LIMITTO(AFFILCOUNTRY, "South Africa") AND (LIMIT-TO(SUBJAREA,"ENGI") OR LIMIT-TO(SUBJAREA,"ENER" ))

C KEY(Power systems) OR KEY(Advanced Metering Infrastructure) OR KEY(Demand response) OR KEY(Demand-side management) OR KEY(Diesel generator) OR KEY(Distributed energy resource mix) OR KEY(Distributed generation) OR KEY(Doubly fed induction generator) OR KEY(Dynamic economic emission dispatch) OR KEY(Economic dispatching) OR KEY(Energy management) OR KEY(Facilities maintenance) OR KEY(Generator maintenance scheduling) OR KEY(Heat pump water heater) OR KEY (Hybrid energy system) OR KEY(Load curtailment) OR KEY(Load profiles) OR KEY(Load shifting) OR KEY(Maintenance Planning) OR KEY(Maximum demand) OR KEY(Peak times) OR KEY(Permanent magnet synchronous generator) OR KEY(Pump-storage system) OR KEY(Rural electrification) OR KEY(Smart Metering) OR KEY(Steam network synthesis) OR KEY(Steam system optimization) OR KEY(Steam utilization) OR KEY(Time-of-use) AND (LIMIT-TOI AFFILCOUNTRY, "South Africa")) AND ( LIMIT-TO (SUBJAREA , "ENGl" ) OR LIMIT-TO (SUBJAREA, "ENER" ) ) AND PUBYEAR > 1985 AND PUBYEAR < 2017

D KEY (advanced metering infrastructure) OR KEY (air conditioner) OR KEY (appliance scheduling) OR KEY (building energy system) OR KEY (building retrofit) OR KEY (building thermal simulation software) OR KEY (buildings) OR KEY (bulk air coolers) OR KEY (cdm) OR KEY (compact fluorescent lamp) OR KEY (cooling system energy efficiency) OR KEY (demand management) OR KEY (demand response) OR KEY (demand-side management) OR KEY (desiccant wheel) OR KEY (diesel generator) OR KEY (distributed energy resource mix) OR KEY (distributed generation) OR KEY (doubly fed induction generator) OR KEY (energy efficient building) OR KEY (energy efficient buildings) OR KEY (energy management) OR KEY (facilities maintenance) OR KEY (heat pump water heater) OR KEY (household appliances) OR KEY (household energy management) OR KEY (hybrid energy system) OR KEY (hybrid system) OR KEY (life cycle cost analysis) OR KEY (load curtailment) OR KEY (load management) OR KEY (load profiles) OR KEY (load scheduling) OR KEY (load shifting) OR KEY (low-cost water heating system) OR KEY (maintenance planning) OR KEY (maximum demand) OR KEY (measurement AND verification) OR KEY (micro-hydrokinetic river system) OR KEY (microhydrokinetic system) OR KEY (micro-hydropower generation) OR KEY (model predictive control) OR KEY (net zero-energy building) OR KEY (operation cost minimization) OR KEY (operation efficiency) OR KEY (operation efficiency optimization) OR KEY (optimal maintenance) OR KEY (optimal planning) OR KEY (peak times) OR KEY (permanent magnet synchronous generator) OR KEY (poet framework) OR KEY (pump-storage system) OR KEY (reliability) OR KEY (residential demand response) OR KEY (rooftop water harvesting) OR KEY (small-scale energy generation) OR KEY (smart metering) OR KEY (solar 
water heaters) OR KEY (temperature set point) OR KEY (thermal efficiency) OR KEY (time-Of-use) OR KEY (variable speed drive based optimal control) OR KEY (variable water flow) OR KEY (water pumping) OR KEY (water supply optimisation) AND PUBYEAR > 1985 AND PUBYEAR < 2017 AND (LIMIT-TO (AFFILCOUNTRY, "SOuth Africa")) AND (LIMIT-TO (SUBJAREA, "ENGI") OR LIMIT-TO (SUBJAREA, "ENER") )

E KEY(Energy storage) OR KEY(Battery) OR KEY(Battery storage system) OR KEY(Battery-integrated) OR KEY(Compressed air energy storage) OR KEY(Dispatch strategy) OR KEY(Fuel cell) OR KEY(Hybrid Energy storage) OR KEY(Hybrid Storage) OR KEY(Life cycle cost analysis) OR KEY(Photovoltaicdiesel-battery) OR KEY(Small-scale energy generation) OR KEY(Storage system) OR KEY(Supercapacitor) OR KEY(Supercapacitor application) OR KEY(Electrode stability) OR KEY(Electrochemical properties) OR KEY(Faradaic electrodes) OR KEY(Electrical double layer capacitor) OR KEY(Asymmetric supercapacitor) OR KEY(Symmetric supercapacitor) AND (LIMIT-TO( AFFILCOUNTRY, "SOuth Africa")) AND ( LIMIT-TO (SUBJAREA, "ENGI") OR LIMIT-TO (SUBJAREA, "ENER") OR LIMIT-TO (SUBJAREA, "CHEM") OR LIMIT-TO (SUBJAREA, "MATE")) AND PUBYEAR > 1985 AND PUBYEAR < 2017

F KEY(Solid-state lighting) OR KEY(High intensity discharge lamps) OR KEY(LED) OR KEY(Light emitting diodes) OR KEY(Lighting) OR KEY(Lighting system) OR KEY(Phosphors) OR KEY(phosphorus compounds) OR KEY(semiconductor device) AND (LIMIT-TO(AFFILCOUNTRY, "South Africa")) AND (LIMIT-TO ( SUBJAREA, "MATE") OR LIMIT-TO (SUBJAREA, "CHEM") OR LIMIT-TO (SUBJAREA , "ENER" ) ) AND PUBYEAR > 1985 AND PUBYEAR < 2017

G KEY(batch process optimization) OR KEY(Batch plants) OR KEY(Heat integration) OR KEY(Steam flowrate minimization) OR KEY(Steam utilization) OR KEY(Batch Chemical Process Integration) OR KEY(Process simulation) OR KEY(Process optimization) OR KEY(Process integration) OR KEY(Batch) AND (LIMIT-TO(AFFILCOUNTRY, "SOuth Africa")) AND (LIMIT-TO (SUBJAREA, "ENER" )) AND (LIMIT-TO (SUBJAREA, "ENGI")) AND PUBYEAR > 1985 AND PUBYEAR < 2017

H KEY (tribology) OR KEY (bearings) OR KEY (boundary lubrication) OR KEY (breakdowns) OR KEY (coefficient of friction) OR KEY (failures) OR KEY (friction) OR KEY (friction AND wear) OR KEY (friction energy) OR KEY (gear oils) OR KEY (gears) OR KEY (grain boundary) OR KEY (hybrid fabric) OR KEY (hydraulic oils) OR KEY (hydraulic pumps) OR KEY (interfacial interaction) OR KEY (lobe pocket bearing) OR KEY (lubricants) OR KEY (lubricating oils) OR KEY (lubrication systems) OR KEY (molecular dynamics) OR KEY (nano scratch) OR KEY (relative humidity) OR KEY (shale oil) OR KEY (sliding wear) OR KEY (surface coatings) OR KEY (surface engineering) OR KEY (synthetic lubricants) OR KEY (tribological property) OR KEY (tribo-surfaces) OR KEY (ultra-short pulse laser surface structuring) OR KEY (water lubrication) AND PUBYEAR > 1985 AND PUBYEAR < 2017 AND (LIMIT-TO (AFFILCOUNTRY, "SOuth Africa")) AND (LIMITTO ( SUBJAREA, "ENER") ) 
I KEY (smart grid) OR KEY (smart grid technologies) OR KEY (smart metering) AND PUBYEAR > 1985 AND PUBYEAR < 2017 AND (LIMIT-TO (AFFILCOUNTRY, "South Africa" )) AND ( LIMIT-TO ( SUBJAREA, "ENGI" ) OR LIMIT-TO ( SUBJAREA , "ENER" | )

J KEY (measurement and verification) OR KEY (lamp failure) OR KEY (lamp failure rate) OR KEY(Longitudinal sampling) OR KEY(M\&V) OR KEY(Measurement and Verification) OR KEY(Polish Efficient Lighting Project) OR KEY(sampling) OR KEY(sampling size) OR KEY(sampling size determination) AND (LIMIT-TO/ AFFILCOUNTRY, "South Africa")) AND (LIMIT-TO ( SUBJAREA, "ENER" )) AND PUBYEAR > 1985 AND PUBYEAR < 2017 


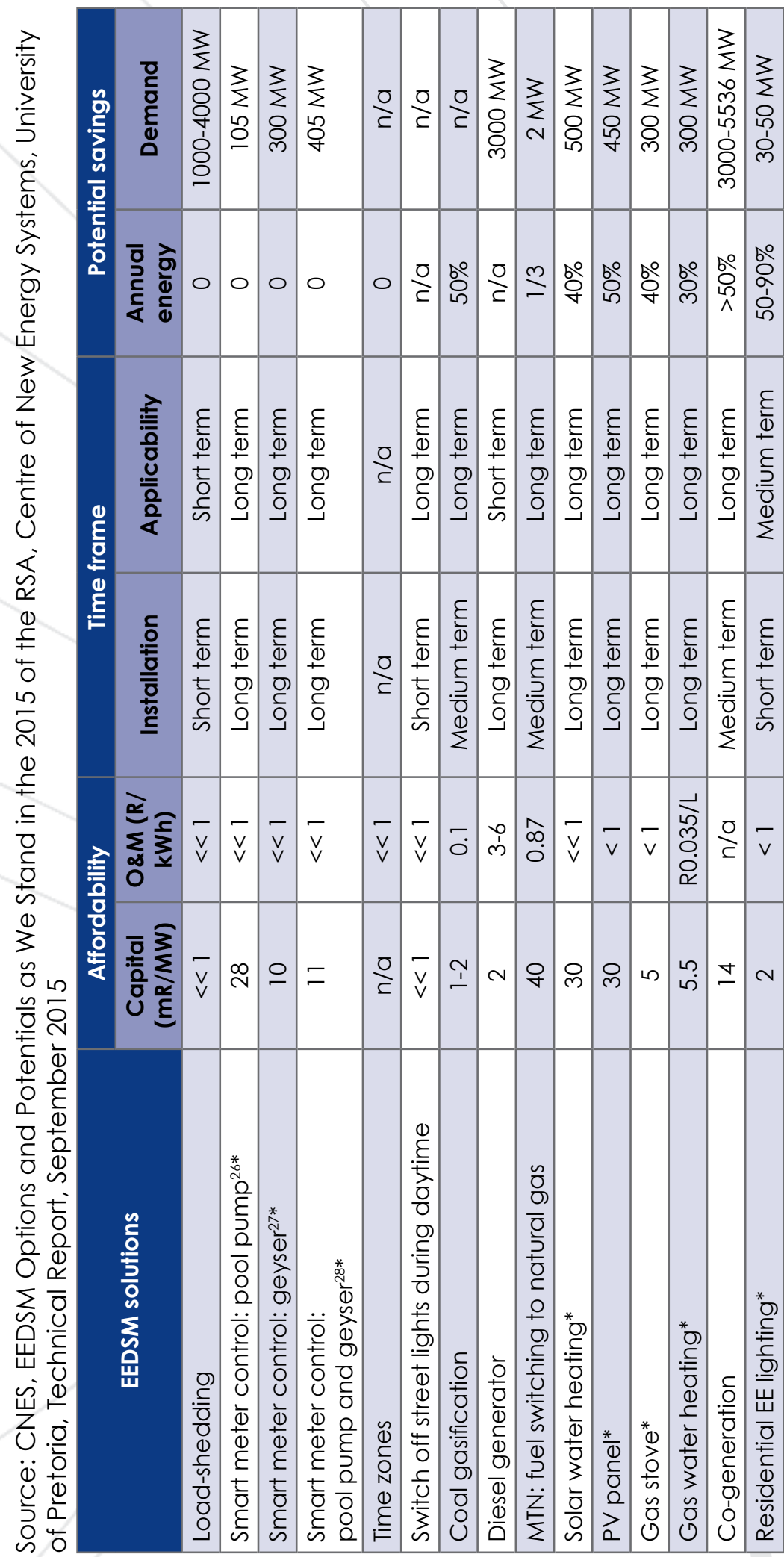




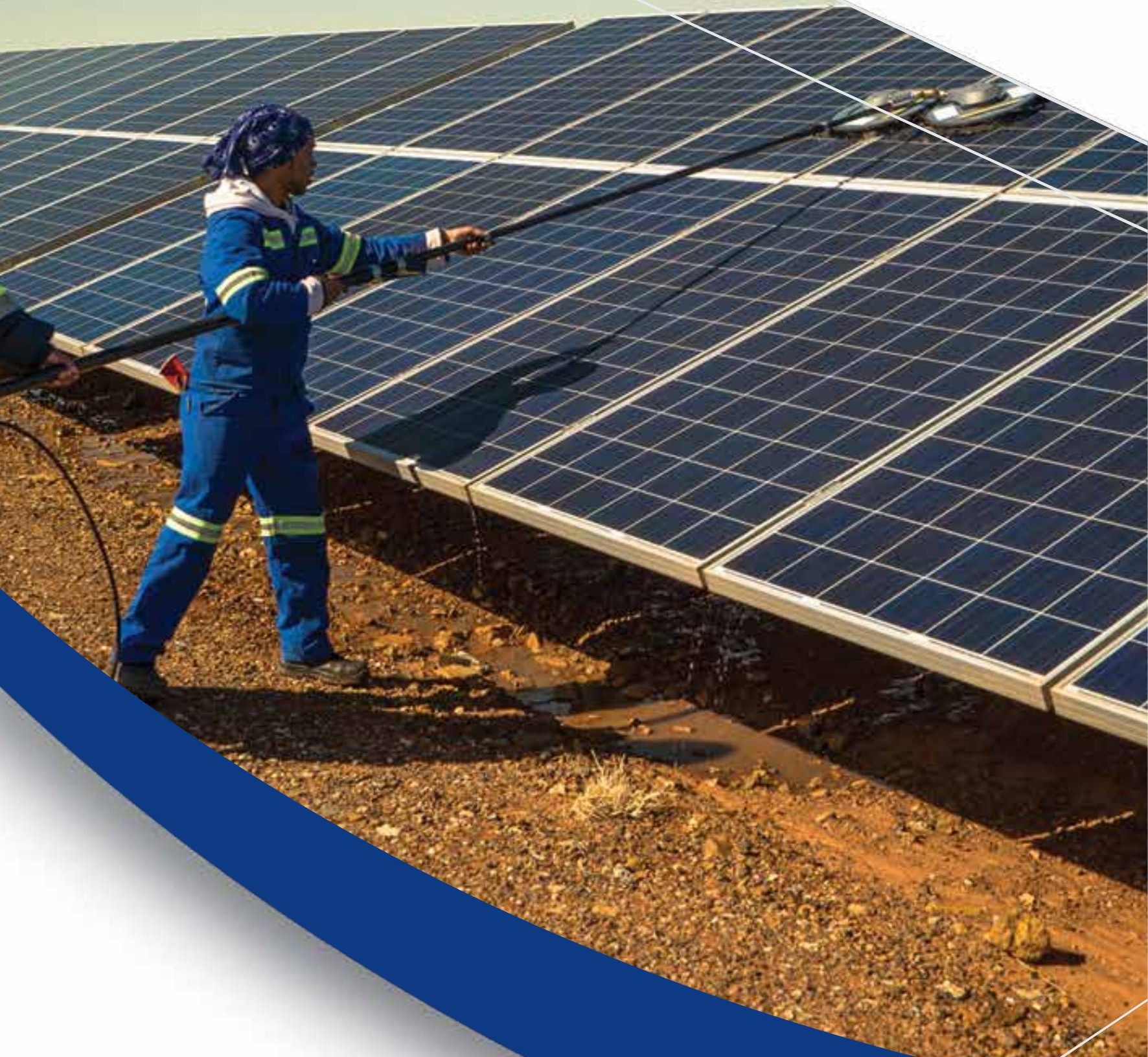




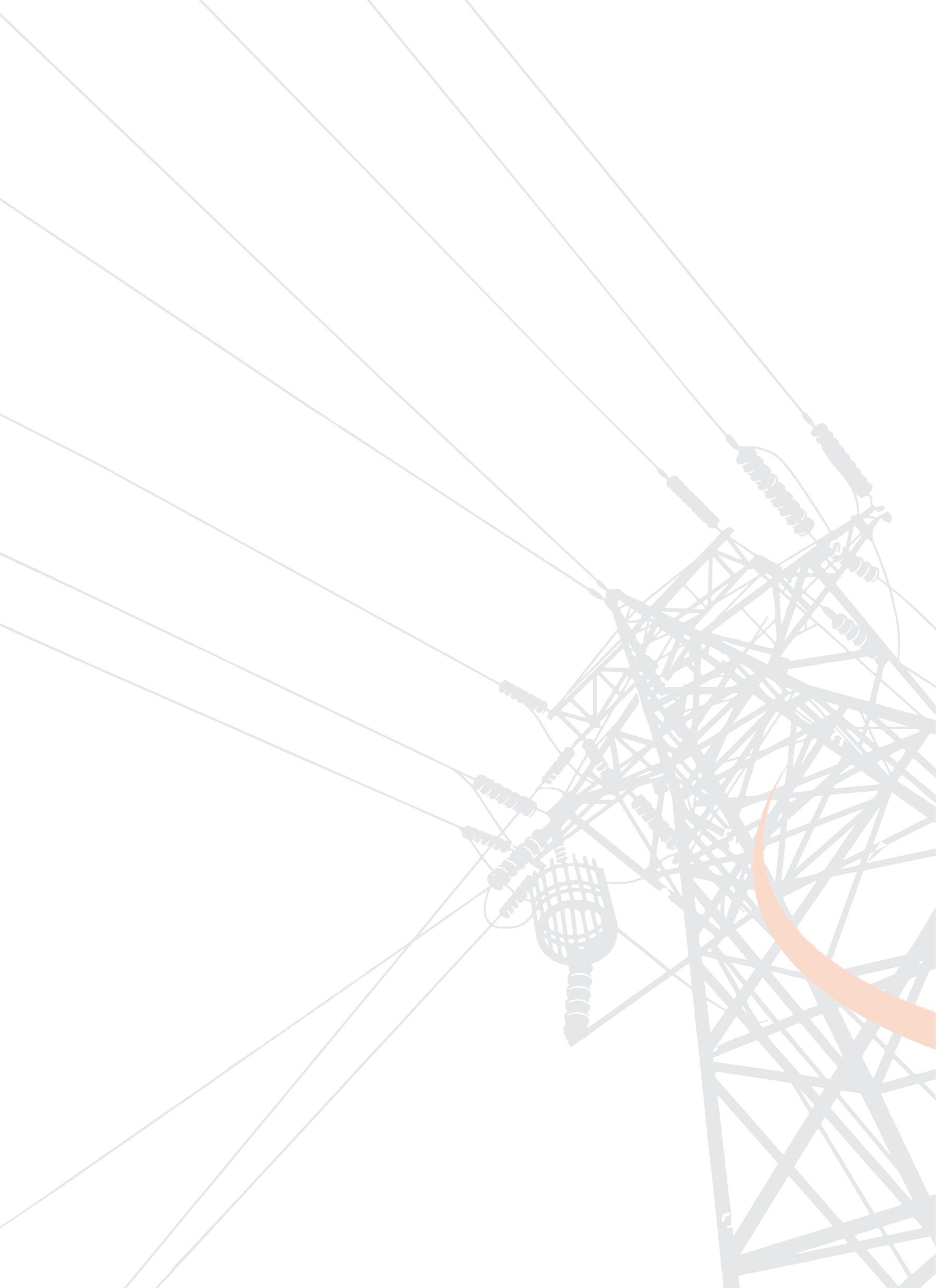




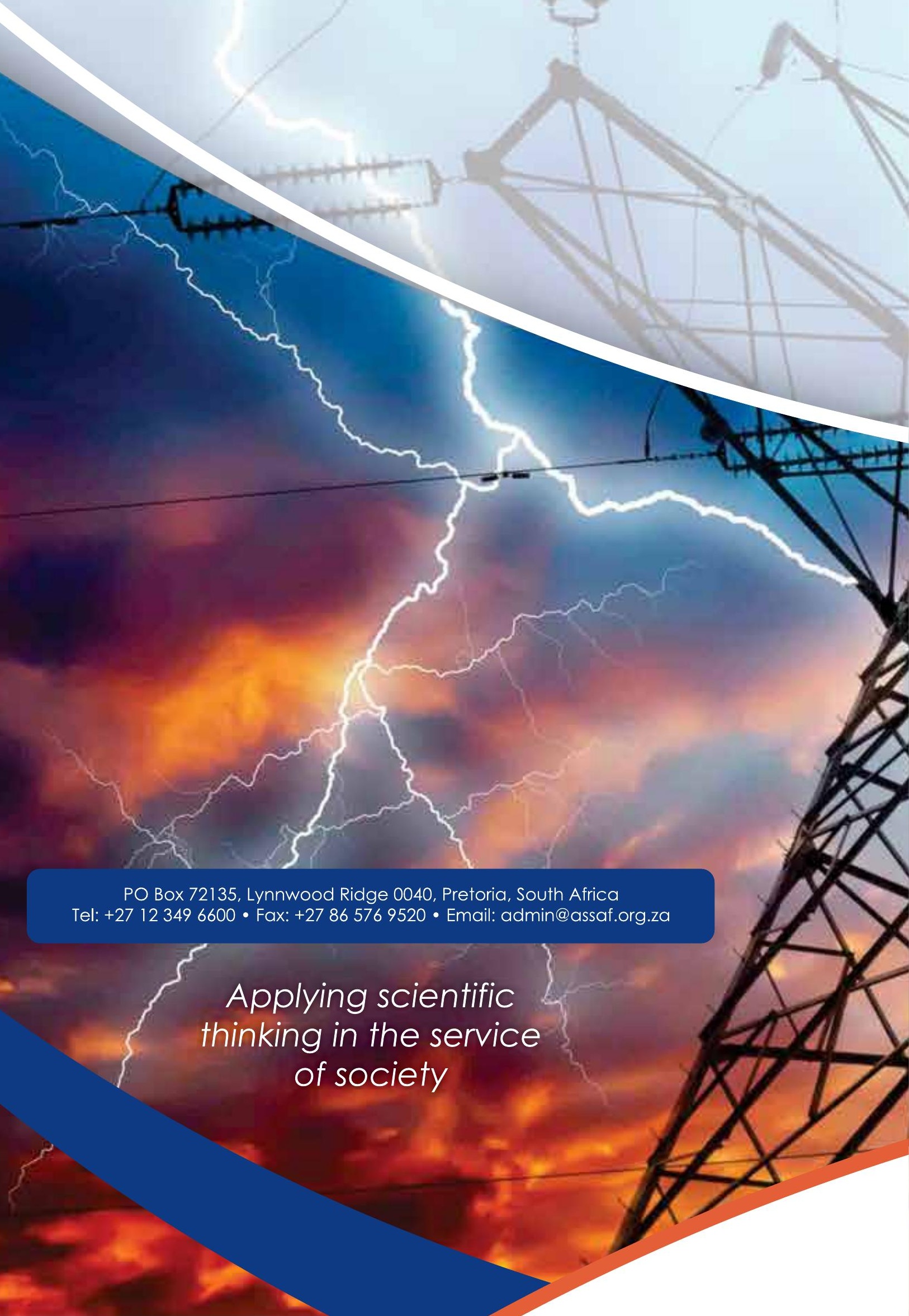




\section{The state of research, development and innovation of electrical energy efficiency technologies in South Africa}

Academy of Science of South Africa (ASSAf)

Academy of Science of South Africa (ASSAf)

Academy of Science of South Africa (ASSAf), (2018). The state of research, development and innovation of electrical energy efficiency technologies in South Africa. [Online] Available at: DOI http://dx.doi.org/10.17159/assaf.2017/0017

http://hdl.handle.net/20.500.11911/93

Downloaded from ASSAf Research Repository, Academy of Science of South Africa (ASSAf) 